\title{
Cochrane
}

Library

Cochrane Database of Systematic Reviews

\section{Pembrolizumab monotherapy versus chemotherapy for treatment of advanced urothelial carcinoma with disease progression during or following platinum-containing chemotherapy. A Cochrane Rapid Review (Review)}

Narayan V, Kahlmeyer A, Dahm P, Skoetz N, Risk MC, Bongiorno C, Patel N, Hwang EC, Jung JH, Gartlehner G, Kunath F

Narayan V, Kahlmeyer A, Dahm P, Skoetz N, Risk MC, Bongiorno C, Patel N, Hwang EC, Jung JH, Gartlehner G, Kunath F. Pembrolizumab monotherapy versus chemotherapy for treatment of advanced urothelial carcinoma with disease progression during or following platinum-containing chemotherapy. A Cochrane Rapid Review.

Cochrane Database of Systematic Reviews 2018, Issue 7. Art. No.: CD012838.

DOI: 10.1002/14651858.CD012838.pub2.

www.cochranelibrary.com 
TABLE OF CONTENTS

ABSTRAC

PLAIN LANGUAGE SUMMARY

SUMMARY OF FINDINGS

BACKGROUND

OBJECTIVES

METHODS

RESULTS

Figure 1.

Figure 2.

Figure 3.

Figure 4.

Figure 5.

Figure 6.

DISCUSSION

AUTHORS' CONCLUSIONS

ACKNOWLEDGEMENTS

REFERENCES

CHARACTERISTICS OF STUDIES

DATA AND ANALYSES

Analysis 1.1. Comparison 1 Pembrolizumab versus chemotherapy, Outcome 1 Overall survival.

Analysis 1.2. Comparison 1 Pembrolizumab versus chemotherapy, Outcome 2 Quality of life (change from baseline to week 15).

Analysis 1.3. Comparison 1 Pembrolizumab versus chemotherapy, Outcome 3 Progression-free survival.

Analysis 1.4. Comparison 1 Pembrolizumab versus chemotherapy, Outcome 4 Response rate (partial and complete response).

Analysis 1.5. Comparison 1 Pembrolizumab versus chemotherapy, Outcome 5 Treatment-related mortality.

Analysis 1.6. Comparison 1 Pembrolizumab versus chemotherapy, Outcome 6 Discontinuation due to adverse event (any grade).

Analysis 1.7. Comparison 1 Pembrolizumab versus chemotherapy, Outcome 7 Serious adverse events (irrespective of attribution to treatment).

Analysis 1.8. Comparison 1 Pembrolizumab versus chemotherapy, Outcome 8 Serious adverse events (irrespective of attribution to treatment).

Analysis 2.1. Comparison 2 Pembrolizumab versus chemotherapy (predefined subgroup analyses), Outcome 1 Overall survival based on performance status.

Analysis 2.2. Comparison 2 Pembrolizumab versus chemotherapy (predefined subgroup analyses), Outcome 2 Overall survival based on time since last chemotherapy.

Analysis 2.3. Comparison 2 Pembrolizumab versus chemotherapy (predefined subgroup analyses), Outcome 3 Overall survival based on degree of pretreatment.

Analysis 2.4. Comparison 2 Pembrolizumab versus chemotherapy (predefined subgroup analyses), Outcome 4 Overall survival based on PD-L1 tumour expression status.

Analysis 3.1. Comparison 3 Pembrolizumab versus chemotherapy (post-hoc included subgroup analyses), Outcome 1 Overall survival based on age.

Analysis 3.2. Comparison 3 Pembrolizumab versus chemotherapy (post-hoc included subgroup analyses), Outcome 2 Overall survival based on sex.

Analysis 3.3. Comparison 3 Pembrolizumab versus chemotherapy (post-hoc included subgroup analyses), Outcome 3 Overall survival based on smoking status.

Analysis 3.4. Comparison 3 Pembrolizumab versus chemotherapy (post-hoc included subgroup analyses), Outcome 4 Overall survival based on histologic type.

Analysis 3.5. Comparison 3 Pembrolizumab versus chemotherapy (post-hoc included subgroup analyses), Outcome 5 Overall survival based on PD-L1 tumour expression status (10\% cutoff).

Analysis 3.6. Comparison 3 Pembrolizumab versus chemotherapy (post-hoc included subgroup analyses), Outcome 6 Overall survival based on location of primary tumour.

Analysis 3.7. Comparison 3 Pembrolizumab versus chemotherapy (post-hoc included subgroup analyses), Outcome 7 Overall survival based on location of metastases.

Pembrolizumab monotherapy versus chemotherapy for treatment of advanced urothelial carcinoma with disease progression during or following platinum-containing chemotherapy. A Cochrane Rapid Review (Review)

Copyright $\odot 2018$ The Cochrane Collaboration. Published by John Wiley \& Sons, Ltd. 
Analysis 3.8. Comparison 3 Pembrolizumab versus chemotherapy (post-hoc included subgroup analyses), Outcome 8 Overall survival based on liver metastases.

Analysis 3.9. Comparison 3 Pembrolizumab versus chemotherapy (post-hoc included subgroup analyses), Outcome 9 Overall survival based on haemoglobin concentration.

Analysis 3.10. Comparison 3 Pembrolizumab versus chemotherapy (post-hoc included subgroup analyses), Outcome 10 Overall survival based on number of risk factors.

Analysis 3.11. Comparison 3 Pembrolizumab versus chemotherapy (post-hoc included subgroup analyses), Outcome 11 Overall survival based on previous platinum therapy.

Analysis 3.12. Comparison 3 Pembrolizumab versus chemotherapy (post-hoc included subgroup analyses), Outcome 12 Overall survival based on investigator's choice of chemotherapy.

ADDITIONAL TABLES

APPENDICES

CONTRIBUTIONS OF AUTHORS

DECLARATIONS OF INTEREST

SOURCES OF SUPPORT

DIFFERENCES BETWEEN PROTOCOL AND REVIEW

NOTES

INDEX TERMS 
[Intervention Review]

\section{Pembrolizumab monotherapy versus chemotherapy for treatment of advanced urothelial carcinoma with disease progression during or following platinum-containing chemotherapy. A Cochrane Rapid Review}

Vikram Narayan¹, Andreas Kahlmeyer², Philipp Dahm³ ${ }^{3}$, Nicole Skoetz ${ }^{4}$, Michael C Risk ${ }^{3}$, Connie Bongiorno ${ }^{5}$, Neil Patel ${ }^{6}$, Eu Chang Hwang7, Jae Hung Jung ${ }^{8}$, Gerald Gartlehner ${ }^{9}$, Frank Kunath ${ }^{2,10}$

1Department of Urology, University of Minnesota, Minneapolis, Minnesota, USA. ${ }^{2}$ Department of Urology, University Hospital Erlangen, Erlangen, Germany. ${ }^{3}$ Urology Section, Minneapolis VA Health Care System, Minneapolis, Minnesota, USA. ${ }^{4}$ Cochrane Haematological Malignancies Group, Department I of Internal Medicine, University Hospital of Cologne, Cologne, Germany. 5 University of Minnesota, Minneapolis, Minnesota, USA. 6 Minneapolis VA Health Care System, Minneapolis, Minnesota, USA. ${ }^{7}$ Department of Urology, Chonnam National University Medical School, Chonnam National University Hwasun Hospital, Hwasun, Korea, South. ${ }^{8}$ Department of Urology, Yonsei University Wonju College of Medicine, Wonju, Korea, South. ${ }^{9}$ Cochrane Austria, Danube University Krems, Krems, Austria. 10UroEvidence@Deutsche Gesellschaft für Urologie, Berlin, Germany

Contact: Frank Kunath, Department of Urology, University Hospital Erlangen, Erlangen, Germany. frank.kunath@uk-erlangen.de.

Editorial group: Cochrane Urology Group.

Publication status and date: New, published in Issue 7, 2018.

Citation: Narayan V, Kahlmeyer A, Dahm P, Skoetz N, Risk MC, Bongiorno C, Patel N, Hwang EC, Jung JH, Gartlehner G, Kunath F. Pembrolizumab monotherapy versus chemotherapy for treatment of advanced urothelial carcinoma with disease progression during or following platinum-containing chemotherapy. A Cochrane Rapid Review. Cochrane Database of Systematic Reviews 2018, Issue 7. Art. No.: CD012838. DOI: 10.1002/14651858.CD012838.pub2.

Copyright ( 2018 The Cochrane Collaboration. Published by John Wiley \& Sons, Ltd.

\section{A B S T R A C T}

\section{Background}

The use of systemic immunotherapy targets is emerging as an important treatment option for metastatic urothelial carcinoma, particularly for patients who cannot tolerate or who fail cisplatin-based chemotherapy. One such target is the inhibition of the checkpoint protein programmed cell death-1 (PD-1) receptor and its ligand (PD-L1) by monoclonal antibodies.

\section{Objectives}

To assess the effects of pembrolizumab monotherapy versus chemotherapy for treatment of advanced urothelial carcinoma with disease progression during or following platinum-containing chemotherapy.

\section{Search methods}

We performed a Cochrane Rapid Review, limiting our search to published studies in the English language. We searched databases of the medical literature, including the Cochrane Central Register of Controlled Trials and MEDLINE, as well as trial registries including ClinicalTrials.gov and the World Health Organization International Clinical Trials Registry Platform (WHO ICTRP). Our search extended from January 2000 to June 2018.

\section{Selection criteria}

We included randomised controlled trials except cross-over trials and cluster randomised trials. We excluded all other study designs. Participants included had locally advanced or metastatic urothelial carcinoma of the bladder, with disease progression during or following platinum-containing chemotherapy (synonymous with second-/third-/fourth-line therapy). This review focused on pembrolizumab (synonyms: MK-3475, lambrolizumab, Keytruda). 


\section{Data collection and analysis}

Two review authors independently classified and abstracted data from the included study. The certainty of evidence was rated according to the Grading of Recommendations Assessment, Development and Evaluation (GRADE) approach.

\section{Main results}

We identified one randomised controlled trial that included 542 participants, which compared the use of pembrolizumab monotherapy versus chemotherapy for the treatment of advanced urothelial carcinoma with disease progression during or following platinumcontaining chemotherapy. Results were reported after a median follow-up of 14.1 months (range 9.9 to 22.1 months).

\section{Primary outcomes}

Pembrolizumab probably reduces the risk of death from any cause (hazard ratio (HR) $0.73,95 \%$ confidence interval (CI) 0.59 to 0.90 ; moderate certainty evidence). This corresponds to 115 fewer deaths ( 191 fewer to 38 fewer) per 1000 participants with pembrolizumab at 12 months. We downgraded the certainty of evidence one level for imprecision.

Pembrolizumab may slightly improve quality of life (change from baseline to week 15 assessed with the Core Quality of Life Questionnaire; higher value reflects better quality of life; scale 0 to 100 ) with a mean difference (MD) of $9.05,95 \% \mathrm{Cl} 4.61$ to 13.50 ; low certainty evidence). We downgraded the certainty of evidence two levels for study limitations and imprecision.

\section{Secondary outcomes}

Pembrolizumab may have little or no effect on disease progression (HR 0.98, 95\% Cl 0.81 to 1.19; low certainty evidence). This corresponds to three fewer patients ( 42 fewer to 24 more) whose disease progressed per 1000 participants at 12 months. We downgraded the certainty of evidence two levels for study limitations and imprecision.

Pembrolizumab probably improves treatment response (based on complete or partial radiologic response) with a risk ratio (RR) of 1.85, $95 \% \mathrm{Cl} 1.24$ to 2.77 ; moderate certainty evidence). This corresponds to 97 more respondents (27 more to 202 more) per 1000 participants with pembrolizumab. We downgraded the certainty of evidence one level for imprecision.

Pembrolizumab may have little or no effect on treatment-related mortality (RR $0.96,95 \% \mathrm{Cl} 0.24$ to 3.79 ; low certainty evidence). This corresponds to one fewer ( 12 fewer to 44 more) treatment-related deaths per 1000 participants with pembrolizumab. We downgraded the certainty of evidence two levels for study limitations and imprecision.

Pembrolizumab may have little or no effect on discontinuations due to adverse events ( $\mathrm{RR} 0.66,95 \% \mathrm{Cl} 0.39$ to 1.10 ). This corresponds to 54 fewer discontinuations per 1000 participants ( $95 \%$ Cl 79 fewer to 7 more). We downgraded the certainty of evidence for study limitations and imprecision.

Pembrolizumab may reduce serious adverse events (RR $0.83,95 \mathrm{Cl} 0.72$ to 0.97 ; low certainty evidence). This corresponds to 107 fewer serious averse events per 1000 participants ( $95 \% \mathrm{Cl} 19$ fewer to 176 fewer). We downgraded two levels for study limitations and imprecision.

\section{Authors' conclusions}

The use of pembrolizumab in men with advanced urothelial carcinoma with disease progression during or following platinum-containing chemotherapy probably improves overall survival when compared with chemotherapy alone. At 12 months follow-up about $70 \%$ of those in the chemotherapy group had died, compared with 59\% of those treated with pembrolizumab. We are very uncertain about the effects of pembolizumab on quality of life. Pembolizumab may also improve treatment response rates, and reduce the risk of serious adverse events, but may make little or no difference to discontinuations of treatment due to adverse events. These conclusions are based on a single trial that was sponsored by the producer of pembrolizumab.

\section{PLAIN LANGUAGE SUMMARY}

\section{Pembrolizumab versus chemotherapy for treating advanced bladder cancer after recurrence/progression following platinum- based chemotherapy}

\section{Review question}

How does pembrolizumab (a newer medicine that works through the body's immune system) compare to chemotherapy in patients with cancer of the inner lining of the urinary system, called urothelial cancer, that has either come back or worsened after treatment?

\section{Background}

Medications that target the body's immune system have been used for a long time to treat urothelial cancer. When the cancer has spread to other organs outside the urinary tract, patients are often treated with chemotherapy using medicines called cisplatin or carboplatin (platinum-containing chemotherapy). However, often the cancer comes back or becomes worse despite treatment. This review considers 
the evidence for pembrolizumab, which is a member of a new class of medications that work through the immune sytem, and compares it to chemotherapy.

\section{Study characteristics}

We considered only randomised controlled trials in this Cochrane Rapid Review, as they offer the most reliable results. This review is current to 20 June 2018.

\section{Key results}

We found only one randomised study for our question. Participants included in this trial had metastatic (cancer that has spread to other parts of the body) or advanced cancer that could not be removed by surgery, that had come back or worsened with other chemotherapy.

We found that pembrolizumab probably improves overall survival a little (evidence of moderate certainty). It may improve quality of life slightly (low certainty evidence).

Pembrolizumab may have little or not effect on the time for the cancer to worsen or advance (low certainty evidence). It probably improves treatment response as seen on X-ray scans such as computer tomography (moderate certainty of evidence).

Pembrolizumab may have little or no effect on deaths resulting from the treatment itself (low certainty evidence) but may result in fewer patients stopping treatment due to unwanted side effects (low certainty evidence). It may also cause less serious side effects.

These conclusions are based on a single trial paid for by the company that makes pembrolizumab.

\section{Certainty of evidence}

The certainty of evidence ranged from moderate to very low. 


\section{SUMMARY OF FINDINGS}

Summary of findings for the main comparison. Pembrolizumab compared to chemotherapy for treatment of advanced urothelial carcinoma with disease progression during or following platinum-containing chemotherapy. A Cochrane Rapid Review

Pembrolizumab compared to chemotherapy for treatment of advanced urothelial carcinoma with disease progression during or following platinum-containing chemotherapy. A Cochrane Rapid Review

Participants: people with advanced urothelial carcinoma with disease progression during or following platinum-containing chemotherapy

Setting: multicentre; 120 sites in 29 countries

Intervention: pembrolizumab

Control: chemotherapy (vinflunine or docetaxel or paclitaxel)

\begin{tabular}{|c|c|c|c|c|c|}
\hline \multirow[t]{2}{*}{ Outcomes } & \multirow{2}{*}{$\begin{array}{l}\text { Number of partici- } \\
\text { pants } \\
\text { (studies) }\end{array}$} & \multirow{2}{*}{$\begin{array}{l}\text { Certainty of the } \\
\text { evidence } \\
\text { (GRADE) }\end{array}$} & \multirow{2}{*}{$\begin{array}{l}\text { Relative effect } \\
(95 \% \mathrm{Cl})\end{array}$} & \multicolumn{2}{|c|}{ Anticipated absolute effects ${ }^{\star}(95 \% \mathrm{CI})$} \\
\hline & & & & $\begin{array}{l}\text { Risk with } \\
\text { chemotherapy }\end{array}$ & $\begin{array}{l}\text { Risk difference with pem- } \\
\text { brolizumab }\end{array}$ \\
\hline \multirow{2}{*}{$\begin{array}{l}\text { Time to death from any cause (here: overall } \\
\text { mortality at } 12 \text {-month follow-up) }\end{array}$} & \multirow{2}{*}{$\begin{array}{l}542 \\
(1 \mathrm{RCT})\end{array}$} & \multirow{2}{*}{$\begin{array}{l}\oplus \oplus \oplus \odot \\
\text { MODERATE } 1\end{array}$} & \multirow{2}{*}{$\begin{array}{l}\text { HR } 0.73 \\
\text { (0.59 to } 0.90)\end{array}$} & \multicolumn{2}{|l|}{ Study population } \\
\hline & & & & 695 per $1000^{a}$ & $\begin{array}{l}115 \text { fewer per } 1000 \\
\text { (191 fewer to } 38 \text { fewer) }\end{array}$ \\
\hline $\begin{array}{l}\text { Quality of life (Change from baseline to week } \\
\text { 15) } \\
\text { Assessed with: EORTC QLQ-C30 } \\
\text { Scale from } 0 \text { to } 100 \text { (a higher score represents } \\
\text { better quality of life) } \\
\text { Follow-up: from baseline to week } 15\end{array}$ & $\begin{array}{l}519 \\
(1 \mathrm{RCT})\end{array}$ & $\begin{array}{l}\oplus \oplus \odot \ominus \\
\text { LOW } 234\end{array}$ & $\begin{array}{l}\text { MD } 9.05 \text { (4.61 to } \\
13.50)\end{array}$ & $\begin{array}{l}\text { The mean quality } \\
\text { of life (change from } \\
\text { baseline to week } \\
\text { 15) was - } 8.3 \text { score } \\
\text { change b }\end{array}$ & $\begin{array}{l}\text { MD } 9.05 \text { score change higher } \\
\text { ( } 4.61 \text { higher to } 13.50 \text { higher) }\end{array}$ \\
\hline Response rate (partial and complete re- & 542 & $\oplus \oplus \oplus \ominus$ & RR 1.85 & Study population & \\
\hline \multirow{2}{*}{$\begin{array}{l}\text { Treatment-related mortality } \\
\text { Follow-up: median } 14.1 \text { months }\end{array}$} & \multirow{2}{*}{$\begin{array}{l}521 \\
(1 \mathrm{RCT})\end{array}$} & \multirow{2}{*}{$\begin{array}{l}\oplus \oplus \odot \ominus \\
\text { LOW } 12\end{array}$} & \multirow{2}{*}{$\begin{array}{l}\text { RR } 0.96 \\
(0.24 \text { to } 3.79)\end{array}$} & \multicolumn{2}{|l|}{ Study population } \\
\hline & & & & 16 per 1000 & $\begin{array}{l}1 \text { less per } 1000 \\
\text { (12 fewer to } 44 \text { more) }\end{array}$ \\
\hline $\begin{array}{l}\text { Discontinuation due to adverse event } \\
\text { Follow-up: median } 14.1 \text { months }\end{array}$ & $\begin{array}{l}521 \\
(1 \mathrm{RCT})\end{array}$ & $\begin{array}{l}\oplus \oplus \ominus \ominus \\
\text { LOW } 12\end{array}$ & $\begin{array}{l}\text { RR } 0.66 \\
\text { (0.39 to } 1.10)\end{array}$ & Study population & \\
\hline
\end{tabular}




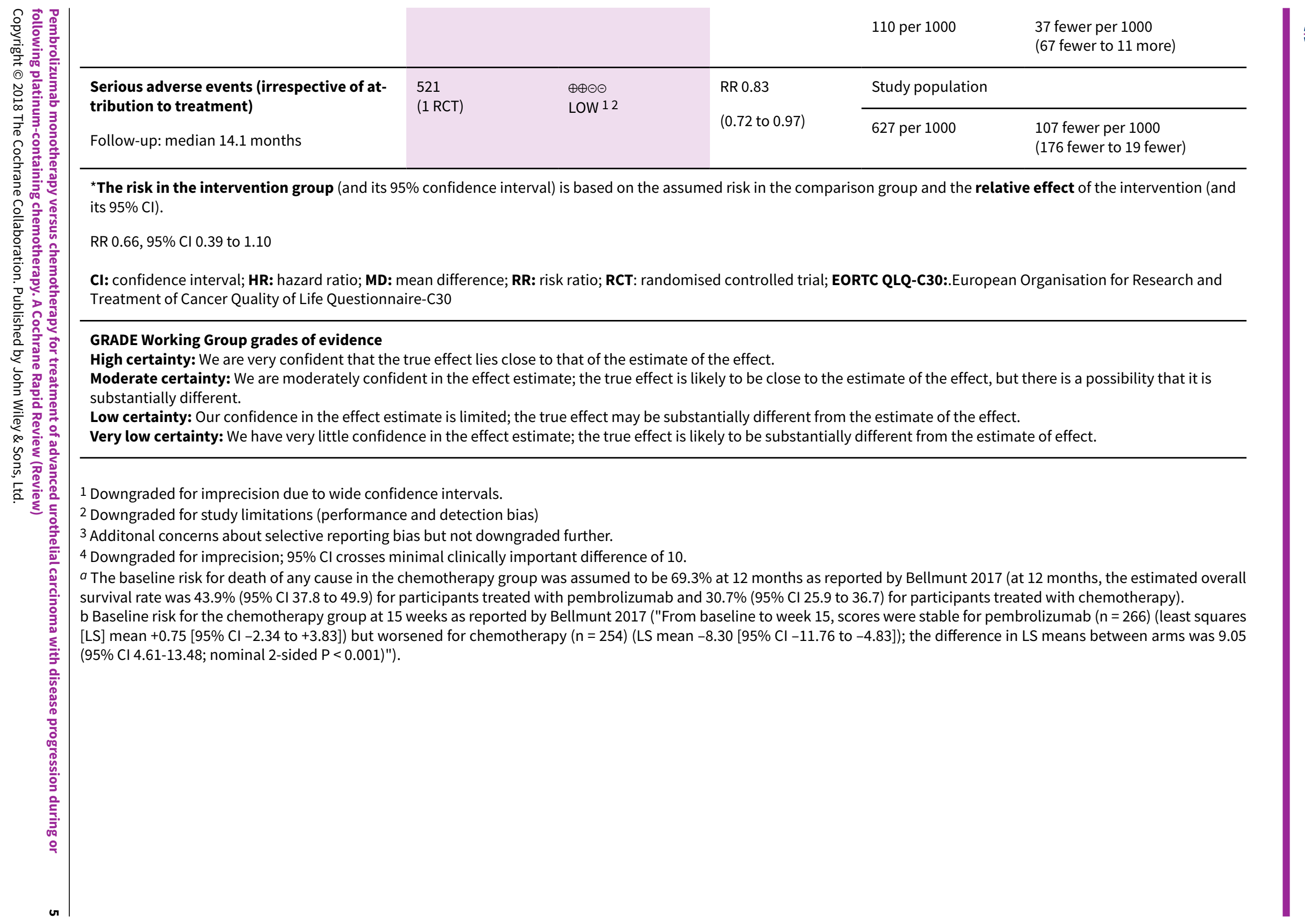




\section{B A C K G R O U N D}

\section{Description of the condition}

According to 2012 GLOBOCAN data (GLOBOCAN 2012), urothelial carcinoma of the bladder is the ninth most common malignancy worldwide, with nearly 429,000 new cases and 165,000 cancerrelated deaths every year. In addition to the bladder, urothelial carcinoma can affect the renal pelvis, ureters, and the urethra. A diagnosis is typically established by visualisation of the tumour using cross-sectional imaging or cystoscopy, or both, followed by transurethral resection, which is both diagnostic and therapeutic. Urothelial carcinoma of the bladder is a heterogeneous entity and can vary in presentation from non-invasive, low-grade disease to invasive, high-grade forms that can rapidly progress to early metastasis and death despite aggressive treatment. Invasive urothelial carcinoma of the bladder is usually treated with radical cystectomy and urinary diversion or with radiotherapy and concomitant chemotherapy (EAU 2017; Leitlinienprogramm Onkologie; NCCN Guideline 2017). The surgical therapy can be combined with neoadjuvant or adjuvant chemotherapy (Leitlinienprogramm Onkologie; NCCN Guideline 2017). Metastatic urothelial carcinoma is usually treated with palliative chemotherapy (EAU 2017; Leitlinienprogramm Onkologie; NCCN Guideline 2017). The most effective chemotherapy regimens are combination platinum-based therapies, such as MVAC (methotrexate, vinblastine, doxorubicin, and cisplatin; Logothetis 1990), or a combination of gemcitabine plus cisplatin or carboplatin (EAU 2017; Leitlinienprogramm Onkologie; NCCN Guideline 2017; von der Maase 2000). Unfortunately, individuals with advanced urothelial carcinoma often have progression or recurrence of urothelial cancer following a first-line platinum-containing regimen for metastatic or inoperable locally advanced disease. These individuals are then often managed supportively or with inferior regimens. Vinflunine is often used in Europe as a second-line chemotherapy regimen and offers a median overall survival of 6.9 months compared to 4.6 months with best supportive care (Bellmunt 2013). The need for novel therapies in this realm is clear.

\section{Description of the intervention}

The use of immunotherapy to treat bladder cancer is well established, particularly the use of intravesical Bacillus CalmetteGuerin for non-muscle invasive high-grade disease (Morales 1976). Systemic immunotherapy targets, such as immune checkpoint receptors and their ligands, have been the focus of several recent clinical trials. For example, the inhibition of the checkpoint protein programmed cell death-1 (PD-1) receptor and its ligand (PD-L1) by monoclonal antibodies ( $\mathrm{mAb}$ ) has elicited effective antitumour responses (Ribas 2015; Sharma 2015). Administered intravenously every two to three weeks, mAbs have shown promising response rates against urothelial carcinoma (Bellmunt 2017; Kim 2015; Plimack 2017; Rosenberg 2016; Sharma 2016). The mAb pembrolizumab targets the PD-1 receptor, and a randomised controlled trial comparing pembrolizumab with paclitaxel, docetaxel, or vinflunine chemotherapy in individuals in whom urothelial carcinoma had recurred or progressed after platinum-based chemotherapy has been reported (Bellmunt 2017). Pembrolizumab was associated with longer overall survival and with a lower rate of treatment-related adverse events than chemotherapy (Bellmunt 2017).

\section{Adverse effects of the intervention}

Grade 3 and 4 treatment- and immune-related adverse events were recently reported in $16 \%$ and $5 \%$, respectively, of individuals with post-platinum-treated advanced urothelial carcinoma using the mAb atezolizumab (Rosenberg 2016). Examples of adverse events included elevated lipase and amylase levels, fatigue, rash, and decreased lymphocyte and neutrophil counts (Rosenberg 2016). Similar adverse events and adverse event rates were reported in a phase lb study of pembrolizumab in metastatic urothelial carcinoma, with 5 of 29 participants reporting grade 3 or 4 adverse events (Gupta 2015). Treatment-related deaths due to pneumonitis and thrombocytopenia were reported in a phase I/II study with nivolumab in a similar population (Sharma 2016).

\section{How the intervention might work}

Checkpoint proteins such as PD-1 work to inhibit a host's immune response against a tumour cell by preventing T-cells from attacking the tumour cells that would otherwise be detected as foreign. Tumour cells, including certain urothelial carcinoma cells, have been shown to express high levels of PD-1 (Faraj 2015), thereby enabling them to evade a host's normal immune response. Checkpoint inhibitors such as mAbs targeting PD-1 and its ligand, PD-L1, can therefore block what would otherwise be an inhibitory effect of T-cells, in turn "reactivating" a host's immune system against tumour cells (Park 2016).

\section{Why it is important to do this review}

Given the paucity of treatment options available for individuals with advanced urothelial carcinoma who had progression or recurrence of urothelial cancer following a first-line platinum-containing chemotherapy (e.g. cisplatin, carboplatin) for metastatic or inoperable locally advanced disease, the need for novel therapeutic targets is evident. Pembrolizumab has emerged as a novel immunotherapy option, but to date no systematic review of the available data has been carried out that has carefully evaluated the certainty of evidence using Grading of Recommendations Assessment, Development and Evaluation (GRADE) methodology to better inform clinical practice.

\section{O B JECTIVES}

To assess the effects of pembrolizumab monotherapy versus chemotherapy for treatment of advanced urothelial carcinoma with disease progression during or following platinum-containing chemotherapy.

\section{METHODS}

\section{Criteria for considering studies for this review \\ Types of studies}

This review is based on a published protocol (Narayan 2017). For details on differences between the protocol and review see 'Differences between protocol and review' section. We included randomised controlled trials except cross-over trials and cluster randomised trials. We excluded all other study designs.

\section{Types of participants}

We included participants with locally advanced $(>\mathrm{T} 2)$ or metastatic (M1) urothelial carcinoma of the bladder as determined by cross- 
sectional imaging or confirmed by biopsy, or both, whose disease progressed during or following platinum-containing chemotherapy (synonymous with second-/third-/fourth-line therapy). We did not include participants receiving pembrolizumab as first-line therapy.

\section{Types of interventions}

This review focused on pembrolizumab (synonyms: MK-3475, lambrolizumab, Keytruda). We investigated the following comparisons of experimental intervention versus comparator intervention.

\section{Experimental interventions}

- Pembrolizumab.

\section{Comparator interventions}

- Second-/third-/fourth-line chemotherapy.

\section{Comparison}

- Pembrolizumab versus second-/third-/fourth-line chemotherapy.

Concomitant interventions have to be the same in the experimental and comparator groups to establish fair comparisons. We planned inclusion of all studies comparing pembrolizumab with second-/ third-/fourth-line chemotherapy, irrespective of dose, route, frequency or duration.

\section{Types of outcome measures}

We predefined the following outcome measures.

\section{Primary outcomes}

- Time to death from any cause as measured from the time of random sequence generation to time of death irrespective of cause (time-to-event outcome).

- Quality of life as measured by validated instruments (continuous outcome).

\section{Secondary outcomes}

- Time to progression as measured from the time of random sequence generation to the time of first confirmed progression, relapse, or death from urothelial carcinoma (time-to-event outcome).

- Response rate (patients with no complete or partial response), measured as complete response or partial response according to Response Evaluation Criteria in Solid Tumors (RECIST) 1.1 criteria (categorical outcome; Eisenhauer 2009).

- Treatment-related mortality (dichotomous outcome).

- Discontinuation due to adverse events (any grade according to the Common Terminology Criteria for Adverse Events (CTCAE)), measured from the time of random sequence generation to discontinuation of therapy because of an adverse event (dichotomous outcome).

- Rate of serious adverse events (grade 3, 4, or 5 according to the CTCAE), such as pruritus, fatigue, diarrhoea, anaemia, constipation, neuropathy, neutropenia, alopecia, hypo-/ hyperthyroidism, pneumonitis, colitis, nephritis, skin reaction, thyroiditis, adrenal insufficiency, myositis, hypophysitis, or cardiovascular events (dichotomous outcome).
If we were unable to retrieve the necessary information to analyse time-to-event outcomes, we planned to assess the number of events per total number of included patients for dichotomised outcomes at 6 months and 12 months.

\section{Main outcomes for 'Summary of findings' table}

We presented a 'Summary of findings' table reporting the following outcomes listed according to priority. Outcome priority was determined by review authors providing content expertise (FK, PD).

- Time to death from any cause (reported as overall mortality at 12 months).

- Quality of life.

- Response rate (complete or partial response radiographically).

- Treatment-related mortality.

- Discontinuations due to adverse events.

\section{Search methods for identification of studies}

We conducted a Cochrane Rapid Review. For details on the search strategy see the Appendices section.

\section{Electronic searches}

We searched the following sources.

- Databases of medical literature:

- Cochrane Central Register of Controlled Trials (CENTRAL; June 2018);

- MEDLINE (via PubMed; January 2000 to June 2018).

- Databases of ongoing trials:

- ClinicalTrials.gov (www.clinicaltrials.gov/; 2000 to June 2018);

- World Health Organization International Clinical Trials Registry Platform (WHO ICTRP; apps.who.int/trialsearch/; 2000 to June 2018).

This being an expedited, rapid review, we limited our search to published studies and to the use of English as the language of publication. We did not search the databases and web-sites of institutions, such as pharmaceutical organisations, agencies, and societies. We began the search in 2000 because the underlying mechanism of action of tumour immunotherapy by PD-L1 blockade was first reported in 2002 (Iwai 2002).

\section{Searching other resources}

We checked the reference lists of all identified trials, relevant review articles, and current treatment guidelines for further literature (EAU 2017; Leitlinienprogramm Onkologie), but as this is an expedited review, did not contact experts in the field, drug manufacturers, or regulatory agencies for additional information on unpublished trials.

\section{Data collection and analysis}

\section{Selection of studies}

We used reference management software to identify and remove potential duplicate records (Endnote 2011). Two review authors (VN, FK) independently scanned the abstract, title, or both, of the remaining records retrieved and investigated all potentially relevant records as full text, mapped records to studies, and classified studies as included studies, excluded

Pembrolizumab monotherapy versus chemotherapy for treatment of advanced urothelial carcinoma with disease progression during or 7 following platinum-containing chemotherapy. A Cochrane Rapid Review (Review)

Copyright (c) 2018 The Cochrane Collaboration. Published by John Wiley \& Sons, Ltd. 
studies, studies awaiting classification, or ongoing studies using Covidence software (Covidence). We resolved discrepancies through consensus or consultation with a third review author (PD). We documented reasons for the exclusion of studies that may have reasonably been expected to be included in the review in a 'Characteristics of excluded studies' table. We present an adapted Preferred Reporting Items for Systematic Reviews and Meta-Analyses ((PRISMA) flow diagram showing the process of study selection (Liberati 2009).

\section{Data extraction and management}

For studies that fulfilled the inclusion criteria, one review author (FK) extracted key participant and intervention characteristics using a data extraction form based on the recommendations of the Cochrane Handbook for Systematic Reviews of Interventions (Higgins 2011a). A second review author checked data entry (VN). We resolved disagreements by consensus or, when required, by consultation with a third review author (PD).

We extracted the following information.

- Study design and number of study centres.

- Run-in period.

- Participant inclusion and exclusion criteria.

- Participant details, baseline demographics such as visceral/liver metastases, age or ECOG (Eastern Cooperative Oncology Group) performance status.

- The number of participants by study/study arm.

- Details of relevant experimental and comparator interventions such as dose, route, frequency, and duration.

- Definitions of primary and secondary outcomes, and method and timing of outcome measurement.

- Study funding sources

- Declarations of interest by primary investigators.

We attempted to provide information, including trial identifier about potentially relevant ongoing studies in the 'Characteristics of ongoing studies' table. We attempted to contact authors of included studies to obtain key missing data when needed.

We extracted outcome data relevant to this review as needed for the calculation of summary statistics and measures of variance. For dichotomous outcomes, we attempted to obtain numbers of events per total number of included participants to enable the population of a $2 \times 2$ table, as well as summary statistics with corresponding measures of variance. For continuous outcomes, we attempted to obtain means and standard deviations or the data necessary to calculate this information. For time-to-event outcomes, we attempted to obtain hazard ratios (HRs) with corresponding measures of variance or the data necessary to calculate this information.

\section{Dealing with duplicate and companion publications}

For duplicate publications, companion documents, or multiple reports of a primary trial, we maximised the information yield by collating all available data and used the most complete data set aggregated across all known publications. We listed multiple reports of the primary trial as secondary references under the study identifier of the included trial. In case of doubt, we gave priority to the publication reporting the longest follow-up associated with our primary or secondary outcomes.

\section{Data from clinical trial registers}

We extracted data from any included studies published in clinical trial registers.

\section{Assessment of risk of bias in included studies}

One review author assessed the risk of bias in each included study (FK), and a second review author checked the data entry (VN). We resolved disagreements by consensus, or by consultation with a third review author (PD).

We assessed the risk of bias in included randomised controlled trials using the Cochrane 'Risk of bias' tool (Higgins 2011b). We assessed the following domains.

- Random sequence generation (selection bias).

- Allocation concealment (selection bias).

- Blinding of participants and personnel (performance bias).

- Blinding of outcome assessment (detection bias).

- Incomplete outcome data (attrition bias).

- Selective reporting (reporting bias).

- Other sources of bias.

We judged the study as being at 'low risk', 'high risk', or 'unclear risk' for each domain and evaluated individual bias items as described in the Cochrane Handbook for Systematic Reviews of Interventions (Higgins 2011b). We present a 'Risk of bias' graph to illustrate these findings.

For performance bias (blinding of participants and personnel) and detection bias (blinding of outcome assessment), we evaluated the risk of bias separately for each outcome (Hróbjartsson 2013), but grouped outcomes as appropriate, as detailed below.

With regard to performance bias, we judged outcomes as being similarly susceptible to performance bias and rated them as one group.

We defined the following endpoints as subjective outcomes in terms of susceptibility to detection bias and rated them as one group.

- Quality of life.

- Progression-free survival.

- Response rate (patients with complete or partial response).

- Treatment-related mortality.

- Rate of serious adverse events.

We defined the following endpoint as an objective outcome in terms of susceptibility to detection bias.

- Overall survival.

We assessed attrition bias (incomplete outcome data) on an outcome-specific basis, and grouped outcomes with like judgements when reporting our findings in the 'Risk of bias' tables.

We summarised the risk of bias across domains for each outcome in each included study, as well as across studies and domains for each outcome. 


\section{Measures of treatment effect}

We expressed dichotomous data as a risk ratio (RR) with $95 \%$ confidence interval $(\mathrm{Cl})$. For continuous outcomes measured on the same scale, we estimated the intervention effect using the mean difference (MD) with $95 \% \mathrm{Cl}$. For continuous outcomes measuring the same underlying concept (e.g. health-related quality of life) but using different measurement scales, we planned to calculate the standardised mean difference (SMD). We expressed time-to-event data as HRs with $95 \% \mathrm{Cls}$ or used an indirect estimation method if HRs were not given (Parmar 1998; Tierney 2007).

\section{Unit of analysis issues}

The unit of analysis was the individual participant. If we had identified trials with more than two intervention groups for inclusion in the review, we would have handled these in accordance with guidance provided in the Cochrane Handbook for Systematic Reviews of Interventions (Higgins 2011c).

\section{Dealing with missing data}

We planned to obtain missing data from study authors, if feasible, and planned to perform intention-to-treat analyses if data were available; we otherwise performed analyses as treated and would have indicated this as a potential source of bias. We investigated attrition rates (e.g. drop-outs, losses to follow up, and withdrawals) and critically appraised issues of missing data. We did not plan to impute missing data.

\section{Assessment of heterogeneity}

We planned to assess heterogeneity; however, we included only one randomised controlled trial and therefore assessment of heterogeneity was not possible.

\section{Assessment of reporting biases}

We obtained the study protocol of the included randomised controlled trial to assess for selective outcome reporting. We also searched for completed but not reported trials in trial registers (ClinicalTrials.gov; WHO ICTRP).

\section{Data synthesis}

We presented data from the included randomised controlled trial using Review Manager software (Review Manager 2014) in accordance with the guidelines contained in the Cochrane Handbook for Systematic Reviews of Interventions (Higgins 2011a). For dichotomous outcomes we used the Mantel-Haenszel method; for continuous outcomes we used the inverse variance method; and for time-to-event outcomes we used the generic inverse variance method.

For the analyses of individual serious adverse events with very low events rates we used Peto's odds ratio method as suggested by the Cochrane Handbook for Systematic Reviews of Interventions (Higgins 2011d).

\section{Subgroup analysis and investigation of heterogeneity}

We expected the following characteristics to potentially introduce clinical heterogeneity, and carried out the following subgroup analyses to test for subgroup differences in Review Manager (Review Manager 2014).

- Performance status (Eastern Cooperative Oncology Group (ECOG) 0 or 1 versus $\geq 2$ ).

- Time since last chemotherapy administration (< three months versus $\geq$ three months).

- Degree of pretreatment (second-versus third-versus fourth-line or more).

- PDL-1 tumour expression status (positive versus negative).

\section{Sensitivity analysis}

We only identified one randomised controlled trial and were therefore not able to perform sensitivity analyses.

\section{'Summary of findings' table}

We present the overall quality of the evidence for each outcome according to the GRADE approach, which takes into account five criteria related not only to internal validity (risk of bias, inconsistency, imprecision, publication bias) but also to external validity (directness of results; Guyatt 2008). We used the GRADEpro Guideline Development Tool to assess the quality of the evidence, according to the recommendations of the GRADE working group (GRADEpro GDT). Two review authors (FK, PD) independently rated the certainty of evidence for each outcome as 'high', 'moderate', 'low', or 'very low'; we resolved discrepancies by consensus or, when needed, by the arbitration of a third review author (NS). We present a summary of the evidence for the main outcomes in a 'Summary of findings' table; these tables provide key information about the best estimate of the magnitude of the effect in relative terms and present absolute differences for each relevant comparison of alternative management strategies; numbers of participants and studies addressing each important outcome; and the rating of the overall confidence in the effect estimates for each outcome (Guyatt 2011; Schünemann 2011). If meta-analysis was not possible, we planned to present results in a narrative 'Summary of findings' table.

See Types of outcome measures for the outcomes included in the 'Summary of findings' table.

\section{RES U L T S}

\section{Description of studies}

\section{Results of the search}

We identified 352 records following our database search, and after screening by title and abstract, evaluated 13 full-text articles for eligibility. Only one study, reported in six records, ultimately met the inclusion criteria for assessment of the study question (for details see 'Figure 1 '). Four of the six records were additionally found by handsearching or screening of reference lists. We did not identify any completed but not reported trials. 
Figure 1. Study flow diagram.

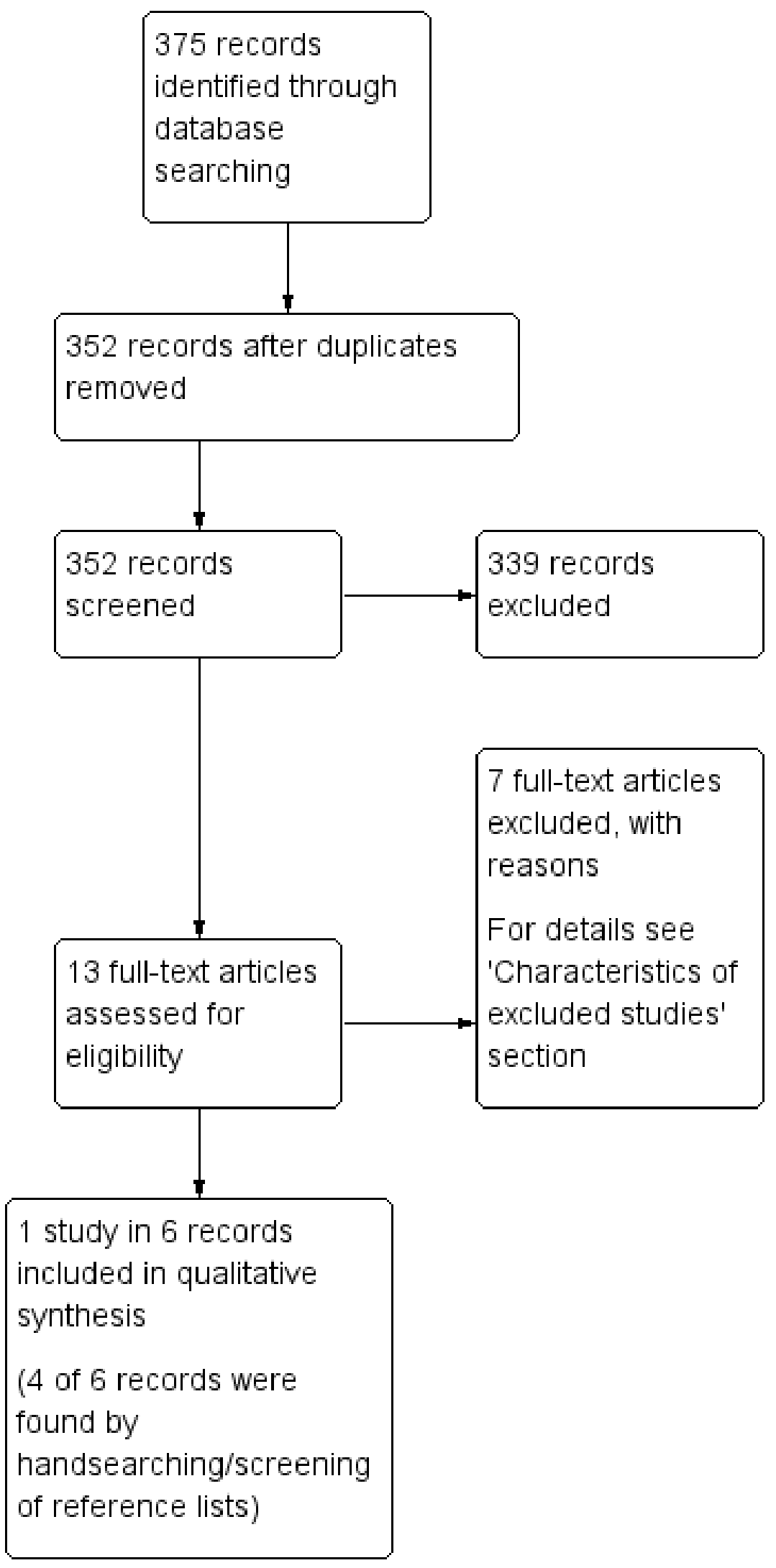




\section{Included studies}

We identified one randomised controlled trial (Bellmunt 2017). For details see 'Characteristics of included studies' table, Table 1 , and Table 2.

The included trial compared pembrolizumab monotherapy with chemotherapy (paclitaxel or vinflunine or docetaxel) for treatment of advanced urothelial carcinoma with disease progression during or following platinum-containing chemotherapy. 748 participants were screened for enrolment in 120 sites in 29 countries (Australia, Austria, Belgium, Canada, Chile, Denmark, France, Germany, Hungary, Ireland, Israel, Italy, Japan, Republic of Korea, Netherlands, New Zealand, Norway, Peru, Poland, Portugal, Puerto Rico, Romania, Singapore, Spain, Sweden, Taiwan, Turkey, United Kingdom, and United States). Between November 2014 and November 2015, 542 participants were randomly assigned in this trial that was sponsored by the producer of pembrolizumab. The median duration of follow-up was 14.1 months (range 9.9 to 22.1 months). The majority of participants had an ECOG performance status of 0 to 1 (pembrolizumab $n=262 / 270$; chemotherapy $n$ $=264 / 272$ ) and a visceral disease (pembrolizumab $n=240 / 270$; chemotherapy $n=233 / 272$ ). Liver metastases were evident in $33.7 \%$ to $35.1 \%$ of participants (pembrolizumab $n=91 / 270$; chemotherapy $n=95 / 272$ ).

\section{Excluded studies}

For details see 'Characteristics of excluded studies' section.

We excluded seven studies after assessing for eligibility (wrong comparator, $n=1$; first-line therapy, $n=2$; comments to other articles/letters, $n=3$; wrong intervention, $n=1$ ).

\section{Risk of bias in included studies}

For details see 'Characteristics of included studies' with 'Risk of bias' table, 'Summary of findings for the main comparison' and 'Figure 2' and 'Figure 3'. 
Figure 2. Risk of bias summary: review authors' judgements about each risk of bias item for each included study.

\begin{tabular}{|c|c|c|c|c|c|c|c|c|c|c|c|c|}
\hline & 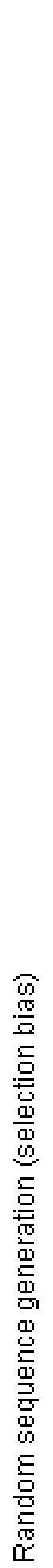 & 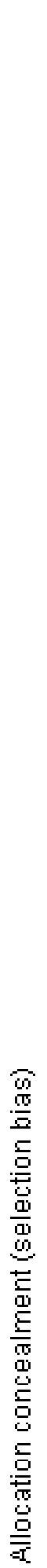 & 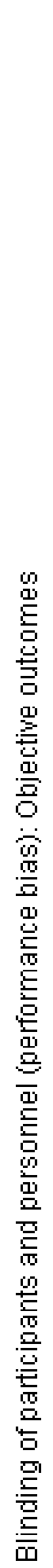 & 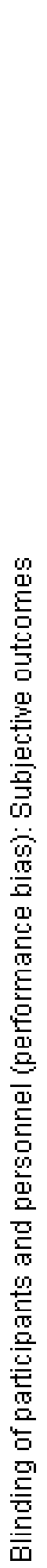 & 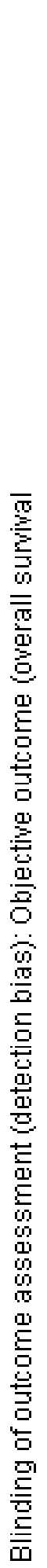 & 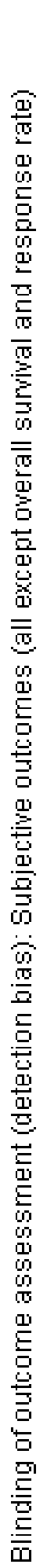 & 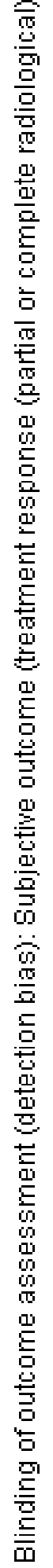 & 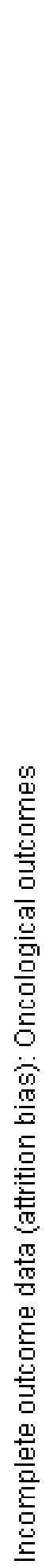 & 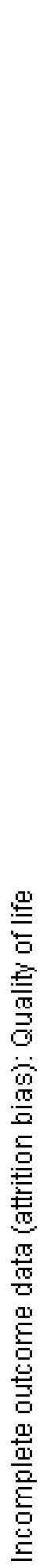 & 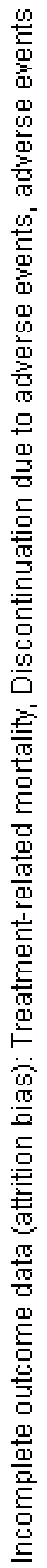 & 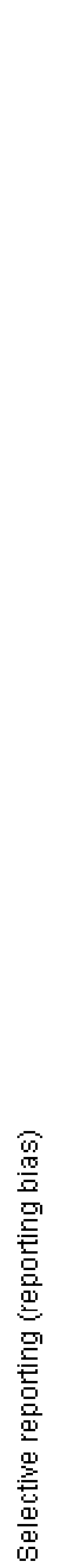 & 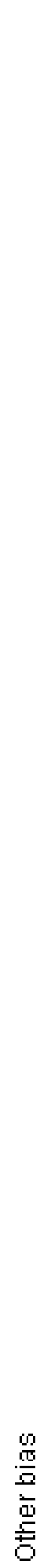 \\
\hline Bellmunt 2017 & & & $?$ & & + & & + & + & + & + & $?$ & + \\
\hline
\end{tabular}

Pembrolizumab monotherapy versus chemotherapy for treatment of advanced urothelial carcinoma with disease progression during or 
Figure 3. Risk of bias graph: review authors' judgements about each risk of bias item presented as percentages across all included studies.

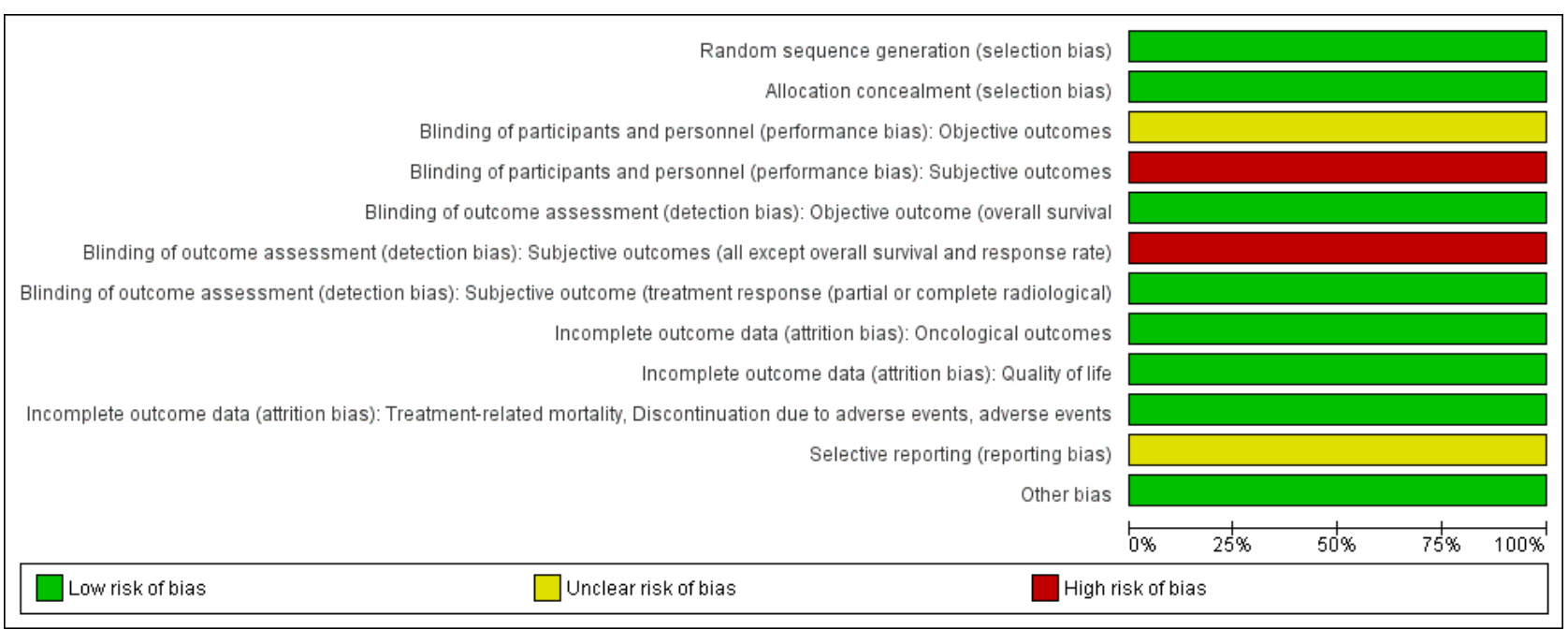

\section{Allocation}

Random sequence generation and allocation concealment were performed adequately, and we judged this study to be at low risk of selection bias.

\section{Blinding}

\section{Performance bias}

Participants and personnel were not blinded but we are uncertain whether this could have plausibly effected overall survival; we therefore rated the risk of bias as unclear for this outcome.

All others outcomes (quality of life, time to progression, response rate, discontinuation due to adverse events and serious adverse events) were judged to be potentially susceptible to cointerventions, thereby making blinding important; we rated the risk of bias as high risk.

\section{Detection bias}

Blinding of outcome assessors is not relevant to overall survival; we rated the risk of bias as low. The assessors of radiographical responses were reported to be blinded; we rated the risk of bias as low also.

All others outcomes (quality of life, time to progression, discontinuation due to adverse events and serious adverse events) which involve judgments on the part of the unblinded participants or investigators, or both, we judged to be potentially susceptible to detection bias, thereby making blinding important; we rated the risk of bias as high risk.

\section{Incomplete outcome data}

All participants who were randomised were included in the analysis for overall survival, progression-free survival, and response rate.
Attrition was less than $10 \%$ in either group for all other outcomes. We judged the risk of attrition bias as low for all outcomes.

\section{Selective reporting}

A protocol was available and the reported outcomes and their analyses in the completed study corresponded to how these had been planned. However, quality of life was not listed as a predefined outcome in the ClinicalTrials.gov registry (NCT02256436). We therefore assigned a judgment of unclear risk of reporting bias for the outcome of quality of life.

\section{Other potential sources of bias}

No other potential sources of bias were identified.

\section{Effects of interventions}

See: Summary of findings for the main comparison Pembrolizumab compared to chemotherapy for treatment of advanced urothelial carcinoma with disease progression during or following platinum-containing chemotherapy. A Cochrane Rapid Review

\section{Pembrolizumab versus chemotherapy}

\subsection{Primary outcomes}

\subsubsection{Time to death from any cause}

Pembrolizumab probably extends time to death from any cause (HR $0.73,95 \% \mathrm{Cl} 0.59$ to 0.90 ; 1 study; 542 participants; median follow-up 14.1 months; Analysis 1.1; Figure 4; moderate certainty evidence). This corresponds to 695 deaths per 1000 participants with chemotherapy and 115 fewer (191 fewer to 38 fewer) deaths per 1000 participants with pembrolizumab. We downgraded the certainty of the evidence by one level for imprecision (Summary of findings for the main comparison). 
Figure 4. Forest plot of comparison: 1 Pembrolizumab versus chemotherapy, outcome: 1.1 Overall survival.

\begin{tabular}{|c|c|c|c|c|c|c|c|c|c|}
\hline \multirow[b]{2}{*}{ Study or Subgroup } & \multirow[b]{2}{*}{ log[Hazard Ratio] } & \multicolumn{3}{|c|}{ pembrolizumab chemotherapy } & \multirow{2}{*}{\multicolumn{2}{|c|}{$\begin{array}{c}\text { Hazard Ratio } \\
\text {. }\end{array}$}} & \multirow{2}{*}{\multicolumn{2}{|c|}{$\begin{array}{c}\text { Hazard Ratio } \\
\text { IV, Random, } 95 \% \mathrm{Cl} \\
\end{array}$}} & Risk of Bias \\
\hline & & SE & Total & Total & & & & & A B C D E F G \\
\hline Bellmunt 2017 & -0.3147 & 0.1086 & 270 & 272 & $100.0 \%$ & $0.73[0.59,0.90]$ & & & 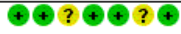 \\
\hline Total $(95 \% \mathrm{Cl})$ & & & 270 & 272 & $100.0 \%$ & $0.73[0.59,0.90]$ & & & \\
\hline $\begin{array}{l}\text { Heterogeneity: Not a } \\
\text { Test for overall effect }\end{array}$ & $\begin{array}{l}\text { plicable } \\
Z=2.90(P=0.004)\end{array}$ & & & & & & $\begin{array}{|ccc|}0.1 & 1 & 1 \\
\text { Favours pembrolizumab }\end{array}$ & $\begin{array}{|ccc|}\frac{1}{2} & 5 & 10 \\
\text { Favours chemotherapy }\end{array}$ & \\
\hline $\begin{array}{l}\text { Risk of bias legend } \\
\text { (A) Random sequen } \\
\text { (B) Allocation concea } \\
\text { (C) Blinding of partici } \\
\text { (D) Blinding of outco } \\
\text { (E) Incomplete outco } \\
\text { (F) Selective reportin } \\
\text { (G) Other bias }\end{array}$ & $\begin{array}{l}\text { e generation (selecti } \\
\text { ment (selection bias } \\
\text { ants and personnel } \\
\text { he assessment (det } \\
\text { ne data (attrition bias } \\
\text { (reporting bias) }\end{array}$ & $\begin{array}{l}\text { ion bias) } \\
\text { ) } \\
\text { (perform } \\
\text { ection bia } \\
\text { s): Oncolc }\end{array}$ & $\begin{array}{l}\text { Objec } \\
\text { ve outc } \\
\text { omes }\end{array}$ & $\begin{array}{l}\text { mes } \\
\text { rall sur }\end{array}$ & & & & & \\
\hline
\end{tabular}

\subsubsection{Quality of life}

Quality of life (change from baseline to week 15) was not listed as a predefined outcome in the ClinicalTrials.gov registry (NCT02256436). Quality of life was assessed with the Core Quality of Life Questionnaire (QLQ-C30). Quality of life scores from baseline to week 15 were stable for pembrolizumab, while they decreased with chemotherapy, but the difference did not quite meet the threshold of a minimal clinically important difference of 10 (MD 9.05, 95\% $\mathrm{Cl} 4.61$ to 13.50 ; 1 study; 520 participants; Analysis 1.2; Figure 5; low quality evidence). A high score represents better quality of life on this scale. We downgraded the certainty of evidence two levels for study limitations and imprecision (Summary of findings for the main comparison).

Figure 5. Forest plot of comparison: 1 Pembrolizumab versus chemotherapy, outcome: 1.2 Quality of life (change from baseline to week 15).

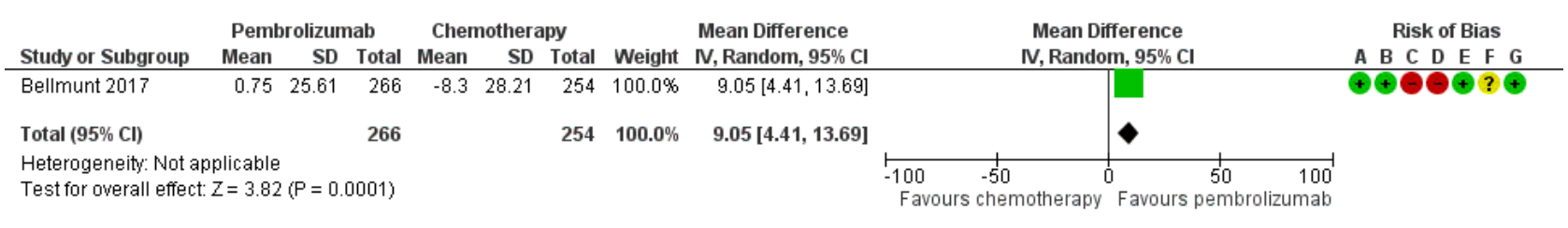

Risk of bias legend

(A) Random sequence generation (selection bias)

(B) Allocation concealment (selection bias)

(C) Blinding of participants and personnel (performance bias): Subjective outcomes

(D) Blinding of outcome assessment (detection bias): Subjective outcomes (all except overall survival and response rate)

(E) Incomplete outcome data (attrition bias): Quality of life

(F) Selective reporting (reporting bias)

(G) Other bias

\subsection{Secondary outcomes}

\subsubsection{Time to progression}

Pembolizumab may have little or no effect on time to progression (HR 0.98, 95\% Cl 0.81 to 1.19; 1 study; 542 participants; median follow-up 14.1 months; Analysis 1.3). This corresponds to three fewer (42 fewer to 24 more) progression events per 1000 participants at 12-month follow-up. We downgraded the certainty of evidence for imprecision.

\subsubsection{Response rate (partial and complete response)}

Response rate (partial or complete radiologic response to therapy) was probably improved slightly with pembrolizumab (RR 1.85, $95 \% \mathrm{Cl} 1.24$ to 2.77 ; 1 study; 542 participants; median follow-up 14.1 months; Analysis 1.4; Figure 6; moderate quality evidence). This corresponds to 114 respondents per 1000 participants with chemotherapy and 97 more ( 27 more to 202 more) respondents per 1000 participants with pembrolizumab. Certainty of evidence was judged to be moderate (downgraded one level for imprecision; Summary of findings for the main comparison). 
Figure 6. Forest plot of comparison: 1 Pembrolizumab versus chemotherapy, outcome: 1.8 Serious adverse events (irrespective of attribution to treatment).

\begin{tabular}{|c|c|c|c|c|c|c|c|}
\hline \multirow[b]{2}{*}{ Study or Subgroup } & \multicolumn{2}{|c|}{ Pembrolizumab } & \multicolumn{2}{|c|}{ Chemotherapy } & \multirow[b]{2}{*}{ Weight } & \multirow{2}{*}{$\begin{array}{l}\text { Peto Odds Ratio } \\
\text { Peto, Fixed, } 95 \% \mathrm{Cl}\end{array}$} & \multirow{2}{*}{$\begin{array}{l}\text { Peto Odds Ratio } \\
\text { Peto, Fixed, } 95 \% \mathrm{Cl}\end{array}$} \\
\hline & Events & Total & Events & Total & & & \\
\hline \multicolumn{8}{|c|}{ 1.8.1 Pruritus (Grade $3, \mathbf{4}$, or 5 ) } \\
\hline $\begin{array}{l}\text { Bellmunt } 2017 \\
\text { Subtotal }(95 \% \mathrm{Cl})\end{array}$ & 0 & $\begin{array}{l}266 \\
266\end{array}$ & 1 & $\begin{array}{l}255 \\
255\end{array}$ & $\begin{array}{l}100.0 \% \\
\mathbf{1 0 0 . 0} \%\end{array}$ & $\begin{array}{r}0.13[0.00,6.54] \\
\mathbf{0 . 1 3}[\mathbf{0 . 0 0 , 6 . 5 4 ]}\end{array}$ & \\
\hline \multicolumn{8}{|c|}{$\begin{array}{l}\text { Heterogeneity: Not applicable } \\
\text { Test for overall effect: } Z=1.02(P=0.31)\end{array}$} \\
\hline \multicolumn{8}{|c|}{ 1.8.2 Fatigue (Grade 3, 4, or 5) } \\
\hline $\begin{array}{l}\text { Bellmunt } 2017 \\
\text { Subtotal }(95 \% \mathrm{Cl})\end{array}$ & 10 & $\begin{array}{l}266 \\
266\end{array}$ & 15 & $\begin{array}{l}255 \\
255\end{array}$ & $\begin{array}{l}100.0 \% \\
\mathbf{1 0 0 . 0} \%\end{array}$ & $\begin{array}{l}0.63[0.28,1.40] \\
\mathbf{0 . 6 3}[\mathbf{0 . 2 8}, \mathbf{1 . 4 0}]\end{array}$ & \\
\hline \multicolumn{8}{|c|}{$\begin{array}{l}\text { Heterogeneity: Not applicable } \\
\text { Test for overall effect: } Z=1.13(P=0.26)\end{array}$} \\
\hline \multicolumn{8}{|c|}{ 1.8.3 Diarrhoea (Grade 3, 4, or 5) } \\
\hline $\begin{array}{l}\text { Bellmunt } 2017 \\
\text { Subtotal }(95 \% \mathrm{Cl})\end{array}$ & 4 & $\begin{array}{l}266 \\
266\end{array}$ & 4 & $\begin{array}{l}255 \\
255\end{array}$ & $\begin{array}{l}100.0 \% \\
\mathbf{1 0 0 . 0} \%\end{array}$ & $\begin{array}{l}0.96[0.24,3.87] \\
\mathbf{0 . 9 6}[0.24,3.87]\end{array}$ & \\
\hline \multicolumn{8}{|c|}{$\begin{array}{l}\text { Heterogeneity: Not applicable } \\
\text { Test for overall effect: } Z=0.06(P=0.95)\end{array}$} \\
\hline \multicolumn{8}{|c|}{ 1.8.4 Anaemia (Grade 3,4 , or 5) } \\
\hline $\begin{array}{l}\text { Bellmunt } 2017 \\
\text { Subtotal }(95 \% \mathrm{Cl})\end{array}$ & 22 & $\begin{array}{l}266 \\
266\end{array}$ & 31 & $\begin{array}{l}255 \\
255\end{array}$ & $\begin{array}{r}100.0 \% \\
\mathbf{1 0 0 . 0} \%\end{array}$ & $\begin{array}{r}0.65[0.37,1.15] \\
\mathbf{0 . 6 5}[\mathbf{0 . 3 7}, \mathbf{1 . 1 5}]\end{array}$ & \\
\hline \multicolumn{8}{|c|}{$\begin{array}{l}\text { Heterogeneity: Not applicable } \\
\text { Test for overall effect: } Z=1.47(P=0.14)\end{array}$} \\
\hline \multicolumn{8}{|c|}{ 1.8.5 Constipation (Grade 3,4 , or 5 ) } \\
\hline $\begin{array}{l}\text { Bellmunt } 2017 \\
\text { Subtotal }(95 \% \mathrm{Cl})\end{array}$ & 3 & $\begin{array}{l}266 \\
266\end{array}$ & 8 & $\begin{array}{l}255 \\
255\end{array}$ & $\begin{array}{l}100.0 \% \\
\mathbf{1 0 0 . 0} \%\end{array}$ & $\begin{array}{r}0.38[0.11,1.25] \\
\mathbf{0 . 3 8}[\mathbf{0 . 1 1}, \mathbf{1 . 2 5}]\end{array}$ & \\
\hline \multicolumn{8}{|c|}{$\begin{array}{l}\text { Heterogeneity: Not applicable } \\
\text { Test for overall effect: } Z=1.59(P=0.11)\end{array}$} \\
\hline \multicolumn{8}{|c|}{ 1.8.6 Peripheral sensory neuropathy (Grade 3,4 , or 5 ) } \\
\hline $\begin{array}{l}\text { Bellmunt } 2017 \\
\text { Subtotal }(95 \% \mathrm{Cl})\end{array}$ & 0 & $\begin{array}{l}266 \\
266\end{array}$ & 5 & $\begin{array}{l}255 \\
255\end{array}$ & $\begin{array}{l}100.0 \% \\
\mathbf{1 0 0 . 0} \%\end{array}$ & $\begin{array}{c}0.13[0.02,0.74] \\
\mathbf{0 . 1 3}[\mathbf{0 . 0 2 , 0 . 7 4 ]}\end{array}$ & \\
\hline $\begin{array}{l}\text { Total events } \\
\text { Heterogeneity: Not a } \\
\text { Test for overall effect }\end{array}$ & $\begin{array}{l}{ }_{\text {plicable }} \\
Z=2.29(\mathrm{P}\end{array}$ & $0.02)$ & 5 & & & & \\
\hline 1.8.7 Neutropenia (G & ade $3,4,0$ & & & & & & \\
\hline $\begin{array}{l}\text { Bellmunt } 2017 \\
\text { Subtotal }(95 \% \mathrm{Cl})\end{array}$ & 0 & $\begin{array}{l}266 \\
266\end{array}$ & 37 & $\begin{array}{l}255 \\
255\end{array}$ & $\begin{array}{l}100.0 \% \\
\mathbf{1 0 0 . 0} \%\end{array}$ & $\begin{array}{r}0.11[0.06,0.22] \\
\mathbf{0 . 1 1}[\mathbf{0 . 0 6}, \mathbf{0 . 2 2}]\end{array}$ & \\
\hline $\begin{array}{l}\text { Total events } \\
\text { Heterogeneity: Not an } \\
\text { Test for overall effect }\end{array}$ & $\begin{array}{l}\text { plicable }^{0} \\
Z=6.44(\mathrm{P}\end{array}$ & 0.0000 & 37 & & & & \\
\hline 1.8.8 Alopecia (Grad & 3,4, or 5 ) & & & & & & \\
\hline $\begin{array}{l}\text { Bellmunt } 2017 \\
\text { Subtotal (95\% Cl) }\end{array}$ & 0 & $\begin{array}{l}266 \\
266\end{array}$ & 3 & $\begin{array}{l}255 \\
255\end{array}$ & $\begin{array}{l}100.0 \% \\
\mathbf{1 0 0 . 0} \%\end{array}$ & $\begin{array}{l}0.13[0.01,1.24] \\
\mathbf{0 . 1 3}[\mathbf{0 . 0 1}, \mathbf{1 . 2 4}]\end{array}$ & \\
\hline $\begin{array}{l}\text { Total events } \\
\text { Heterogeneity: Not a } \\
\text { Test for overall effect }\end{array}$ & $\begin{array}{l}\quad{ }^{0} \\
\text { plicable } \\
Z=1.77(P\end{array}$ & $0.08)$ & 3 & & & & \\
\hline 1.8.9 Hypothyr oidisn & (Grade 3, & 5) & & & & & \\
\hline $\begin{array}{l}\text { Bellmunt } 2017 \\
\text { Subtotal }(95 \% \mathrm{Cl})\end{array}$ & 0 & $\begin{array}{l}266 \\
266\end{array}$ & 0 & $\begin{array}{l}255 \\
255\end{array}$ & & $\begin{array}{l}\text { Not estimable } \\
\text { Not estimable }\end{array}$ & \\
\hline $\begin{array}{l}\text { Total events } \\
\text { Heterogeneity: Not a } \\
\text { Test for overall effect }\end{array}$ & $\begin{array}{l}\text { plicable } \\
\text { Not applic }\end{array}$ & & 0 & & & & \\
\hline 1.8.10 Skin reaction & Grade 3, 4 & 5) & & & & & \\
\hline $\begin{array}{l}\text { Bellmunt } 2017 \\
\text { Subtotal }(95 \% \mathrm{Cl})\end{array}$ & 1 & $\begin{array}{l}266 \\
266\end{array}$ & 6 & $\begin{array}{l}255 \\
255\end{array}$ & $\begin{array}{l}100.0 \% \\
\mathbf{1 0 0 . 0} \%\end{array}$ & $\begin{array}{c}0.23[0.05,1.00] \\
\mathbf{0 . 2 3}[\mathbf{0 . 0 5}, \mathbf{1 . 0 0}]\end{array}$ & \\
\hline $\begin{array}{l}\text { Total events } \\
\text { Heterogeneity: Not ap }\end{array}$ & plicable $^{1}$ & & 6 & & & & \\
\hline
\end{tabular}


Figure 6. (Continued)

\author{
Total events \\ Heterogeneity: Not applicable \\ Test for overall effect: $Z=1.96(P=0.05)$
}

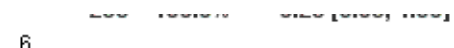

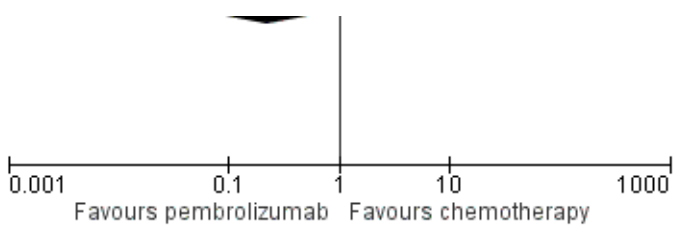

\subsubsection{Treatment-related mortality}

Pembrolizumab may have little or no impact on treatment-related mortality (HR 0.96, 95\% Cl 0.24 to 3.79; 1 study; 521 participants; median follow-up 14.1 months; Analysis 1.5). This corresponds to one less treatment-related death per 1000 participants (95\% Cl: 12 fewer to 44 more). The certainty of evidence was judged to be low, we downgraded two levels for study limitations and imprecision; Summary of findings for the main comparison).

\subsubsection{Discontinuation due to adverse events (any grade)}

Pembrolizumab may have little of no effect on discontinuations due to adverse events (RR $0.66,95 \% \mathrm{Cl} 0.39$ to $1.10 ; 1$ study; 521 participants; median follow-up 14.1 months; Analysis 1.6). This corresponds to 54 fewer discontinuations per 1000 participants (95\% Cl 79 fewer to 7 fewer). We downgraded the certainty of evidence for study limitations and imprecision (Summary of findings for the main comparison).

\subsubsection{Serious adverse events (irrespective of attribution to treatment)}

We included adverse events data of grade 3, 4, or 5 according to CTCAE regardless of attribution to treatment by the investigator. Pembrolizumab may reduce serious adverse events (RR $0.83,95 \mathrm{Cl}$ 0.72 to 0.97 ; low certainty evidence Analysis 1.7). This corresponds to 107 fewer serious averse events per 1000 participants $(95 \% \mathrm{Cl} 19$ fewer to 176 fewer). We downgraded two levels for study limitations and imprecision.

\section{Individual serious adverse events (any adverse events of grade 3, 4, or 5} according to (TCAE)

Pembrolizumab probably decreases the rate of neutropenia (OR $0.11,95 \% \mathrm{Cl} 0.06$ to $0.22 ; 1$ study; 521 participants; Analysis 1.8; Figure 6). We are uncertain whether pembrolizumab improves or reduces the rate of pruritus, fatigue, diarrhoea, anaemia, constipation, peripheral sensory neuropathy, alopecia, hypothyroidism, or skin reaction as the certainty of the evidence is limited by imprecision, as well as performance and detection bias.

We identified no adverse events data regardless of attribution to treatment by the investigators for pneumonitis (only treatmentrelated events were reported: pembrolizumab 6/266 versus chemotherapy $0 / 255$ ), hyperthyroidism (only treatment-related events were reported: pembrolizumab $0 / 266$ versus chemotherapy $0 / 255$ ), colitis (only treatment-related events were reported: pembrolizumab $3 / 266$ vs. chemotherapy $0 / 255$ ), nephritis (only treatment-related events were reported: pembrolizumab 2/266 versus chemotherapy $0 / 255$ ), thyroiditis (only treatment-related events were reported: pembrolizumab $0 / 266$ versus chemotherapy $0 / 255$ ), adrenal insufficiency (only treatment-related events were reported: pembrolizumab $1 / 266$ versus chemotherapy $0 / 255$ ), and myositis (only treatment-related events were reported: pembrolizumab $0 / 266$ versus chemotherapy $1 / 255$ ).
We identified no adverse events data for hypophysitis and cardiovascular events.

\section{Subgroup analyses \\ Preplanned subgroup analyses}

We performed preplanned subgroup analyses with regard to overall survival.

\section{Performance status (ECOG 0 or 1 versus $\geq 2$ )}

For details see Analysis 2.1. Of 542 participants, 526 had an ECOG 0 to 1 (262 in the pembrolizumab group, 264 in the chemotherapy group); and 6 had an ECOG $\geq 2$ ( 2 in the pembrolizumab group, 4 in the chemotherapy group; 10 participants had missing data). We did not find evidence for subgroup differences (ECOG 0 to 1 versus $\geq 2$; $=0.66$ ).

Time since last chemotherapy administration (< three months versus $\geq$ three months)

For details see Analysis 2.2. Of 542 participants, 207 received chemotherapy for less than three months (103 in the pembrolizumab group, 104 in the chemotherapy group) and 333 received chemotherapy for greater than or equal to three months (166 in the pembrolizumab group, 167 in the chemotherapy group). We did not find evidence for subgroup differences (last chemotherapy administration $<$ three months versus $\geq$ three months; $P=0.35$ ).

\section{Degree of pretreatment (second- versus third- versus fourth-line or more)}

For details see Analysis 2.3. Of 542 participants, 84 had adjuvant or neoadjuvant chemotherapy, 340 had one prior treatment for metastatic disease, and 115 had two prior treatments for metastatic disease. We did not find evidence for subgroup differences (degree of pretreatment; $\mathrm{P}=0.79$ ).

\section{PD-L1 tumour expression status (positive versus negative; $1 \%$ cutoff)}

For details see Analysis 2.4. Of 298 participants, 184 had a tumour PD-L1 combined positive score of less than one per cent (negative according to our definition) and 142 of 230 participants had a positive score greater than or equal to one per cent (positive according to our definition). We did not find evidence for subgroup differences $(P=0.11)$.

\section{Post-hoc included subgroup analyses}

We also included further not-preplanned subgroup analyses (see Analysis 3.1 - Analysis 3.12).

\section{Smoking status}

For details see Analysis 3.3. Of 542 participants, 67 were current smokers ( 29 in the pembrolizumab group, 38 in the chemotherapy 
group), 284 were former smokers (136 in the pembrolizumab group, 148 in the chemotherapy group), and 187 never smoked (104 in the pembrolizumab group, 83 in the chemotherapy group). We found heterogeneity between these two subgroups $\left(1^{2}=75 \%\right)$. The test for subgroup differences showed a difference between the subgroups $(P=0.02)$. Overall survival was probably more improved with pembrolizumab in current smokers ( $\mathrm{HR} 0.32,95 \% \mathrm{Cl} 0.15-0.68$ ) compared to former smokers ( $\mathrm{HR} 0.71,95 \% \mathrm{Cl} 0.52$ to 0.97 ) or participants who had never smoked (HR $1.06,95 \% \mathrm{Cl} 0.72$ to 1.55$)$.

For all other subgroup analyses, the test for subgroup differences showed no difference ( $P>0.05$; Analysis 3.1; Analysis 3.2; Analysis 3.4; Analysis 3.5; Analysis 3.6; Analysis 3.7; Analysis 3.8; Analysis 3.9; Analysis 3.10; Analysis 3.11; Analysis 3.12).

\section{DISCUSSION}

\section{Summary of main results}

We identified one randomised controlled trial with 542 participants that compared pembrolizumab monotherapy with chemotherapy for treatment of advanced urothelial carcinoma with disease progression during or following platinum-containing chemotherapy. Pembrolizumab probably extends time to death from any cause (moderate certainty of evidence) and may improve quality of life slightly. It may not impact treatment related mortality, but may reduce discontinuations due to adverse events and serious adverse events.

\section{Overall completeness and applicability of evidence}

This Cochrane Rapid Review is based on only one randomised controlled trial (Bellmunt 2017). However, the included study evaluated the drug pembrolizumab in a clinically important population seen in daily clinical practice. The participants and interventions conformed to the review question and the study reported on all predefined outcomes. Our patient important coprimary outcome quality of life was not listed as a predefined outcome in the ClinicalTrials.gov registry (NCT02256436), but results were presented in abstract form at ASCO GU 2017 conference. No quality of life data were presented in the published manuscript.

The included study analysed only a few relevant adverse events, and the confidence intervals for adverse events are wide, leading to the presumption that current evidence is limited by imprecision. Further research including post-market phase IV studies appear necessary for the evaluation of safety and rare adverse events.

In a letter to the editor regarding Bellmunt 2017, Liang and Zhu remarked that the prespecified subgroup analysis for geographic region (East Asia versus non-East Asia and European Union versus non-European Union) was not reported, and raised concerns that variations in the geographic regions could affect the response to pembrolizumab (Liang 2017). We were unable to address this concern.

Additionally, no platinum-containing second-line chemotherapy (e.g. MVAC or gemcitabine plus cisplatin or carboplatin) was used to compare against pembrolizumab. Pembrolizumab was compared only with vinflunine, docetaxel, or paclitaxel, which may represent inferior regimens with reported minimal or non-durable response rates. This may cast a more favourable light on the new agent, pembrolizumab.
A detailed review of Kaplan-Meier curves of pembrolizumab show characteristics that are noteworthy. Treatment response is seen as a parameter of uncertain value in check-point-blockade-inhibition because it is observed that in certain participants there is a short progression initially after therapy start with objective response in the late therapy process and that certain participants will profit from continuing immunotherapy beyond first progression (Hodi 2016). In the case of this study, second-line chemotherapy appeared to be more superior to pembrolizumab in the first four months. Only afterwards did the survival curves cross and favour pembrolizumab. Additionally, only a certain fraction of participants appeared to benefit from pembrolizumab treatment; however, these individuals saw markedly long survival. There is further research necessary for improved selection of participants that will profit from pembrolizumab therapy.

\section{Quality of the evidence}

We rated the certainty of evidence about effects as moderate to low. Reasons for downgrading included concerns over performance and detection bias (due to lack of blinding) and imprecision. For details on certainty of evidence see Summary of findings for the main comparison.

\section{Potential biases in the review process}

This Cochrane Rapid Review provides an overview of current evidence in a limited time frame and therefore uses streamlined systematic review methods for providing available evidence with shorter turnaround time. Nevertheless, this rapid review was performed with a broad search strategy in multiple biomedical databases and the evaluation of the literature and data extraction were performed by two independent review authors. While it is theoretically possible that additional studies may have been conducted but not yet published, or that additional studies may not have been identified, this is unlikely.

\section{Agreements and disagreements with other studies or reviews}

A systematic review published by Wang and colleagues assessed immune-related adverse events and included 46 studies representing 12,808 oncologic patients (including melanomas, Hodgkin lymphomas, urothelial carcinomas, breast cancers, nonsmall cell lung cancers, renal cell carcinomas, colorectal cancers, and others; Wang 2017). They evaluated different immunecheckpoint inhibitors including nivolumab, pembrolizumab, atezolizumab, durvalumab, avelumab, and BMS-936559. The authors found that in patients treated with PD-1 signalling inhibitors, the overall incidence of immune-related adverse events was $26.82 \%\left(I^{2}=92.80\right)$ in any grade and $6.10 \%\left(1^{2}=52.00\right)$ in severe grades (Wang 2017). However, interpretation of the data is limited because of missing control group evaluation data and high heterogeneity.

A systematic review published by Rijinder et al. evaluated immune checkpoint inhibitors in urological cancers (Rijnders 2017). They similarly identified one study of pembrolizumab in second-line treatment for urothelial carcinoma and concluded that this therapy may be safe and confers a survival benefit in advanced urothelial carcinoma (Rijnders 2017). However, there is no 'Risk of bias' assessment or grading of certainty of evidence provided. 
The guideline of the European Association of Urology recommends that vinflunine should be offered to patients progressing after platinum-based combination chemotherapy for metastatic disease. However, vinflunine has not been approved by the FDA for this indication in the United States (EAU 2017). There is also a statement that it may be a reasonable strategy to re-challenge former cisplatin-sensitive patients if progression occurs at least six to twelve months after first-line cisplatin-based combination chemotherapy (EAU 2017). The bladder cancer guideline of the National Comprehensive Cancer Network recommends that consideration of checkpoint inhibitors must be integrated into therapeutic planning for all patients with locally advanced and metastatic disease and both guidelines recommend an enrolment of participants treated with immunotherapy in clinical trials (EAU 2017; NCCN Guideline 2017).

Also, the Institute for Quality and Efficiency in Healthcare (Institut für Qualität und Wirtschaftlichkeit im Gesundheitswesen), a German agency that is responsible for assessing the quality and efficacy of medical treatments, concluded that there is evidence of a considerable additional benefit with pembrolizumab (IQWiG 2017).

\section{AUTHORS' CONCLUSIONS}

\section{Implications for practice}

Pembrolizumab monotherapy for treatment of advanced urothelial carcinoma with disease progression during or following platinum- containing chemotherapy compared to chemotherapy probably improves overall survival to a small degree and may also improve quality of life although we are uncertain about this. It may also offer benefits in terms of response rate and rates of serious adverse events. In the setting of limited therapeutic alternatives, there appears to be a role for this agent in the therapeutic armamentarium.

\section{Implications for research}

This review identified only one randomised controlled trial to contribute to its findings, and conclusions are limited primarily by imprecision and performance or detection biases. More rigorous trials are necessary in the future. In particular, future studies should place greater emphasis on quality of life assessment.

Only a subset of participants appear to benefit from pembrolizumab treatment. There is an urgent need for research to identify such patients prospectively in the future.

Furthermore, phase IV post-marketing studies should be conducted for the evaluation of long-term drug safety and assessment of rare yet potentially serious adverse events.

\section{ACKNOWLEDGEMENTS}

The authors thank the Cochrane Urology staff members and the peer-reviewers Maximilian Burger, Mark Klein, and Angelika Borkowetz for their support. 


\section{R E F E R E N C E S}

\section{References to studies included in this review}

\section{Bellmunt 2017 \{published data only\}}

Bellmunt J, Sonpavde G, Wit R, Choueiri TK, Siefker-Radtke AO, Plimack ER, et al. KEYNOTE-045: randomized phase 3 trial of pembrolizumab (MK-3475) versus paclitaxel, docetaxel, or vinflunine for previously treated metastatic urothelial cancer. Journal of Clinical Oncology 2015 [Epub ahead of print]; Vol. 33, issue 15 Suppl. [DOI: 10.1200/jco.2015.33.15_suppl.tps4571]

* Bellmunt J, de Wit R, Vaughn DJ, Fradet Y, Lee J-L, Fong L, et al. Pembrolizumab as second-line therapy for advanced urothelial carcinoma. New England Journal of Medicine 2017;376(11):1015-26. [DOI: 10.1056/NEJMoa1613683]

De Wit R, Bajorin DF, Bellmunt J, Fradet Y, Lee J-L, Fong L. Health-related quality of life (HRQoL) of pembrolizumab (pembro) vs chemotherapy (chemo) for previously treated advanced urothelial cancer (UC) in KEYNOTE-045. Journal of Clinical Oncology 2017;35(15 Suppl):4530. [DOI: 10.1200/ JCO.2017.35.15_suppl.4530]

Merck Sharp, Dohme Corp. A study of pembrolizumab (MK-3475) versus paclitaxel, docetaxel, or vinflunine for participants with advanced urothelial cancer (MK-3475-045/ KEYNOTE-045). clinicaltrials.gov/ct2/show/NCT02256436 (accessed 1 November 2017).

Quinn D, Bellmunt J, Wit R, Vaughn DJ, Fradet Y, Lee JL, et al. Keynote-045: open-label, phase 3 study of pembrolizumab versus investigator's choice of paclitaxel, docetaxel, or vinflunine for previously treated advanced urothelial cancer. Asia-Pacific Journal of Clinical Oncology 2017; Vol. 13, issue Suppl S1:35.

Vaughn DJ, Bellmunt J, Fradet Y, Lee JL, Fong L, Vogelzang NJ, et al. Health-Related Quality-of-Life Analysis From KEYNOTE-045: A Phase III Study of Pembrolizumab Versus Chemotherapy for Previously Treated Advanced Urothelial Cancer. Journal of Clinical Oncology 2018;36(16):1579-1587.

\section{References to studies excluded from this review}

\section{Acerta 2017 \{published data only\}}

Acerta Pharma BV, Merck Sharp, Dohme Corp. Study of the combination of ACP-196 and pembrolizumab in subjects with platinum resistant urothelial bladder cancer. clinicaltrials.gov/ ct2/show/NCT02351739 (accessed 1 November 2017).

\section{Alva 2016 \{published data only\}}

Alva A, Gschwendt J, Loriot Y, Bellmunt J, Feng D, Poehlein C, et al. KEYNOTE-361: randomized phase III study of pembrolizumab with or without chemotherapy versus chemotherapy alone in advanced urothelial carcinoma. Journal for ImmunoTherapy of Cancer 2016; Vol. 4, issue Suppl 1.

\section{Guo 2017 \{published data only\}}

Guo T, Feng C. Pembrolizumab for advanced urothelial carcinoma. New England Journal of Medicine 2017;376(23):2303-4.
Matthew 2015 \{published data only\}

Galsky M, Hoosier Cancer Research Network and Merck Sharp \& Dohme Corp. Testing the PD-1 inhibitor pembrolizumab as maintenance therapy after initial chemotherapy in metastatic bladder cancer. clinicaltrials.gov/ct2/show/NCT02500121 accessed 1 November 2017.

\section{Mitchell 2017 \{published data only\}}

Mitchell F. Pembrolizumab as second-line treatment for urothelial cancer. Lancet Oncology 2017;18(4):e197. [DOI: 10.1016/S1470-2045(17)30156-0]

\section{Powles 2017 \{published data only\}}

Powles T, Gschwend JE, Loriot Y, Bellmunt J, Geczi L, Vulsteke C, et al. Phase 3 KEYNOTE-361 trial: pembrolizumab (pembro) with or without chemotherapy versus chemotherapy alone in advanced urothelial cancer. Journal of Clinical Oncology 2017 [Epub ahead of print]; Vol. 35, issue 15 Suppl. [DOI: 10.1200/ JCO.2017.35.15_suppl.TPS4590]

\section{Venniyoor 2017 \{published data only\}}

Venniyoor A. Pembrolizumab for advanced urothelial carcinoma. New England Journal of Medicine 2017;376(23):2302-3. [DOI: 10.1056/NEJMc1704612]

\section{Additional references}

\section{Bellmunt 2013}

Bellmunt J, Fougeray R, Rosenberg JE, von der Maase $\mathrm{H}$, Schutz FA, Salhi Y, et al. Long-term survival results of a randomized phase III trial of vinflunine plus best supportive care versus best supportive care alone in advanced urothelial carcinoma patients after failure of platinum-based chemotherapy. Annals of Oncology 2013;24(6):1466-72.

\section{Covidence [Computer program]}

Veritas Health Innovation. Covidence. Version accessed 28 August 2017. Melbourne, Australia: Veritas Health Innovation, 2017.

\section{EAU 2017}

Witjes JA, Compérat E, Cowan NC, Gakis G, Hernández V, Lebret $\mathrm{T}$, et al. EAU guidelines on muscle-invasive and metastatic bladder cancer. uroweb.org/guideline/bladdercancer-muscle-invasive-and-metastatic/ (accessed 1 October 2017).

\section{Eisenhauer 2009}

Eisenhauer EA, Therasse P, Bogaerts J, Schwartz LH, Sargent D, Ford R, et al. New response evaluation criteria in solid tumours: revised RECIST guideline (version 1.1). European Journal of Cancer 2009; Vol. 45, issue 2:228-47.

\section{Endnote 2011 [Computer program]}

Thomson Reuters. EndNote X5. Version X5. Thomson Reuters, 2011. 


\section{Faraj 2015}

Faraj SF, Munari E, Guner G, Taube J, Anders R, Hicks J, et al. Assessment of tumoral PD-L1 expression and intratumoral CD8+ T cells in urothelial carcinoma. Urology 2015;85(3):703.e1-6.

\section{GLOBOCAN 2012}

Ferlay J, Soerjomataram I, Ervik M, Dikshit R, Eser S, Mathers C, et al. GLOBOCAN 2012 v1.0, Cancer Incidence and Mortality Worldwide: IARC CancerBase No. 11 [Internet]. Lyon, France: International Agency for Research on Cancer 2013;Available from: http://globocan.iarc.fr:accessed 10/2017.

\section{GRADEpro GDT [Computer program]}

McMaster University (developed by Evidence Prime). GRADEpro GDT. Version accessed 1 February 2017. Hamilton (ON): McMaster University (developed by Evidence Prime), 2015.

\section{Gupta 2015}

Gupta S, O'Donnell P, Plimack ER, Berger R, Montgomery B, Heath K, et al. Mp68-11 a Phase 1B Study of Pembrolizumab (Pembro; Mk-3475) for Advanced Urothelial Cancer. The Journal of Urology 2015;193(4):e861-2.

\section{Guyatt 2008}

Guyatt GH, Oxman AD, Vist GE, Kunz R, Falck-Ytter Y, Schünemann HJ, et al. GRADE: what is "quality of evidence" and why is it important to clinicians?. BMJ (Clinical Research Ed.) 2008;336(7651):995-8.

\section{Guyatt 2011}

Guyatt G, Oxman AD, Akl EA, Kunz R, Vist G, Brozek J, et al. GRADE guidelines: 1. Introduction-GRADE evidence profiles and summary of findings tables. Journal of Clinical Epidemiology 2011;64(4):383-94

\section{Higgins 2011a}

Higgins JP, Green S, editor(s). Cochrane Handbook for Systematic Reviews of Interventions. Version 5.1.0 (updated March 2011). The Cochrane Collaboration, 2011. Available from www.handbook.cochrane.org.

\section{Higgins 2011b}

Higgins JP, Altman DG, Sterne JA (editors). Chapter 8: Assessing risk of bias in included studies. In: Higgins JPT, Green S (editors). Cochrane Handbook for Systematic Reviews of Interventions. Version 5.1.0 [updated March 2011]. The Cochrane Collaboration, 2011. Available from www.cochranehandbook.org.

\section{Higgins 2011c}

Higgins JP, Deeks JJ, Altman DG. Chapter 16: Special topics in statistics. In: Higgins JPT, Green S, editor(s). Cochrane Handbook for Systematic Reviews of Interventions. Version 5.1.0 (updated March 2011). The Cochrane Collaboration, 2011. Available from handbook.cochrane.org.

\section{Higgins 2011d}

Deeks JJ, Higgins JP, Altman DG (editors). Chapter 9: Analysing data and undertaking meta-analyses. In: Higgins JPT, Green $\mathrm{S}$ (editors). Cochrane Handbook for Systematic Reviews of Interventions. Version 5.1.0 [updated March 2011]. The
Cochrane Collaboration, 2011. Available from www.cochranehandbook.org.

\section{Hodi 2016}

Hodi FS, Hwu WJ, Kefford R, Weber JS, Daud A, Hamid O, et al. Evaluation of immune-related response criteria and RECIST V1.1 in patients with advanced melanoma treated with pembrolizumab. Journal of Clinical Oncology 2016;34(13):1510-7.

\section{Hróbjartsson 2013}

Hróbjartsson A, Thomsen AS, Emanuelsson F, Tendal B, Hilden J, Boutron I, et al. Observer bias in randomized clinical trials with measurement scale outcomes: a systematic review of trials with both blinded and nonblinded assessors. Canadian Medical Association Journal 2013;185(4):E201-11.

\section{IQWiG 2017}

Institut für Qualität und Wirtschaftlichkeit im Gesundheitswesen (IQWiG). Pembrolizumab (urothelial carcinoma) [Pembrolizumab (Urothelkarzinom)]. Institute for Quality and Efficiency in Health Care 2017; Vol. Dossierbewertung A17-46, issue Version 1.0:3-9.

\section{Iwai 2002}

Iwai Y, Ishida M, Tanaka Y, Okazaki T, Honjo T, Minato N. Involvement of PD-L1 on tumor cells in the escape from host immune system and tumor immunotherapy by PD-L1 blockade. Proceedings of the National Academy of Sciences of the United States of America 2002;99(19):12293-7.

\section{Kim 2015}

Kim JW, Bellmunt J, Powles T, Loriot Y, Vogelzang MJ, Zambrano CC, et al. Clinical activity, safety, and biomarkers of MPDL3280A in metastatic urothelial bladder cancer: Additional analysis from phase IA study. Journal of Clinical Oncology 2015;33(7 Suppl):297.

\section{Leitlinienprogramm Onkologie}

Leitlinienprogramm Onkologie, Deutsche Krebsgesellschaft, Deutsche Krebshilfe, AWMF. S3 - Guideline for early detection, diagnosis, therapy and aftercare for bladder cancer [S3 Leitlinie Früherkennung, Diagnose, Therapie und Nachsorge des Harnblasenkarzinoms]. leitlinienprogramm-onkologie.de/ Harnblasenkarzinom.92.0.html (accessed 1 October 2017).

\section{Liang 2017}

Liang F, Zhu J. Pembrolizumab for advanced urothelial carcinoma. New England Journal of Medicine 2017;376(23):2302.

\section{Liberati 2009}

Liberati A, Altman DG, Tetzlaff J, Mulrow C, Gøtzsche PC, loannidis JP, et al. The PRISMA statement for reporting systematic reviews and meta-analyses of studies that evaluate health care interventions: explanation and elaboration. PLoS Medicine 2009;6(7):e1000100. [DOI: 10.1371/ journal.pmed.1000100]

\section{Logothetis 1990}

Logothetis CJ, Dexeus FH, Finn L, Sella A, Amato RJ, Ayala AG, et al. A prospective randomized trial comparing MVAC and CISCA 
chemotherapy for patients with metastatic urothelial tumors. Journal of Clinical Oncology 1990;8(6):1050-5.

\section{Morales 1976}

Morales A, Eidinger D, Bruce AW. Intracavitary Bacillus CalmetteGuerin in the treatment of superficial bladder tumors. The Journal of Urology 1976;116(2):180-3.

\section{NCCN Guideline 2017}

Spiess PE, Agarwal N, Bangs R, Boorjian SA, Buyyounouski MK, Clark PE, et al. Bladder Cancer, Version 5.2017, NCCN Clinical Practice Guidelines in Oncology. Journal of the National Comprehensive Cancer Network 2017;15(10):1240-67.

\section{Park 2016}

Park JC, Hahn NM. Emerging role of immunotherapy in urothelial carcinoma-Future directions and novel therapies. Urologic Oncology: Seminars and Original Investigations 2016;34(12):566-76.

\section{Parmar 1998}

Parmar MK, Torri V, Stewart L. Extracting summary statistics to perform meta-analyses of the published literature for survival endpoints. Statistics in Medicine 1998;17(24):2815-34. [PUBMED: 9921604]

\section{Plimack 2017}

Plimack ER, Bellmunt J, Gupta S, Berger R, Chow LQ, Juco J. Safety and activity of pembrolizumab in patients with locally advanced or metastatic urothelial cancer (KEYNOTE-012): a non-randomised, open-label, phase $1 \mathrm{~b}$ study. Lancet Oncology 2017;18(2):212-20

\section{Review Manager 2014 [Computer program]}

Nordic Cochrane Centre, The Cochrane Collaboration. Review Manager 5 (RevMan 5). Version 5.3. Copenhagen: Nordic Cochrane Centre, The Cochrane Collaboration, 2014.

\section{Ribas 2015}

Ribas A. Releasing the brakes on cancer immunotherapy. New England Journal of Medicine 2015;373(16):1490-2.

\section{Rijnders 2017}

Rijnders M, de Wit R, Boormans JL, Lolkema MP, van der Veldt AA. Systematic review of immune checkpoint inhibition in urological cancers. European Urology 2017;72(3):411-23

\section{Rosenberg 2016}

Rosenberg JE, Hoffman-Censits J, Powles T, van der Heijden MS, Balar AV, Necchi A, et al. Atezolizumab in patients with locally advanced and metastatic urothelial carcinoma who have progressed following treatment with platinum-based

\section{CHARACTERISTICS OF STUDIES}

Characteristics of included studies [ordered by study ID] chemotherapy: a single-arm, multicentre, phase 2 trial. The Lancet 2016;387(10031):1909-20.

\section{Schünemann 2011}

Schünemann HJ, Oxman AD, Higgins JP, Vist GE, Glasziou P, Guyatt GH. Chapter 11: Presenting results and 'Summary of findings' tables. In: Higgins JPT, Green S, editor(s). Cochrane Handbook for Systematic Reviews of Interventions. Version 5.1.0 (updated March 2011). The Cochrane Collaboration, 2011. Available from handbook.cochrane.org.

\section{Sharma 2015}

Sharma P, Allison JP. The future of immune checkpoint therapy. Science 2015;348(6230):56-61.

\section{Sharma 2016}

Sharma P, Callahan MK, Bono P, Kim J, Spiliopoulou P, Calvo E, et al. Nivolumab monotherapy in recurrent metastatic urothelial carcinoma (CheckMate 032): a multicentre, open-label, two-stage, multi-arm, phase $1 / 2$ trial. The Lancet Oncology 2016;17(11):1590-8.

\section{Tierney 2007}

Tierney JF, Stewart LA, Ghersi D, Burdett S, Sydes MR. Practical methods for incorporating summary time-to-event data into meta-analysis. Trials 2007;8:16. [PUBMED: 17555582]

\section{von der Maase 2000}

von der Maase H, Hansen SW, Roberts JT, Dogliotti L, Oliver T, Moore MJ, et al. Gemcitabine and cisplatin versus methotrexate, vinblastine, doxorubicin, and cisplatin in advanced or metastatic bladder cancer: results of a large, randomized, multinational, multicenter, phase III study. Journal of Clinical Oncology 2000;18(17):3068-77.

\section{Wang 2017}

Wang PF, Chen Y, Song SY, Wang TJ, Ji WJ, Li SW, et al. ImmuneRelated Adverse Events Associated with Anti-PD-1/PD-L1 Treatment for Malignancies: A Meta-Analysis. Frontiers in Pharmacology 2017;8:730.

\section{References to other published versions of this review \\ Narayan 2017}

Narayan V, Dahm P, Skoetz N, Risk MC, Bonfiorno C, Patel N, et al. Pembrolizumab monotherapy versus chemotherapy for treatment of advanced urothelial carcinoma with disease progression during or following platinum-containing chemotherapy. A Cochrane Rapid Review. Cochrane Database of Systematic Reviews 2017, Issue 11. [DOI: 10.1002/14651858.CD012838]

* Indicates the major publication for the study 
Bellmunt 2017

$\begin{array}{ll}\text { Methods } & \text { Parallel RCT } \\ & \text { Randomisation ratio: 1:1 } \\ & \text { Superiority design }\end{array}$

Superiority design

Participants

\section{Inclusion criteria:}

- Histologically or cytologically confirmed urothelial carcinoma of the renal pelvis, ureter, bladder, or urethra that showed predominantly transitional-cell features on histologic testing.

- Progression or recurrence of urothelial cancer following a first-line platinum-containing regimen (e.g. cisplatin, carboplatin) for metastatic or inoperable locally advanced disease; or adjuvant platinum-based therapy following cystectomy for localized muscle-invasive urothelial cancer with recurrence/progression <=12 months following completion of therapy; or neoadjuvant platinum-containing therapy prior to cystectomy for localized muscle-invasive urothelial cancer with recurrence $<=12$ months following completion of therapy.

- No more than 2 prior lines of systemic chemotherapy for metastatic urothelial cancer.

- Able to provide tissue for biomarker analysis from an archival tissue sample or newly obtained core or excisional biopsy of a tumour lesion not previously irradiated.

- Measurable disease.

- ECOG performance status of 0,1 , or 2 .

- Adequate organ function.

- Female participants of childbearing potential have a negative urine or serum pregnancy test and willing to use 2 acceptable methods of birth control or abstain from heterosexual activity for the course of the study through 120 days after the last dose of pembrolizumab or 180 days after the last dose of paclitaxel, docetaxel, or vinflunine; or are surgically sterile.

- Male participants must be willing to use an adequate method of contraception starting with the first dose of study medication through 120 days after the last dose of pembrolizumab or 180 days after the last dose of paclitaxel, docetaxel, or vinflunine.

\section{Exclusion criteria:}

- Urothelial cancer that is suitable for local therapy administered with curative intent.

- Currently participating in or has participated in a study of an investigational agent or using an investigational device within 4 weeks prior to the first dose of trial medication.

- Diagnosis of immunodeficiency or receiving systemic steroid therapy or any other form of immunosuppressive therapy within 7 days prior to the first dose of study medication.

- Anti-cancer mAb within 4 weeks prior to study Day 1.

- Not recovered from adverse events due to agents administered more than 4 weeks earlier, prior chemotherapy, targeted small molecule therapy, or radiation therapy within 2 weeks of study Day 1.

- Not recovered from adverse events due to a previously administered agent or prior therapy with all choices of active comparator.

- Known additional malignancy that is progressing or requires active treatment with the exception of basal cell carcinoma of the skin, squamous cell carcinoma of the skin that has undergone potentially curative therapy, or in situ cancer; or prostate cancer that was identified incidentally following cystoprostatectomy for bladder cancer that is Stage T2NOM0 or lower, Gleason score $<=6$, or PSA undetectable.

- Known active CNS metastases and/or carcinomatous meningitis.

- Active autoimmune disease requiring systemic treatment within the past 3 months or a documented history of clinically severe autoimmune disease, or a syndrome that requires systemic or immunosuppressive agents, active cardiac disease, evidence of interstitial lung disease or active non-infectious pneumonitis, or active infection requiring systemic therapy.

- History of severe hypersensitivity reaction to paclitaxel, docetaxel, or to other drugs formulated with polysorbate 80 or polyoxyethylated castor oil, or to vinflunine or other vinca alkaloids.

- Requires ongoing therapy with a medication that is a strong inhibitor or inducer of the cytochrome 3A4 (CYP3A4) enzymes. 
- Pregnant, breastfeeding, or expecting to conceive or father children within the projected duration of the trial, starting with the screening visit through 120 days after the last dose of pembrolizumab or 180 days after the last dose of paclitaxel, docetaxel, or vinflunine.

- Prior therapy with an anti-PD-1 or anti-PD-ligand 1 agent, or with an agent directed to another coinhibitory T-cell receptor.

- HIV or active hepatitis B or hepatitis C.

- Received a live virus vaccine within 30 days of planned start of trial treatment.

\section{Characteristics:}

- Total number randomly assigned: 542 .

- Baseline imbalances: no.

- Mean (range) age: pembrolizumab 67 (29-88) years, chemotherapy 65 (26-84) years.

- Number of patients with ECOG 0: pembrolizumab 119, chemotherapy 106.

- Number of patients with ECOG 1: pembrolizumab 143, chemotherapy 158.

- Number of patients with ECOG $\geq 2$ : pembrolizumab 2, chemotherapy 4 .

- Number of patients with liver metastases: pembrolizumab 91, chemotherapy 95.

- Number of patients with visceral metastases: pembrolizumab 240, chemotherapy 233.

- Male sex: pembrolizumab 200 (74.1\%), chemotherapy 202 (74.3\%).

Interventions

Number of study centres: 748 patients were screened for enrolment in 120 sites in 29 countries (Australia, Austria, Belgium, Canada, Chile, Denmark, France, Germany, Hungary, Ireland, Israel, Italy, Japan, Republic of Korea, Netherlands, New Zealand, Norway, Peru, Poland, Portugal, Puerto Rico, Romania, Singapore, Spain, Sweden, Taiwan, Turkey, United Kingdom, United States).

Run-in period: $11 / 2014-11 / 2015$

Extension period: no.

Intervention: pembrolizumab 200 mg IV on Day 1 Q3W; 270 randomised patients, 266 patients received treatment.

Comparison: paclitaxel $175 \mathrm{mg} / \mathrm{m}^{2} \mathrm{IV}$ or docetaxel $75 \mathrm{mg} / \mathrm{m}^{2} \mathrm{IV}$ or vinflunine $320 \mathrm{mg} / \mathrm{m}^{2} \mathrm{IV}$, on Day 1 Q3W, 272 randomised patients, 255 received treatment, 84 patients received docetaxel, 84 received paclitaxel, and 87 received vinflunine.

Other co-interventions for both groups: no.

Outcomes

\section{Primary outcome measures}

Overall survival:

- time points measured: up to 30 months

- time point reported: median duration of follow-up was 14.1 months (range 9.9 to 22.1)

- outcome definition: overall survival was defined as the time from randomisation to death from any cause

- subgroups (of interest): performance status (ECOG 0 or 1 versus $\geq 2$ ); time since last chemotherapy administration (< three months versus $\geq$ three months); degree of pretreatment; PDL-1 tumour expression status (positive versus negative; $1 \%$ cutoff)

Progression-free survival:

- time points measured: up to 30 months

- time point reported: median duration of follow-up was 14.1 months (range 9.9 to 22.1)

- outcome definition: progression-free survival was defined as the time from randomisation to disease progression or death from any cause, per RECIST 1.1

- subgroups: none (subgroup of participants with PD-L1 positive score (10\% cutoff) not relevant for this review)

\section{Secondary outcome measures}

Pembrolizumab monotherapy versus chemotherapy for treatment of advanced urothelial carcinoma with disease progression during or 
Bellmunt 2017 (Continued)

Objective response rate:

- time points measured: up to 30 months

- time point reported: median duration of follow-up was 14.1 months (range 9.9 to 22.1)

- outcome definition: per RECIST 1.1; complete/partial response

- subgroups: none

Progression-free survival per modified RECIST 1.1:

- time points measured: up to 30 months

- time point reported: median duration of follow-up was 14.1 months (range 9.9 to 22.1)

- outcome definition: per modified RECIST 1.1

- subgroups: none

Objective response reaction per modified RECIST 1.1:

- time points measured: up to 30 months

- time point reported: median duration of follow-up was 14.1 months (range 9.9 to 22.1)

- outcome definition: per modified RECIST 1.1

- subgroups: none

Adverse event (time frame: up to 31 months):

- time points measured: up to 30 months

- time point reported: median duration of follow-up was 14.1 months (range 9.9 to 22.1)

- subgroups: none

Discontinuation of study drug due to an adverse event:

- time points measured: up to 30 months

- time point reported: median duration of follow-up was 14.1 months (range 9.9 to 22.1)

- subgroups: none

Quality of life:

- was not listed as predefined outcome in ClinicalTrials.gov registry (NCT02256436)

- Dr Bellmunt reports receiving consulting fees from Merck and Genentech.

- Dr de Wit reports receiving fees for serving on an advisory board for Eli Lilly.

- DrVaughn reports receiving fees for serving on a data and safety monitoring board from Astellas Pharma.

- Dr Fradet reports receiving consulting fees from Astellas Pharma, Bayer, Amgen, Merck, Roche, Sanofi, and AstraZeneca, and grant support from Astellas Pharma, Amgen, and AstraZeneca.

- Dr Lee reports receiving fees for serving on advisory boards for AstraZeneca, Astellas Pharma, Eisai, and Pfizer.

- Dr Fong reports receiving grant support from Dendreon, Bristol-Myers Squibb, Roche/Genentech, AbbVie, and Amgen

- Dr. Climent reports receiving fees for serving on advisory boards for Roche, Pierre Fabre Laboratories, and Bristol-Myers Squibb.

- Dr Petrylak reports receiving consulting fees from Millennium Pharmaceuticals, Dendreon, Sanofi Aventis, Roche, Bayer, Johnson \& Johnson, Exelixis, Ferring Pharmaceuticals, Medivation, Pfizer, Bellicum Pharmaceuticals, and Tyme Pharmaceuticals; grant support from Merck, Celgene, Agensys, Eli Lilly, Millennium Pharmaceuticals, Dendreon, Sanofi Aventis, and Roche Laboratories; and having ownership interest or involvement in Bellicum Pharmaceuticals and Tyme Pharmaceuticals.

- Dr Choueiri reports receiving fees for serving on an advisory board for Merck. 
- Dr Necchi reports receiving consulting fees from Merck Sharp \& Dohme, Roche, AstraZeneca, and Bayer, and grant support from Millennium Pharmaceuticals, Amgen, Novartis Pharmaceuticals, Merck Sharp \& Dohme, Roche, and AstraZeneca.

- Dr Gerritsen reports receiving fees for serving on advisory boards from Amgen, Astellas Pharma, Janssen-Cilag, CureVac, Merck Sharp \& Dohme, and Bayer; lecture fees from Bristol-Myers Squibb, Janssen-Cilag, and Bayer; and grant support from Astellas Pharma and Janssen-Cilag.

- Dr Gurney reports receiving fees for serving on advisory boards for Bristol-Myers Squibb, Astellas Pharma, and Roche, and grant support from Pfizer.

- Dr Quinn reports receiving fees for serving on advisory boards for Merck, Bristol-Myers Squibb, Genentech, AstraZeneca, Pfizer, Novartis Pharmaceuticals, Astellas Pharma, Peloton Therapeutics, Dendreon, Exelixis, Bayer, Piramal Life Sciences, and Sanofi.

- Dr Sternberg reports receiving honoraria from OncoGeneX, Eli Lilly, Merck, and Bristol-Myers Squibb, and grant support from Eli Lilly, Janssen Pharmaceuticals, AstraZeneca, and Roche/Genentech.

- Drs Mai, Poehlein, and Perini report being employees of and holding stock or stock options in Merck.

- Dr Poehlein reports having been employed in the past by and holding stock options in Bayer Health Care Oncology and holding a patent related to the augmentation of immune response to a cancer vaccine (U.S. patent number, 20090317407A1).

- Dr Perini reports holding pending patents related to the combination of a PD-1 antagonist and a listeria-based vaccine for treating prostate cancer (U.S. patient application number $20160022814 \mathrm{~A} 1$ ) and treating cancer with a combination of a PD-1 antagonist and a vascular endothelial growth factor receptor inhibitor (U.S. patent application number 15101409).

- Dr Bajorin reports receiving lecture fees and travel support from Merck.

- No other potential conflict of interest relevant to this article was reported.

- The trial was designed by academic advisors and employees of the sponsor (Merck). Data were collected by investigators and their site personnel and analysed by statisticians who were employees of the sponsor. Results were interpreted by the academic authors, by authors who were employees of the sponsor, and by other employees of the sponsor who did not fulfil all the authorship criteria as outlined by the International Committee of Medical Journal Editors. An external data and safety monitoring committee oversaw the trial and assessed efficacy and safety at the time of prespecified interim analyses that were performed by statisticians from QuintilesIMS, with funding by the sponsor.

- The first draft of the manuscript was written by the first and last authors, with input from authors who were employees of the sponsor. Assistance with manuscript preparation was provided by a medical writer employed by the sponsor.

- "The data and safety monitoring committee reviewed the results of the second interim analysis on October 18, 2016, and recommended early termination of the trial because pembrolizumab met the superiority thresholds for overall survival in the co-primary populations".

- Manuscript was published in English.

\section{Risk of bias}

\section{Bias \\ Authors' judgement Support for judgement}

Random sequence genera- Low risk tion (selection bias)
Quote from publication: "...central randomisation as described in the protocol".

Comment: Randomization was performed adequately.

Allocation concealment Low risk
(selection bias)

Quote from publication: "Centrally...interactive voice response system/integrated web response system".

Comment: allocation concealment was performed adequately.
Quote from publication: "...there was no blinding".

Comment: overall survival was measured and reported. It might be conceivable that even objective outcomes are influenced by lack of blinding. We finally judge that there is an unclear risk of bias. 
Bellmunt 2017 (Continued)

Blinding of participants and personnel (performance bias)

Subjective outcomes
High risk Quote from publication: "...there was no blinding".

Comment: progression-free survival, treatment-related mortality, discontinuation due to adverse events, and adverse events were measured and reported (quality of life was not listed as a predefined outcome in ClinicalTrials.gov registry (NCT02256436) and was not reported in the full text publication, but results were presented in abstract form at ASCO GU 2017 conference (Bellmunt 2017)). We judge that subjective outcomes are likely to be influenced by lack of blinding leading to high risk of bias. For response rate, we are uncertain if lack of blinding of participants and personnel might have influenced results, and therefore judged that there is unclear risk of bias for this outcome.

$\begin{array}{ll}\begin{array}{l}\text { Blinding of outcome as- } \\ \text { sessment (detection bias) } \\ \text { Objective outcome (over- } \\ \text { all survival }\end{array} & \text { Low risk }\end{array} \quad \begin{aligned} & \text { Quote from publication: no applicable quote. } \\ & \text { Comment: Not likely that outcome assessment for overall survival would be } \\ & \text { influenced by lack of blinding. }\end{aligned}$

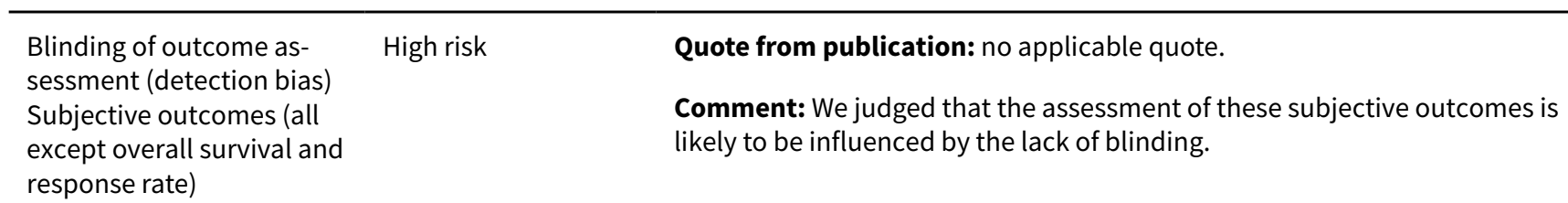

\begin{tabular}{|c|c|c|}
\hline $\begin{array}{l}\text { Blinding of outcome as- } \\
\text { sessment (detection bias) } \\
\text { Subjective outcome }\end{array}$ & Low risk & $\begin{array}{l}\text { Quote from publication: "Imaging data were centrally reviewed, central } \\
\text { imaging vendor were blinded to the subject treatment, imaging results were } \\
\text { blinded to the clinical study team". }\end{array}$ \\
\hline
\end{tabular}

(treatment response (par-

tial or complete radiologi-

cal)
Comment: Adequate assurance of blinding
All patients randomised were included in the analysis for overall survival, progression-free survival, and response rate.

\begin{tabular}{|c|c|c|}
\hline $\begin{array}{l}\text { ncomplete outcome data } \\
\text { attrition bias) }\end{array}$ & Low risk & $\begin{array}{l}\text { All patients randomised were included in the analysis for overall survival, pro- } \\
\text { gression-free survival, and response rate. }\end{array}$ \\
\hline
\end{tabular}

Oncological outcomes
Missing outcome data are less than $10 \%$ in both groups (randomised: 270 pembrolizumab, 272 chemotherapy; in evaluation: 266 pembrolizumab, 253 chemotherapy). We judge that this number of withdrawals is not enough to have a clinically relevant effect.

\begin{tabular}{|c|c|c|}
\hline $\begin{array}{l}\text { Incomplete outcome data } \\
\text { (attrition bias) } \\
\text { Treatment-related mor- } \\
\text { tality, Discontinuation due }\end{array}$ & Low risk & $\begin{array}{l}\text { Missing outcome data are less than } 10 \% \text { in both groups (randomised: } 270 \\
\text { pembrolizumab, } 272 \text { chemotherapy; in evaluation: } 255 \text { pembrolizumab, } 255 \\
\text { chemotherapy). We judge that this number of withdrawals is not enough to } \\
\text { have a clinically relevant effect. }\end{array}$ \\
\hline
\end{tabular}
events

\begin{tabular}{lll}
\hline $\begin{array}{l}\text { Selective reporting (re- } \\
\text { porting bias) }\end{array}$ & Unclear risk & $\begin{array}{l}\text { Quality of life was not listed as a predefined outcome in the ClinicalTrials.gov } \\
\text { registry (NCT02256436) }\end{array}$ \\
\hline Other bias & Low risk & No other potential bias identified.
\end{tabular}

ASCO GU: Genitourinary Cancers Symposium of the American Society of Clinical Oncology; CNS: central nervous system; ECOG: Eastern Cooperative Oncology Group; HIV: human immunodeficiency virus; IV: intravenous; mAb: monoclonal antibody; NCT: ClinicalTrials.gov identifier; PD-1: programmed cell death protein 1; PD-L1: programmed cell death protein 1 ligand; PSA: prostatic-specific antigen; Q3W: every three weeks; RCT: randomised controlled trial; RECIST: Response Evaluation Criteria in Solid Tumors.

Characteristics of excluded studies [ordered by study ID] 


\begin{tabular}{ll}
\hline Study & Reason for exclusion \\
\hline Acerta 2017 & Wrong comparator. \\
\hline Alva 2016 & First-line therapy. \\
\hline Guo 2017 & Comment to another article. \\
\hline Matthew 2015 & Wrong intervention. \\
\hline Mitchell 2017 & Comment to another article. \\
\hline Powles 2017 & First-line therapy. \\
\hline Venniyoor 2017 & Comment to another article. \\
\hline
\end{tabular}

\section{DATA AND ANALYSES}

Comparison 1. Pembrolizumab versus chemotherapy

\begin{tabular}{|c|c|c|c|c|}
\hline Outcome or subgroup title & No. of studies & $\begin{array}{l}\text { No. of partici- } \\
\text { pants }\end{array}$ & Statistical method & Effect size \\
\hline 1 Overall survival & 1 & 542 & $\begin{array}{l}\text { Hazard Ratio (Random, 95\% } \\
\mathrm{Cl} \text { ) }\end{array}$ & $0.73[0.59,0.90]$ \\
\hline $\begin{array}{l}2 \text { Quality of life (change from base- } \\
\text { line to week 15) }\end{array}$ & 1 & 520 & $\begin{array}{l}\text { Mean Difference (IV, Random, } \\
95 \% \mathrm{CI})\end{array}$ & $9.05[4.41,13.69]$ \\
\hline 3 Progression-free survival & 1 & 542 & $\begin{array}{l}\text { Hazard Ratio (Random, 95\% } \\
\mathrm{Cl} \text { ) }\end{array}$ & $0.98[0.81,1.19]$ \\
\hline $\begin{array}{l}4 \text { Response rate (partial and com- } \\
\text { plete response) }\end{array}$ & 1 & 542 & $\begin{array}{l}\text { Risk Ratio (M-H, Random, 95\% } \\
\text { Cl) }\end{array}$ & $1.85[1.24,2.77]$ \\
\hline 5 Treatment-related mortality & 1 & 521 & $\begin{array}{l}\text { Risk Ratio (M-H, Random, 95\% } \\
\text { Cl) }\end{array}$ & $0.96[0.24,3.79]$ \\
\hline $\begin{array}{l}6 \text { Discontinuation due to adverse } \\
\text { event (any grade) }\end{array}$ & 1 & 521 & $\begin{array}{l}\text { Risk Ratio (M-H, Random, 95\% } \\
\mathrm{Cl} \text { ) }\end{array}$ & $0.66[0.39,1.10]$ \\
\hline $\begin{array}{l}7 \text { Serious adverse events (irrespec- } \\
\text { tive of attribution to treatment) }\end{array}$ & 1 & & $\begin{array}{l}\text { Risk Ratio (M-H, Random, 95\% } \\
\mathrm{Cl} \text { ) }\end{array}$ & Subtotals only \\
\hline $\begin{array}{l}\text { 7.1 Serious adverse events (Grade } 3 \text {, } \\
4 \text {, or } 5 \text { ) }\end{array}$ & 1 & 521 & $\begin{array}{l}\text { Risk Ratio (M-H, Random, 95\% } \\
\mathrm{CI})\end{array}$ & $0.83[0.72,0.97]$ \\
\hline $\begin{array}{l}8 \text { Serious adverse events (irrespec- } \\
\text { tive of attribution to treatment) }\end{array}$ & 1 & & $\begin{array}{l}\text { Peto Odds Ratio (Peto, Fixed, } \\
95 \% \mathrm{Cl} \text { ) }\end{array}$ & Subtotals only \\
\hline 8.1 Pruritus (Grade 3, 4, or 5) & 1 & 521 & $\begin{array}{l}\text { Peto Odds Ratio (Peto, Fixed, } \\
95 \% \mathrm{Cl} \text { ) }\end{array}$ & $0.13[0.00,6.54]$ \\
\hline
\end{tabular}




\begin{tabular}{|c|c|c|c|c|}
\hline Outcome or subgroup title & No. of studies & $\begin{array}{l}\text { No. of partici- } \\
\text { pants }\end{array}$ & Statistical method & Effect size \\
\hline 8.2 Fatigue (Grade 3,4 , or 5 ) & 1 & 521 & $\begin{array}{l}\text { Peto Odds Ratio (Peto, Fixed, } \\
95 \% \mathrm{CI} \text { ) }\end{array}$ & $0.63[0.28,1.40]$ \\
\hline 8.3 Diarrhoea (Grade 3, 4, or 5) & 1 & 521 & $\begin{array}{l}\text { Peto Odds Ratio (Peto, Fixed, } \\
95 \% \mathrm{Cl} \text { ) }\end{array}$ & $0.96[0.24,3.87]$ \\
\hline 8.4 Anaemia (Grade 3, 4, or 5) & 1 & 521 & $\begin{array}{l}\text { Peto Odds Ratio (Peto, Fixed, } \\
95 \% \mathrm{CI} \text { ) }\end{array}$ & $0.65[0.37,1.15]$ \\
\hline 8.5 Constipation (Grade 3, 4, or 5) & 1 & 521 & $\begin{array}{l}\text { Peto Odds Ratio (Peto, Fixed, } \\
95 \% \mathrm{Cl} \text { ) }\end{array}$ & $0.38[0.11,1.25]$ \\
\hline $\begin{array}{l}\text { 8.6 Peripheral sensory neuropathy } \\
\text { (Grade } 3,4 \text {, or } 5 \text { ) }\end{array}$ & 1 & 521 & $\begin{array}{l}\text { Peto Odds Ratio (Peto, Fixed, } \\
95 \% \mathrm{Cl} \text { ) }\end{array}$ & $0.13[0.02,0.74]$ \\
\hline 8.7 Neutropenia (Grade 3, 4, or 5) & 1 & 521 & $\begin{array}{l}\text { Peto Odds Ratio (Peto, Fixed, } \\
95 \% \mathrm{CI} \text { ) }\end{array}$ & $0.11[0.06,0.22]$ \\
\hline 8.8 Alopecia (Grade 3, 4, or 5) & 1 & 521 & $\begin{array}{l}\text { Peto Odds Ratio (Peto, Fixed, } \\
95 \% \mathrm{Cl} \text { ) }\end{array}$ & $0.13[0.01,1.24]$ \\
\hline 8.9 Hypothyroidism (Grade 3, 4, or 5) & 1 & 521 & $\begin{array}{l}\text { Peto Odds Ratio (Peto, Fixed, } \\
95 \% \mathrm{CI} \text { ) }\end{array}$ & $0.0[0.0,0.0]$ \\
\hline 8.10 Skin reaction (Grade 3,4 , or 5 ) & 1 & 521 & $\begin{array}{l}\text { Peto Odds Ratio (Peto, Fixed, } \\
95 \% \mathrm{CI} \text { ) }\end{array}$ & $0.23[0.05,1.00]$ \\
\hline
\end{tabular}

Analysis 1.1. Comparison 1 Pembrolizumab versus chemotherapy, Outcome 1 Overall survival.

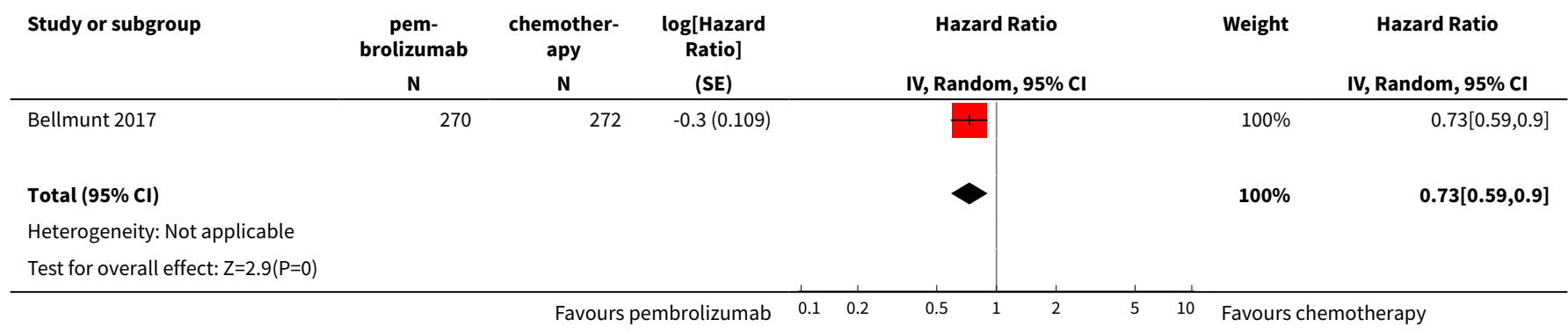

Analysis 1.2. Comparison 1 Pembrolizumab versus chemotherapy, Outcome 2 Quality of life (change from baseline to week 15).

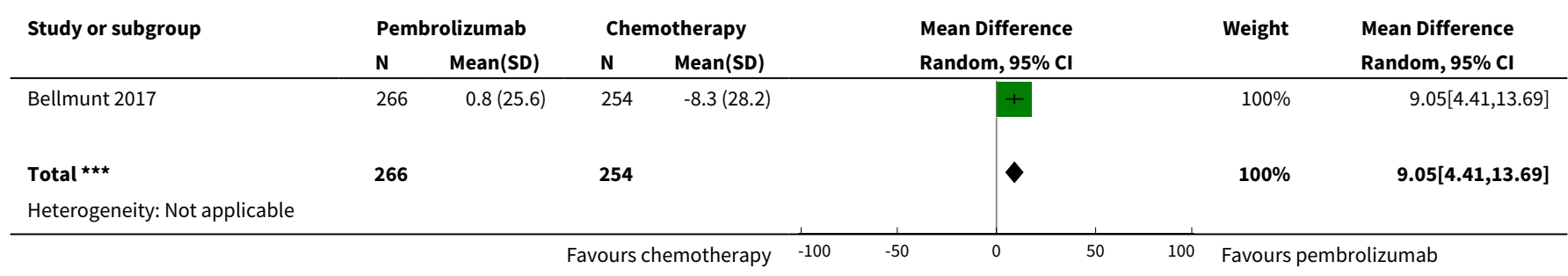




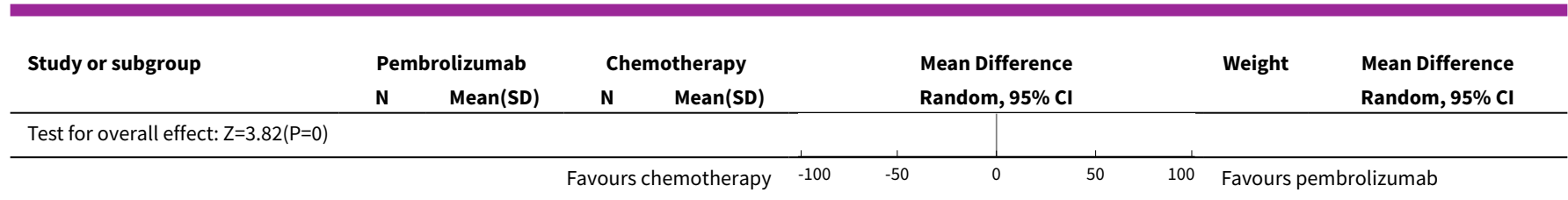

Analysis 1.3. Comparison 1 Pembrolizumab versus chemotherapy, Outcome 3 Progression-free survival.

\begin{tabular}{|c|c|c|c|c|c|c|}
\hline Study or subgroup & $\begin{array}{c}\text { Pem- } \\
\text { brolizumab } \\
\mathbf{N} \\
\end{array}$ & $\begin{array}{c}\text { Chemother- } \\
\text { apy } \\
\text { N }\end{array}$ & $\begin{array}{c}\log [\text { Hazard } \\
\text { Ratio] } \\
\text { (SE) }\end{array}$ & $\begin{array}{c}\text { Hazard Ratio } \\
\text { IV, Random, } 95 \% \text { CI }\end{array}$ & Weight & $\begin{array}{c}\text { Hazard Ratio } \\
\text { IV, Random, } 95 \% \mathrm{CI}\end{array}$ \\
\hline Bellmunt 2017 & 270 & 272 & $-0(0.097)$ & + & $100 \%$ & $0.98[0.81,1.19]$ \\
\hline Total $(95 \% \mathrm{Cl})$ & & & & $\gamma$ & $100 \%$ & $0.98[0.81,1.19]$ \\
\hline \multicolumn{7}{|c|}{ Heterogeneity: Not applicable } \\
\hline
\end{tabular}

Analysis 1.4. Comparison 1 Pembrolizumab versus chemotherapy, Outcome 4 Response rate (partial and complete response).

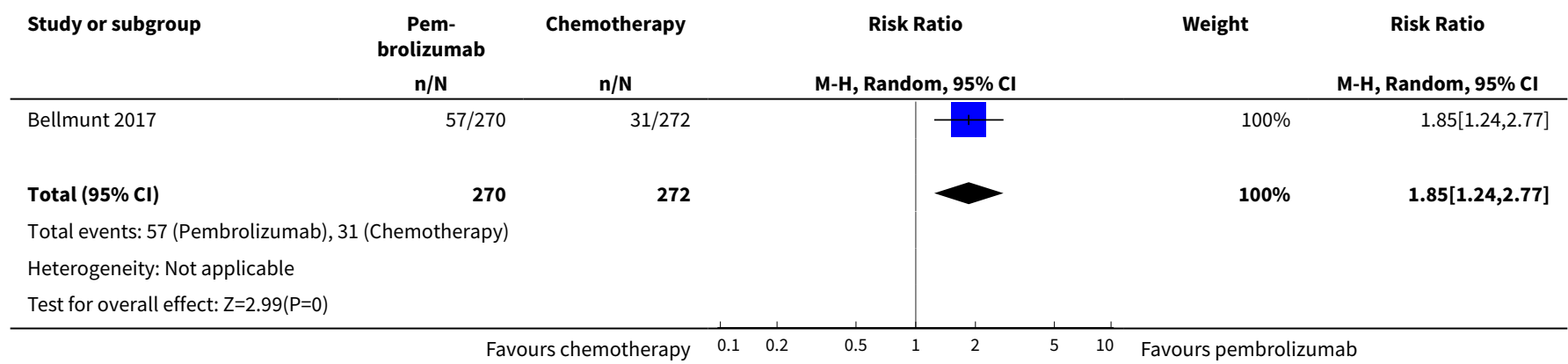

Analysis 1.5. Comparison 1 Pembrolizumab versus chemotherapy, Outcome 5 Treatment-related mortality.

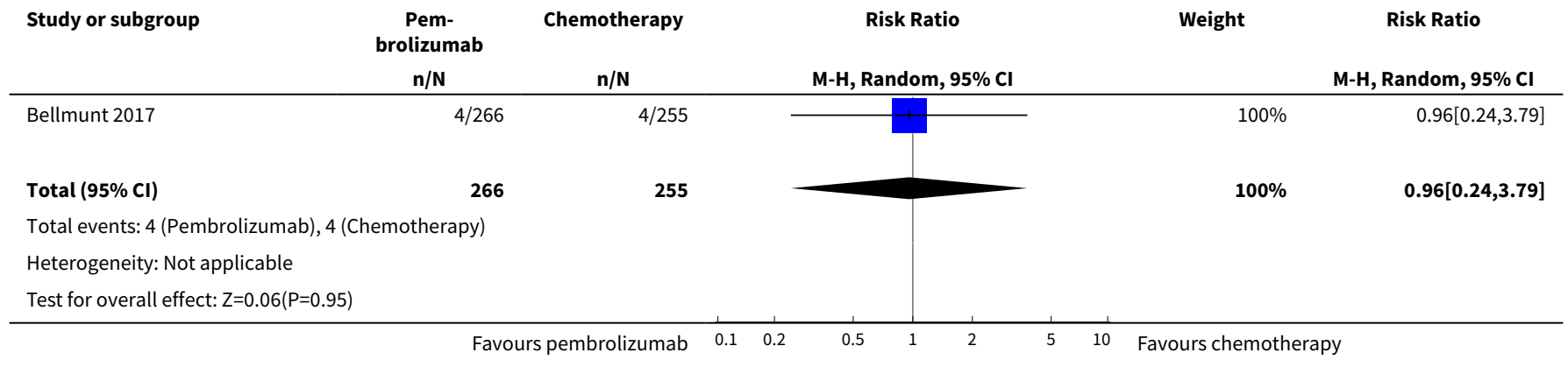


Analysis 1.6. Comparison 1 Pembrolizumab versus chemotherapy, Outcome 6 Discontinuation due to adverse event (any grade).

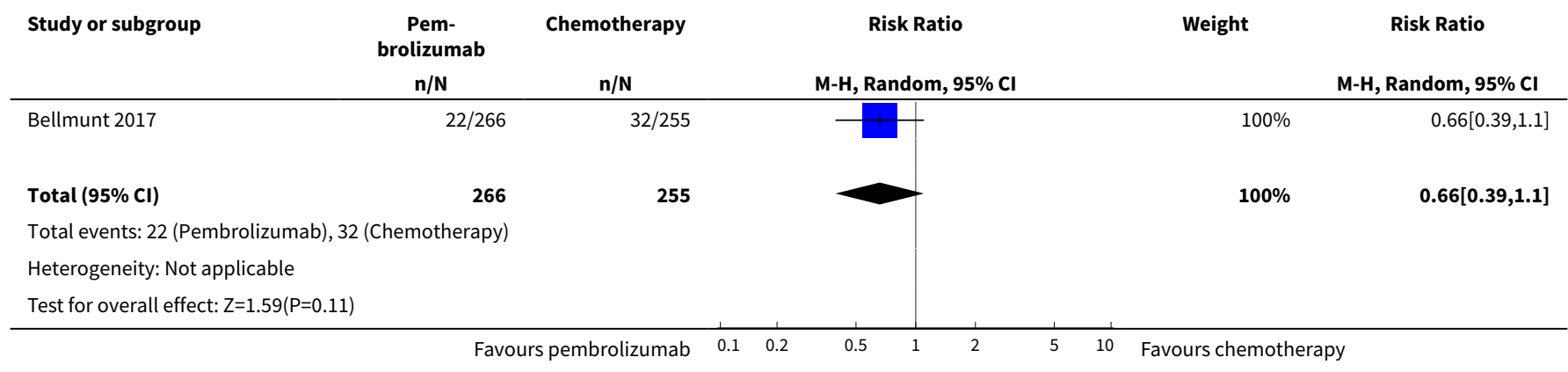

Analysis 1.7. Comparison 1 Pembrolizumab versus chemotherapy, Outcome 7 Serious adverse events (irrespective of attribution to treatment).

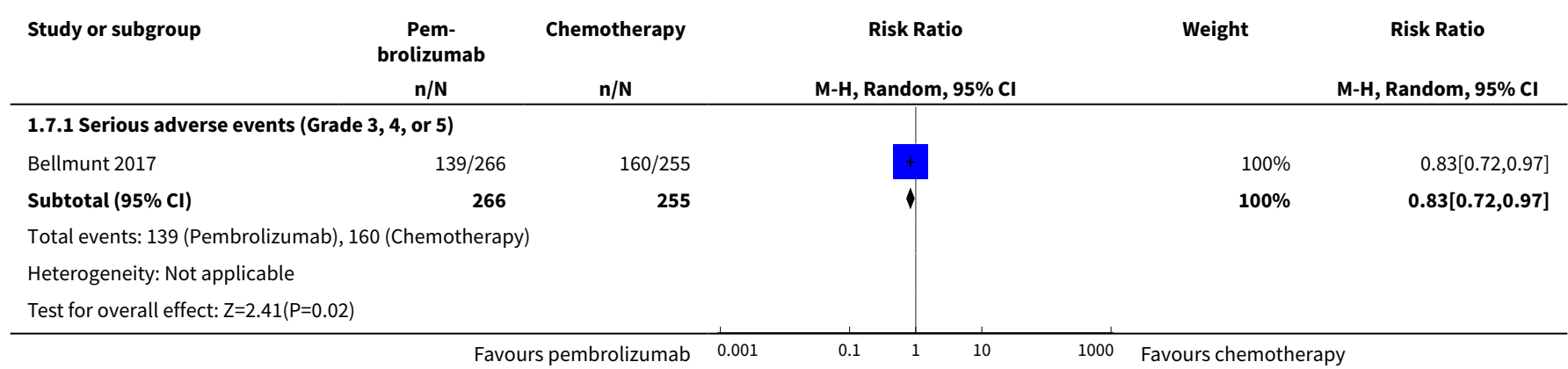

Analysis 1.8. Comparison 1 Pembrolizumab versus chemotherapy, Outcome 8 Serious adverse events (irrespective of attribution to treatment).

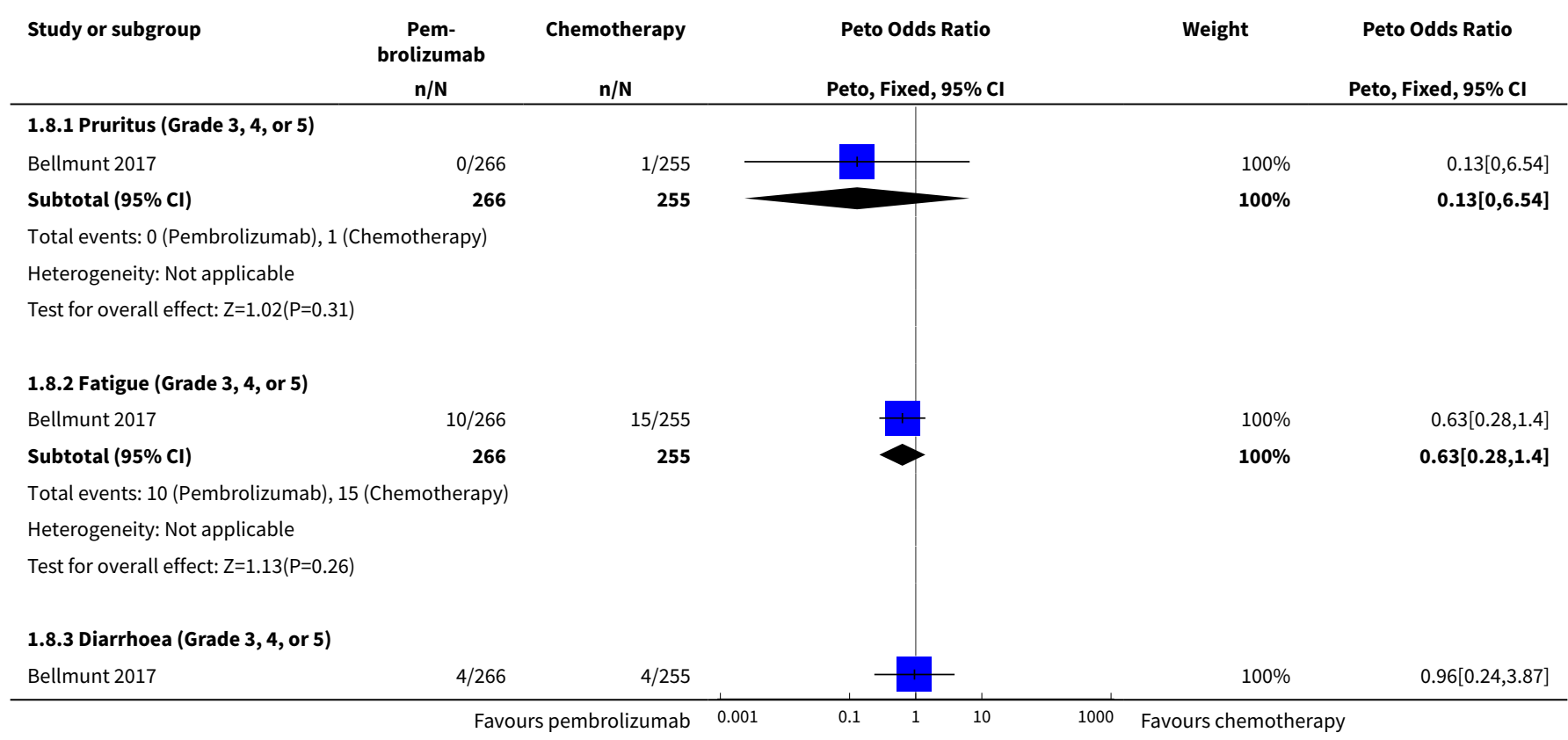




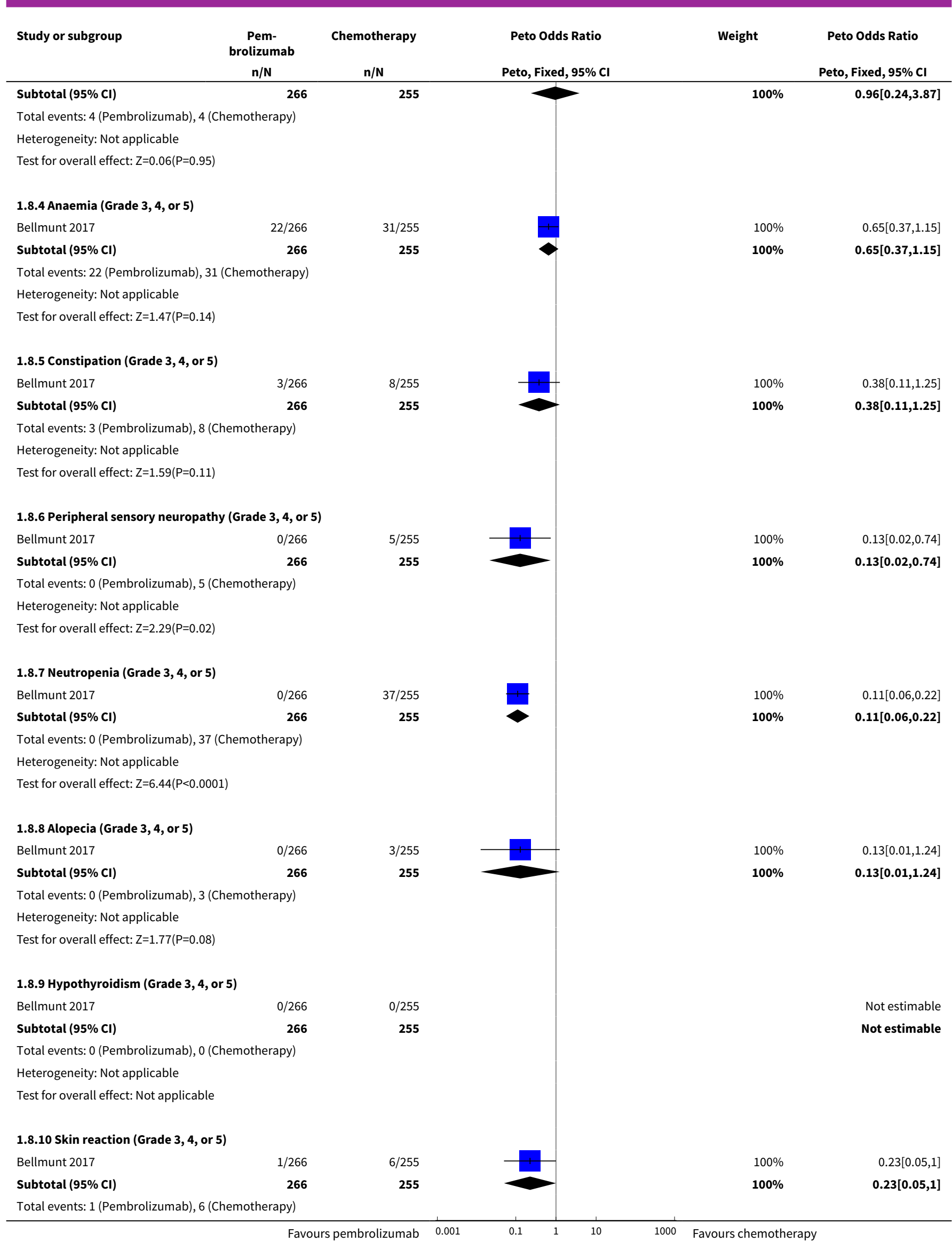

Pembrolizumab monotherapy versus chemotherapy for treatment of advanced urothelial carcinoma with disease progression during or 


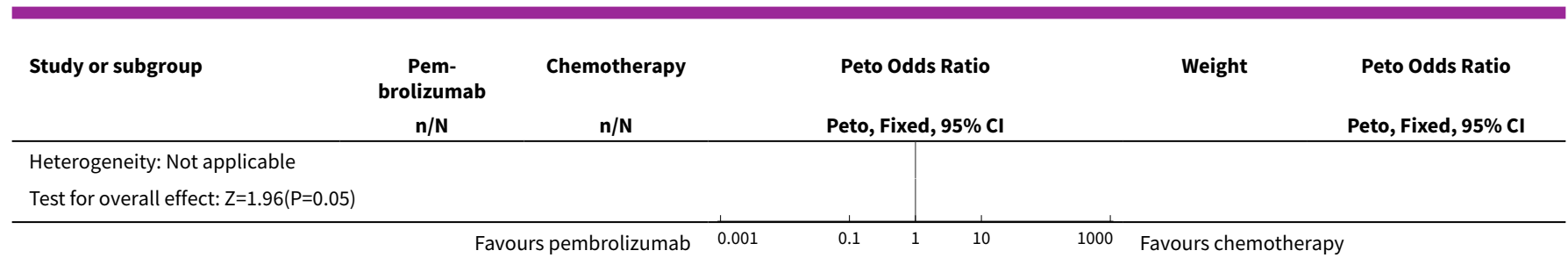

\section{Comparison 2. Pembrolizumab versus chemotherapy (predefined subgroup analyses)}

\begin{tabular}{|c|c|c|c|c|}
\hline Outcome or subgroup title & No. of studies & $\begin{array}{l}\text { No. of partici- } \\
\text { pants }\end{array}$ & Statistical method & Effect size \\
\hline $\begin{array}{l}1 \text { Overall survival based on per- } \\
\text { formance status }\end{array}$ & 1 & & $\begin{array}{l}\text { Hazard Ratio (Random, 95\% } \\
\mathrm{Cl} \text { ) }\end{array}$ & $0.74[0.59,0.92]$ \\
\hline 1.1 ECOG $0-1$ & 1 & & $\begin{array}{l}\text { Hazard Ratio (Random, 95\% } \\
\mathrm{Cl} \text { ) }\end{array}$ & $0.74[0.59,0.93]$ \\
\hline 1.2 ECOG 2 & 1 & & $\begin{array}{l}\text { Hazard Ratio (Random, 95\% } \\
\mathrm{Cl} \text { ) }\end{array}$ & $0.43[0.04,4.62]$ \\
\hline $\begin{array}{l}2 \text { Overall survival based on time } \\
\text { since last chemotherapy }\end{array}$ & 1 & & $\begin{array}{l}\text { Hazard Ratio (Random, 95\% } \\
\mathrm{Cl} \text { ) }\end{array}$ & $0.72[0.58,0.91]$ \\
\hline 2.1 Less than 3 months & 1 & & $\begin{array}{l}\text { Hazard Ratio (Random, 95\% } \\
\mathrm{Cl} \text { ) }\end{array}$ & $0.82[0.58,1.16]$ \\
\hline $\begin{array}{l}2.2 \text { Equal or greater than } 3 \\
\text { months }\end{array}$ & 1 & & $\begin{array}{l}\text { Hazard Ratio (Random, 95\% } \\
\mathrm{Cl} \text { ) }\end{array}$ & $0.66[0.49,0.89]$ \\
\hline $\begin{array}{l}3 \text { Overall survival based on de- } \\
\text { gree of pretreatment }\end{array}$ & 1 & & $\begin{array}{l}\text { Hazard Ratio (Random, 95\% } \\
\mathrm{Cl} \text { ) }\end{array}$ & $0.72[0.57,0.91]$ \\
\hline $\begin{array}{l}\text { 3.1 Two prior treatments for } \\
\text { metastatic disease }\end{array}$ & 1 & & $\begin{array}{l}\text { Hazard Ratio (Random, 95\% } \\
\mathrm{Cl} \text { ) }\end{array}$ & $0.83[0.52,1.32]$ \\
\hline $\begin{array}{l}3.2 \text { One prior treatment for } \\
\text { metastatic disease }\end{array}$ & 1 & & $\begin{array}{l}\text { Hazard Ratio (Random, 95\% } \\
\mathrm{Cl} \text { ) }\end{array}$ & $0.72[0.54,0.96]$ \\
\hline 3.3 Neoadjuvant & 1 & & $\begin{array}{l}\text { Hazard Ratio (Random, 95\% } \\
\mathrm{Cl} \text { ) }\end{array}$ & $0.53[0.20,1.40]$ \\
\hline 3.4 Adjuvant & 1 & & $\begin{array}{l}\text { Hazard Ratio (Random, 95\% } \\
\mathrm{Cl} \text { ) }\end{array}$ & $0.53[0.18,1.56]$ \\
\hline $\begin{array}{l}4 \text { Overall survival based on PD-L1 } \\
\text { tumour expression status }\end{array}$ & 1 & & $\begin{array}{l}\text { Hazard Ratio (Random, 95\% } \\
\mathrm{Cl} \text { ) }\end{array}$ & $0.75[0.51,1.08]$ \\
\hline 4.1 PD-L1 positive (>1\% cut off) & 1 & & $\begin{array}{l}\text { Hazard Ratio (Random, 95\% } \\
\mathrm{Cl} \text { ) }\end{array}$ & $0.61[0.43,0.87]$ \\
\hline 4.2 PD-L1 negative (<1\% cut off) & 1 & & $\begin{array}{l}\text { Hazard Ratio (Random, 95\% } \\
\mathrm{Cl} \text { ) }\end{array}$ & $0.89[0.66,1.20]$ \\
\hline
\end{tabular}


Analysis 2.1. Comparison 2 Pembrolizumab versus chemotherapy (predefined subgroup analyses), Outcome 1 Overall survival based on performance status.

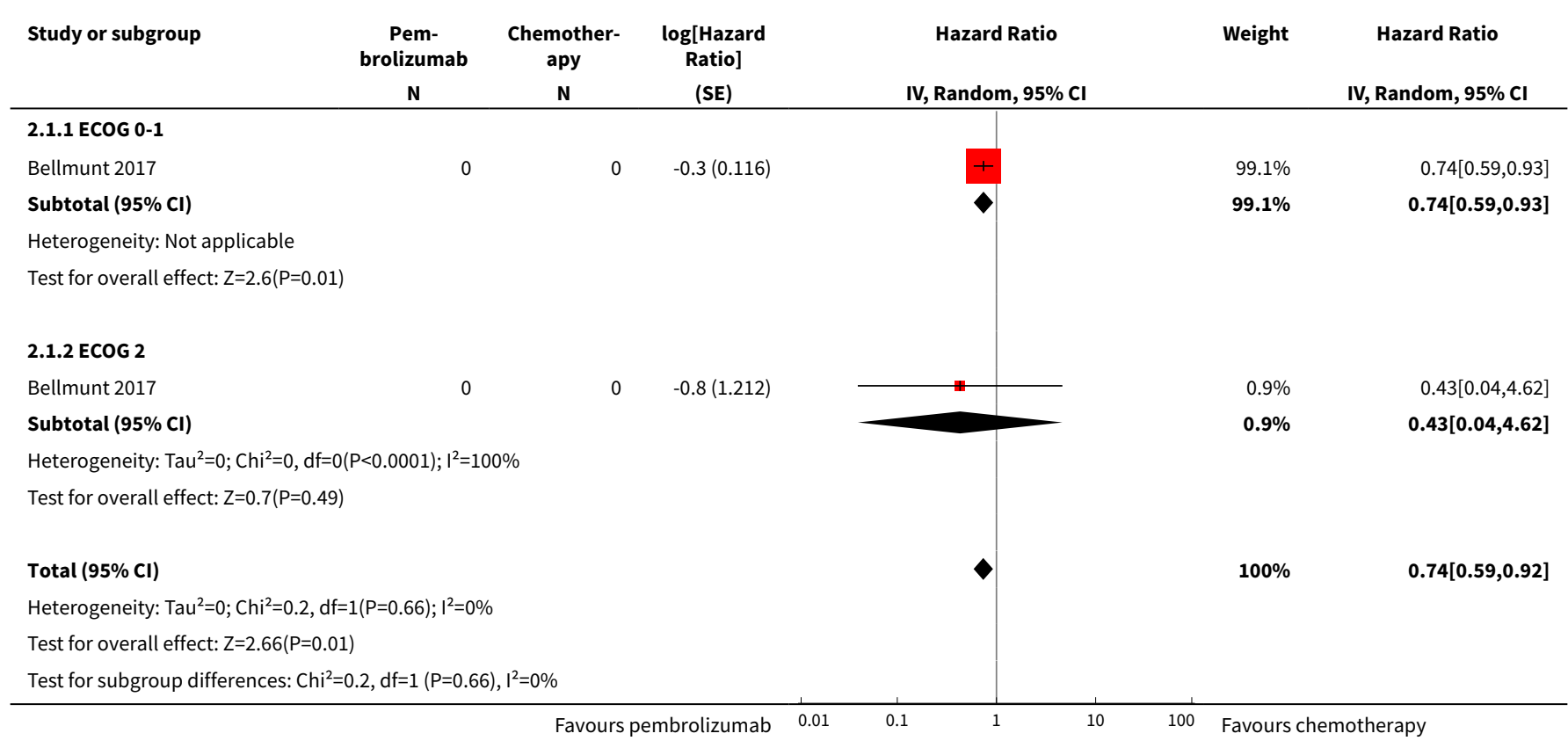

Analysis 2.2. Comparison 2 Pembrolizumab versus chemotherapy (predefined subgroup analyses), Outcome 2 Overall survival based on time since last chemotherapy.

\begin{tabular}{|c|c|c|c|c|c|c|}
\hline Study or subgroup & $\begin{array}{c}\text { Pem- } \\
\text { brolizumab } \\
\text { N }\end{array}$ & $\begin{array}{c}\text { Chemother- } \\
\text { apy } \\
\text { N }\end{array}$ & \multirow[t]{2}{*}{$\begin{array}{c}\log [\text { Hazard } \\
\text { Ratio] } \\
\text { (SE) }\end{array}$} & $\begin{array}{c}\text { Hazard Ratio } \\
\text { IV, Random, 95\% CI }\end{array}$ & Weight & \multirow[t]{2}{*}{$\begin{array}{c}\text { Hazard Ratio } \\
\text { IV, Random, 95\% CI }\end{array}$} \\
\hline \multicolumn{5}{|c|}{ 2.2.1 Less than 3 months } & & \\
\hline Bellmunt 2017 & 0 & 0 & $-0.2(0.177)$ & \# & $42.53 \%$ & $0.82[0.58,1.16]$ \\
\hline Subtotal $(95 \% \mathrm{Cl})$ & & & & & $42.53 \%$ & $0.82[0.58,1.16]$ \\
\hline \multicolumn{7}{|c|}{ Heterogeneity: Not applicable } \\
\hline \multicolumn{7}{|c|}{ 2.2.2 Equal or greater than 3 months } \\
\hline Bellmunt 2017 & 0 & 0 & $-0.4(0.152)$ & + & $57.47 \%$ & $0.66[0.49,0.89]$ \\
\hline Subtotal $(95 \% \mathrm{CI})$ & & & & $\gamma$ & $\mathbf{5 7 . 4 7 \%}$ & $0.66[0.49,0.89]$ \\
\hline \multicolumn{7}{|c|}{ Heterogeneity: $\operatorname{Tau}^{2}=0 ; \mathrm{Chi}^{2}=0, \mathrm{df}=0(\mathrm{P}<0.0001) ; \mathrm{I}^{2}=100 \%$} \\
\hline \multicolumn{7}{|c|}{ Test for overall effect: $Z=2.73(P=0.01)$} \\
\hline Total $(95 \% \mathrm{Cl})$ & & & & $\boldsymbol{\nabla}$ & $100 \%$ & $0.72[0.58,0.91]$ \\
\hline \multicolumn{7}{|c|}{ Heterogeneity: $\operatorname{Tau}^{2}=0 ; \mathrm{Chi}^{2}=0.87, \mathrm{df}=1(\mathrm{P}=0.35) ; \mathrm{I}^{2}=0 \%$} \\
\hline \multicolumn{7}{|c|}{ Test for overall effect: $Z=2.8(P=0.01)$} \\
\hline Test for subgroup dif & $87, d f=1(P=0$ & ), $1^{2}=0 \%$ & & & & \\
\hline
\end{tabular}


Analysis 2.3. Comparison 2 Pembrolizumab versus chemotherapy (predefined subgroup analyses), Outcome 3 Overall survival based on degree of pretreatment.

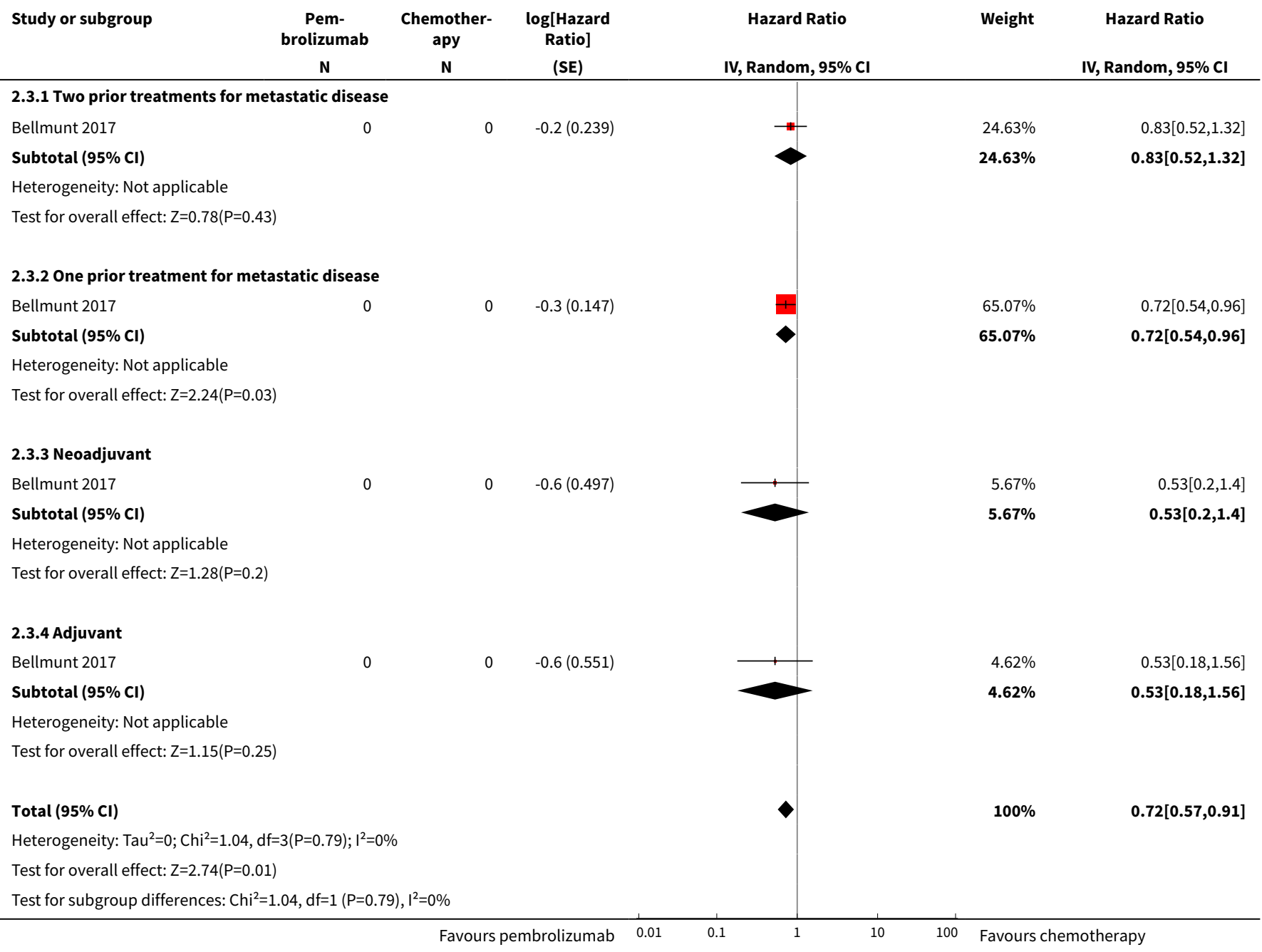

\section{Analysis 2.4. Comparison 2 Pembrolizumab versus chemotherapy (predefined subgroup} analyses), Outcome 4 Overall survival based on PD-L1 tumour expression status.

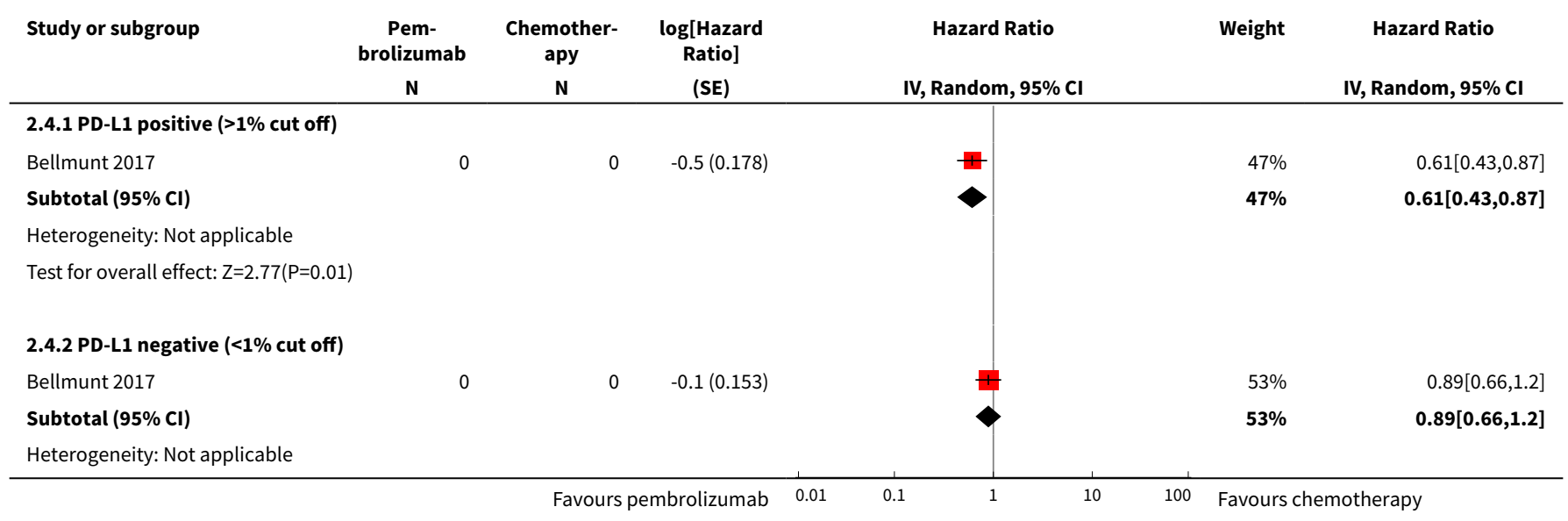

Pembrolizumab monotherapy versus chemotherapy for treatment of advanced urothelial carcinoma with disease progression during or 34

following platinum-containing chemotherapy. A Cochrane Rapid Review (Review)

Copyright (C) 2018 The Cochrane Collaboration. Published by John Wiley \& Sons, Ltd. 


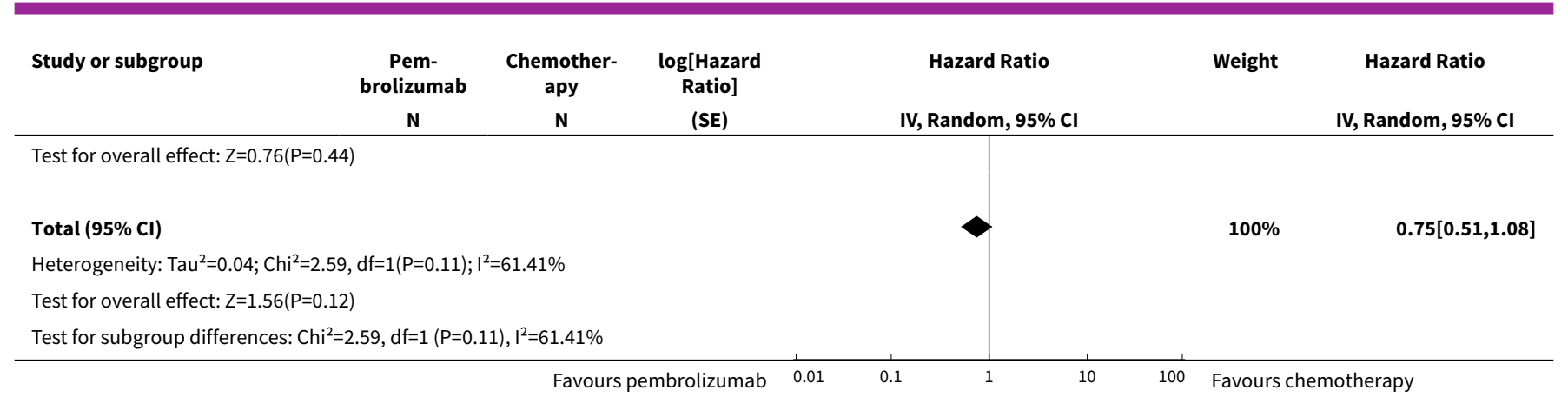

\section{Comparison 3. Pembrolizumab versus chemotherapy (post-hoc included subgroup analyses)}

\begin{tabular}{|c|c|c|c|c|}
\hline Outcome or subgroup title & No. of studies & $\begin{array}{l}\text { No. of partici- } \\
\text { pants }\end{array}$ & Statistical method & Effect size \\
\hline $\begin{array}{l}1 \text { Overall survival based on } \\
\text { age }\end{array}$ & 1 & & Hazard Ratio (Random, 95\% Cl) & $0.76[0.60,0.95]$ \\
\hline $1.1<65$ years & 1 & & Hazard Ratio (Random, 95\% CI) & $0.75[0.53,1.06]$ \\
\hline $1.2 \geq 65$ years & 1 & & Hazard Ratio (Random, 95\% Cl) & $0.76[0.56,1.03]$ \\
\hline $\begin{array}{l}2 \text { Overall survival based on } \\
\text { sex }\end{array}$ & 1 & & Hazard Ratio (Random, 95\% CI) & $0.74[0.59,0.93]$ \\
\hline 2.1 Male & 1 & & Hazard Ratio (Random, 95\% CI) & $0.73[0.56,0.95]$ \\
\hline 2.2 Female & 1 & & Hazard Ratio (Random, 95\% Cl) & $0.78[0.49,1.24]$ \\
\hline $\begin{array}{l}3 \text { Overall survival based on } \\
\text { smoking status }\end{array}$ & 1 & & Hazard Ratio (Random, 95\% Cl) & $0.68[0.41,1.15]$ \\
\hline 3.1 Current & 1 & & Hazard Ratio (Random, 95\% Cl) & $0.32[0.15,0.68]$ \\
\hline 3.2 Former & 1 & & Hazard Ratio (Random, 95\% Cl) & $0.71[0.52,0.97]$ \\
\hline 3.3 Never & 1 & & Hazard Ratio (Random, 95\% Cl) & $1.06[0.72,1.56]$ \\
\hline $\begin{array}{l}4 \text { Overall survival based on } \\
\text { histologic type }\end{array}$ & 1 & & Hazard Ratio (Random, 95\% Cl) & $0.72[0.54,0.97]$ \\
\hline 4.1 Transitional cell & 1 & & Hazard Ratio (Random, 95\% Cl) & $0.80[0.62,1.03]$ \\
\hline 4.2 Mixed & 1 & & Hazard Ratio (Random, 95\% CI) & $0.58[0.37,0.91]$ \\
\hline $\begin{array}{l}5 \text { Overall survival based on } \\
\text { PD-L1 tumour expression sta- } \\
\text { tus ( } 10 \% \text { cutoff) }\end{array}$ & 1 & & Hazard Ratio (Random, 95\% CI) & $0.71[0.51,0.97]$ \\
\hline $5.1<10 \%$ & 1 & & Hazard Ratio (Random, 95\% Cl) & $0.80[0.61,1.05]$ \\
\hline $5.2 \geq 10 \%$ & 1 & & Hazard Ratio (Random, 95\% CI) & $0.57[0.37,0.88]$ \\
\hline
\end{tabular}




\begin{tabular}{|c|c|c|c|c|}
\hline Outcome or subgroup title & No. of studies & $\begin{array}{l}\text { No. of partici- } \\
\text { pants }\end{array}$ & Statistical method & Effect size \\
\hline $\begin{array}{l}6 \text { Overall survival based on } \\
\text { location of primary tumour }\end{array}$ & 1 & & Hazard Ratio (Random, 95\% Cl) & $0.72[0.54,0.95]$ \\
\hline 6.1 Upper tract & 1 & & Hazard Ratio (Random, 95\% Cl) & $0.53[0.28,1.00]$ \\
\hline 6.2 Lower tract & 1 & & Hazard Ratio (Random, 95\% Cl) & $0.77[0.60,0.99]$ \\
\hline $\begin{array}{l}7 \text { Overall survival based on } \\
\text { location of metastases }\end{array}$ & 1 & & Hazard Ratio (Random, 95\% Cl) & $0.73[0.59,0.91]$ \\
\hline 7.1 Lymph node only & 1 & & Hazard Ratio (Random, 95\% Cl) & $0.46[0.18,1.18]$ \\
\hline 7.2 Visceral disease & 1 & & Hazard Ratio (Random, 95\% Cl) & $0.75[0.60,0.94]$ \\
\hline $\begin{array}{l}8 \text { Overall survival based on } \\
\text { liver metastases }\end{array}$ & 1 & & Hazard Ratio (Random, 95\% Cl) & $0.74[0.59,0.94]$ \\
\hline 8.1 Liver metastases & 1 & & Hazard Ratio (Random, 95\% Cl) & $0.85[0.61,1.18]$ \\
\hline 8.2 No liver metastases & 1 & & Hazard Ratio (Random, 95\% Cl) & $0.67[0.50,0.90]$ \\
\hline $\begin{array}{l}9 \text { Overall survival based on } \\
\text { haemoglobin concentration }\end{array}$ & 1 & & Hazard Ratio (Random, 95\% Cl) & $0.72[0.57,0.90]$ \\
\hline $9.1<10 \mathrm{~g} / \mathrm{dl}$ & 1 & & Hazard Ratio (Random, 95\% Cl) & $0.75[0.46,1.22]$ \\
\hline $9.2 \geq 10 \mathrm{~g} / \mathrm{dl}$ & 1 & & Hazard Ratio (Random, 95\% Cl) & $0.71[0.55,0.92]$ \\
\hline $\begin{array}{l}10 \text { Overall survival based on } \\
\text { number of risk factors }\end{array}$ & 1 & & Hazard Ratio (Random, 95\% Cl) & $0.78[0.62,0.98]$ \\
\hline 10.1 No risk factor & 1 & & Hazard Ratio (Random, 95\% Cl) & $0.82[0.42,1.60]$ \\
\hline 10.21 risk factor & 1 & & Hazard Ratio (Random, 95\% Cl) & $0.73[0.49,1.09]$ \\
\hline 10.32 risk factors & 1 & & Hazard Ratio (Random, 95\% Cl) & $0.84[0.56,1.26]$ \\
\hline 10.43 or 4 risk factors & 1 & & Hazard Ratio (Random, 95\% Cl) & $0.76[0.47,1.23]$ \\
\hline $\begin{array}{l}11 \text { Overall survival based on } \\
\text { previous platinum therapy }\end{array}$ & 1 & & Hazard Ratio (Random, 95\% Cl) & $0.73[0.58,0.92]$ \\
\hline 11.1 Cisplatin & 1 & & Hazard Ratio (Random, 95\% Cl) & $0.73[0.56,0.95]$ \\
\hline 11.2 Carboplatin & 1 & & Hazard Ratio (Random, 95\% Cl) & $0.74[0.47,1.17]$ \\
\hline $\begin{array}{l}12 \text { Overall survival based } \\
\text { on investigator's choice of } \\
\text { chemotherapy }\end{array}$ & 1 & & Hazard Ratio (Random, 95\% Cl) & $0.73[0.61,0.88]$ \\
\hline 12.1 Paclitaxel & 1 & & Hazard Ratio (Random, 95\% Cl) & $0.76[0.55,1.05]$ \\
\hline 12.2 Docetaxel & 1 & & Hazard Ratio (Random, 95\% Cl) & $0.76[0.55,1.05]$ \\
\hline
\end{tabular}




\begin{tabular}{lllll}
\hline Outcome or subgroup title & No. of studies & $\begin{array}{l}\text { No. of partici- } \\
\text { pants }\end{array}$ & Statistical method & Effect size \\
\hline 12.3 Vinflunine & 1 & Hazard Ratio (Random, 95\% Cl) & $0.69[0.51,0.93]$ \\
\hline
\end{tabular}

Analysis 3.1. Comparison 3 Pembrolizumab versus chemotherapy (posthoc included subgroup analyses), Outcome 1 Overall survival based on age.

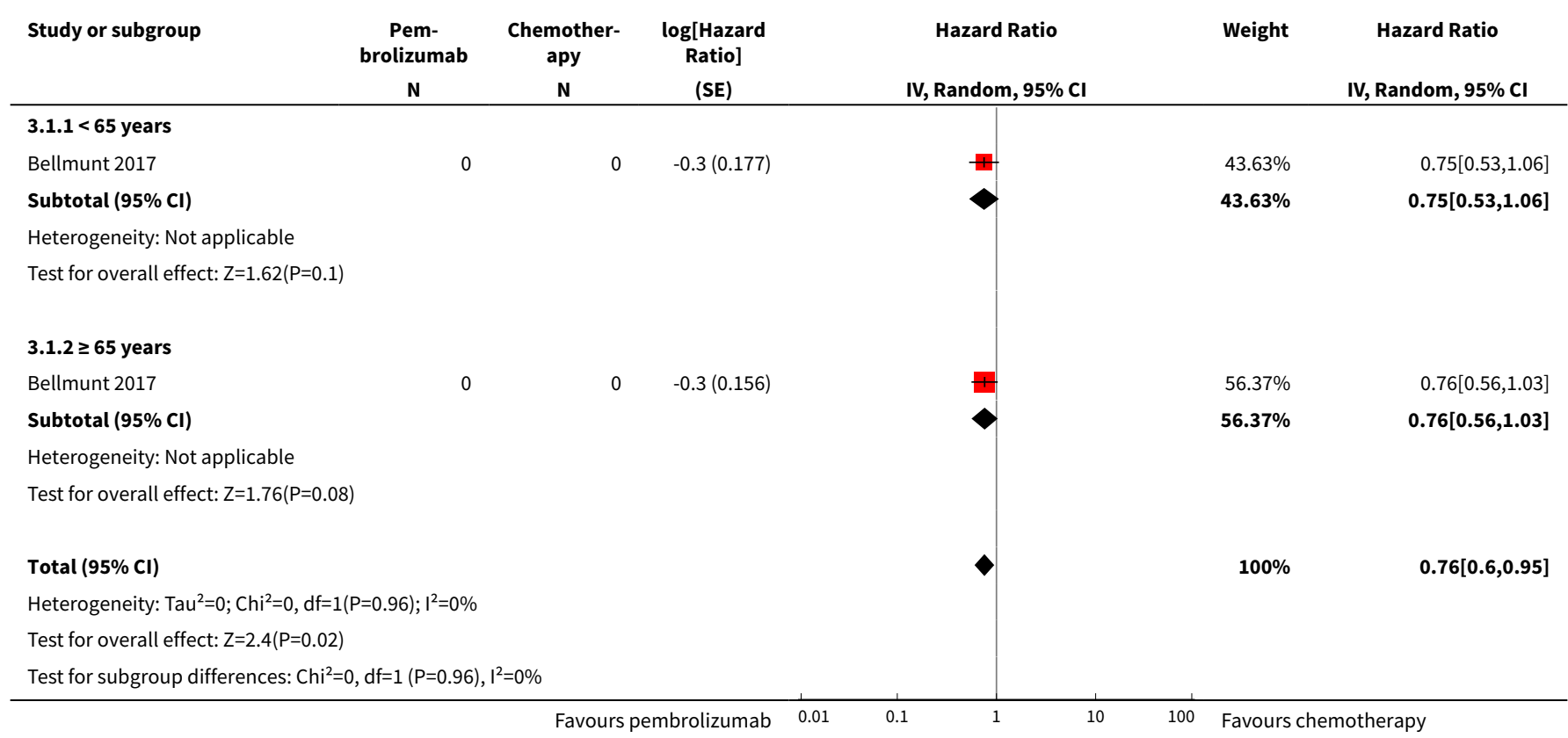

Analysis 3.2. Comparison 3 Pembrolizumab versus chemotherapy (posthoc included subgroup analyses), Outcome 2 Overall survival based on sex.

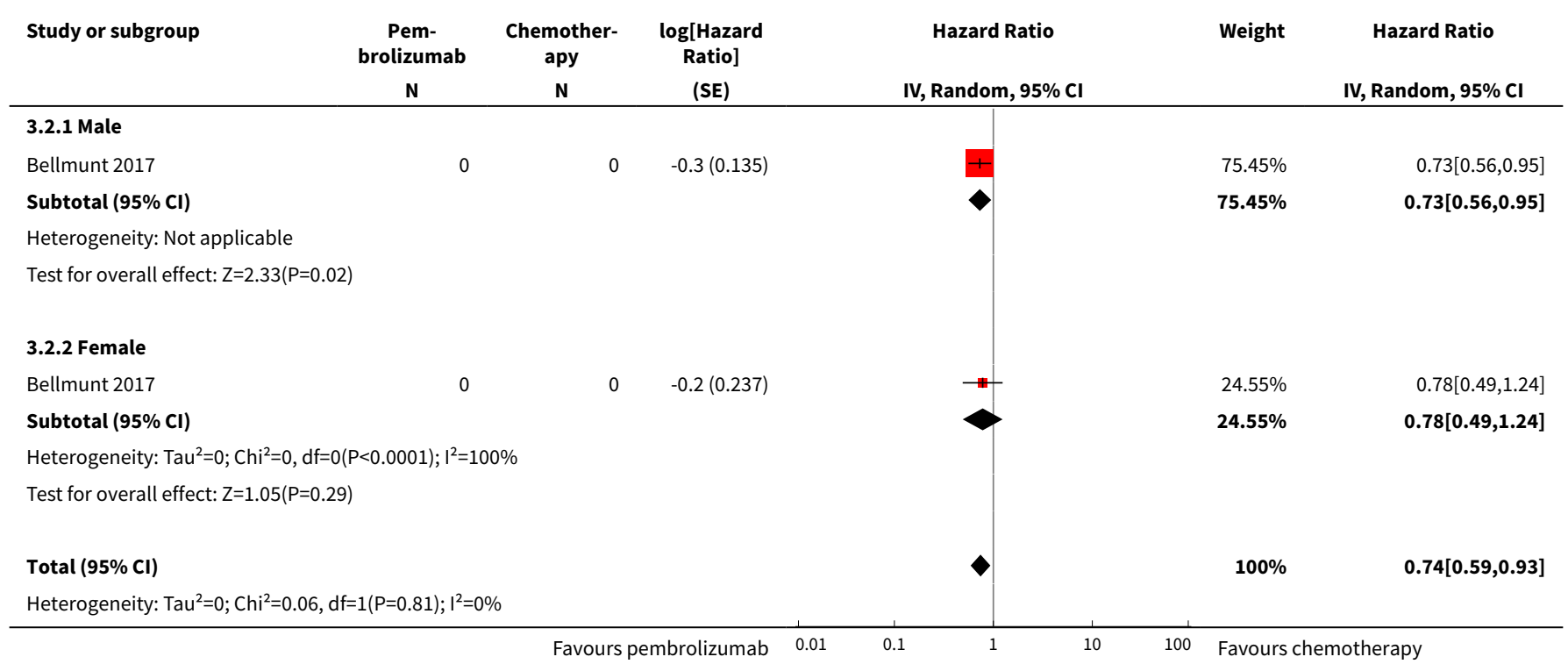




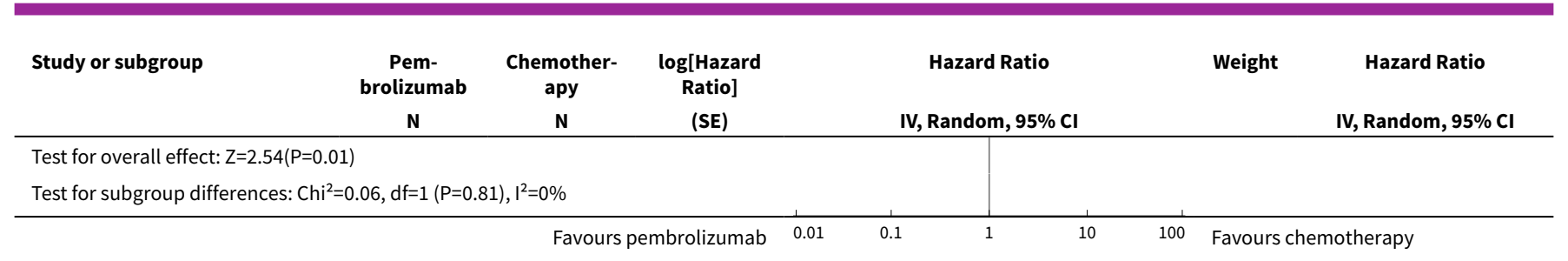

Analysis 3.3. Comparison 3 Pembrolizumab versus chemotherapy (post-hoc included subgroup analyses), Outcome 3 Overall survival based on smoking status.

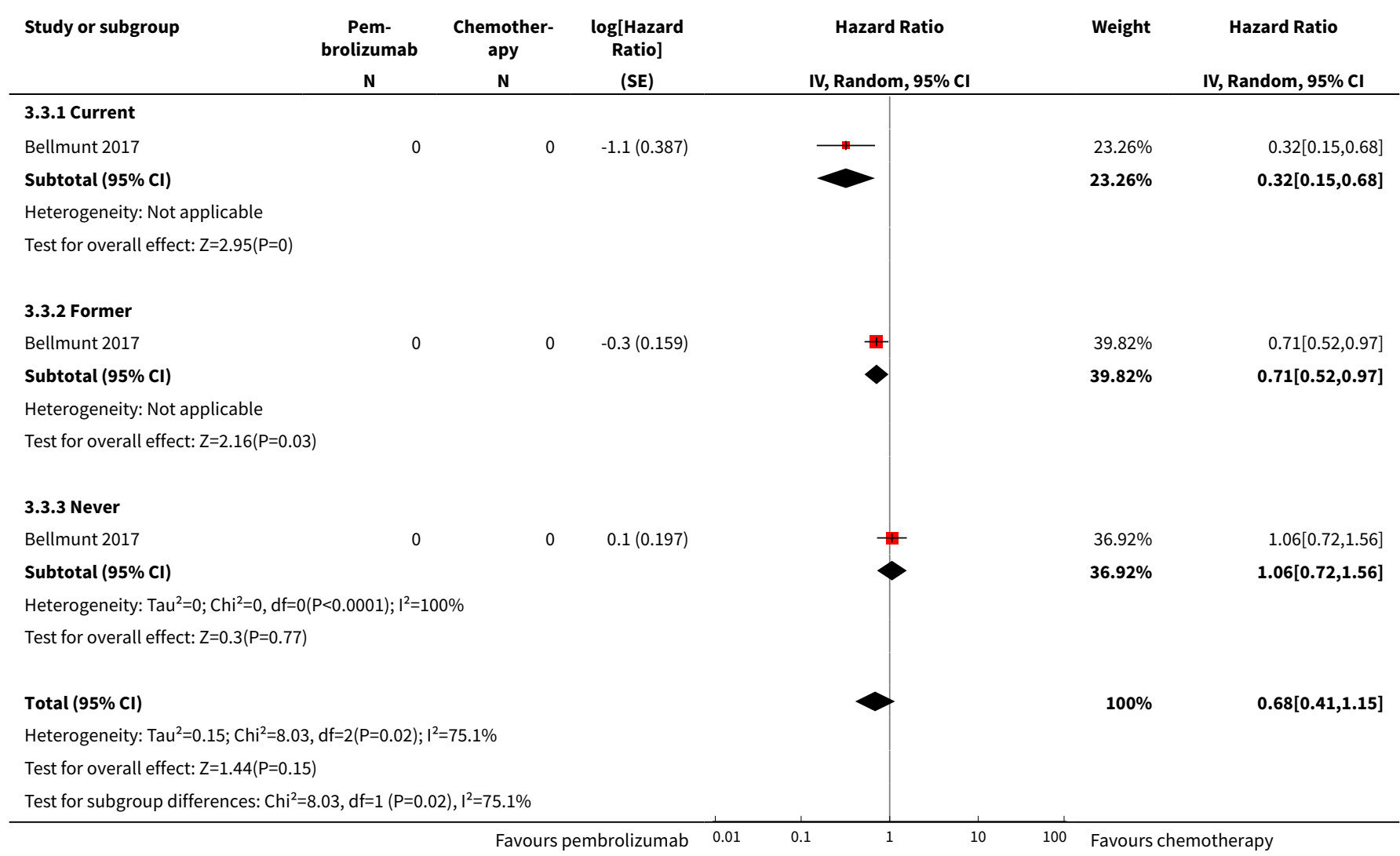

Analysis 3.4. Comparison 3 Pembrolizumab versus chemotherapy (post-hoc included subgroup analyses), Outcome 4 Overall survival based on histologic type.

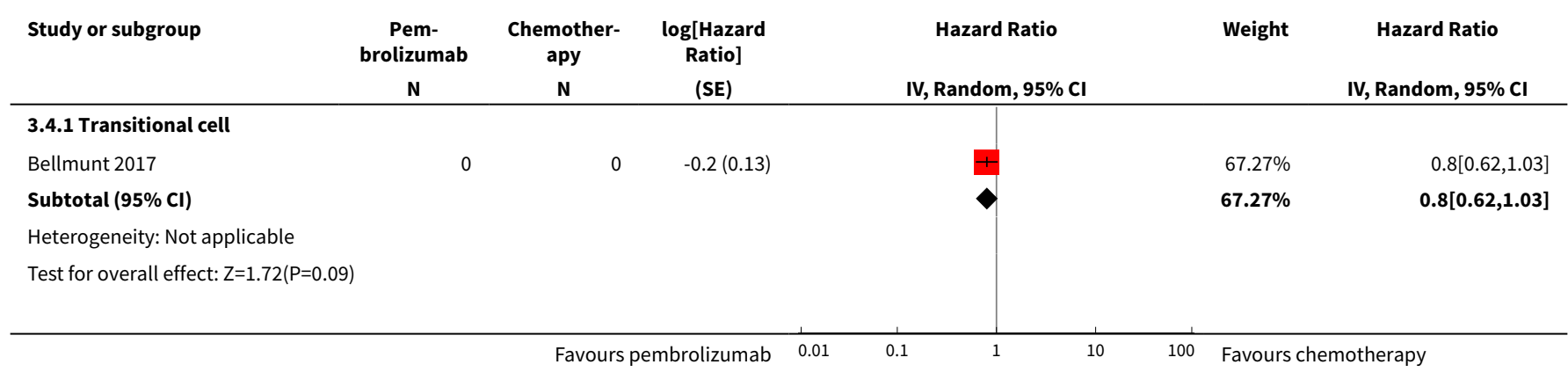




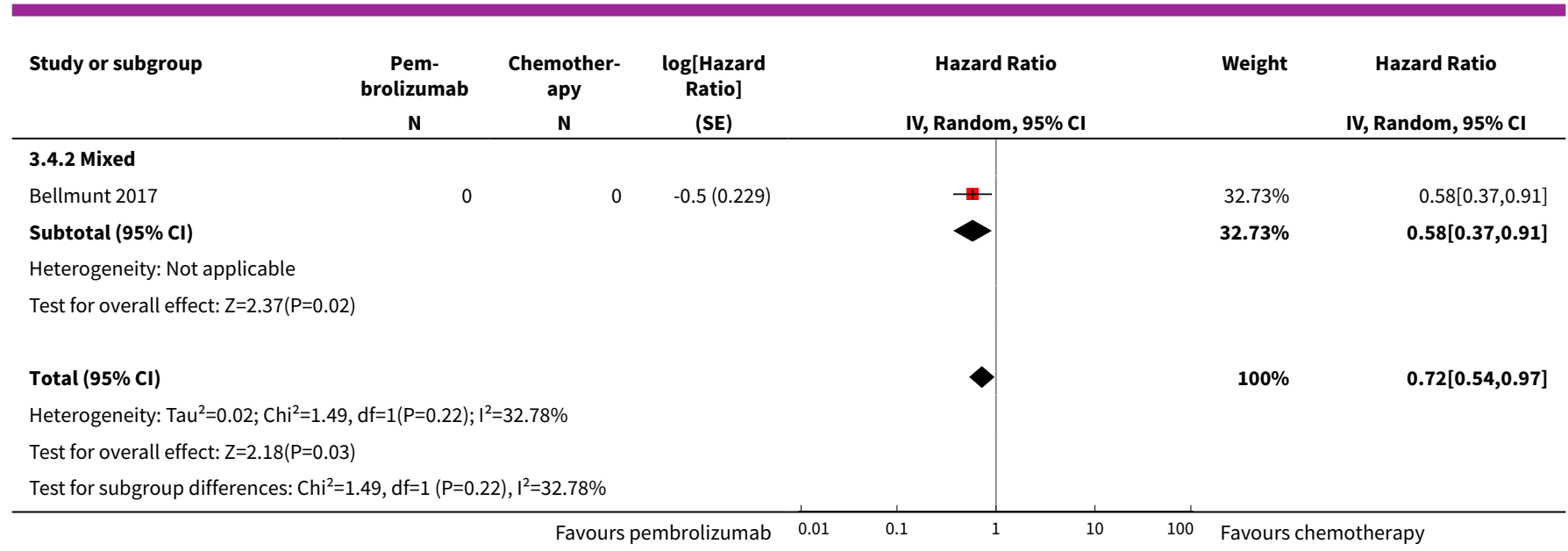

\section{Analysis 3.5. Comparison 3 Pembrolizumab versus chemotherapy (post-hoc included subgroup analyses), Outcome 5 Overall survival based on PD-L1 tumour expression status (10\% cutoff).}

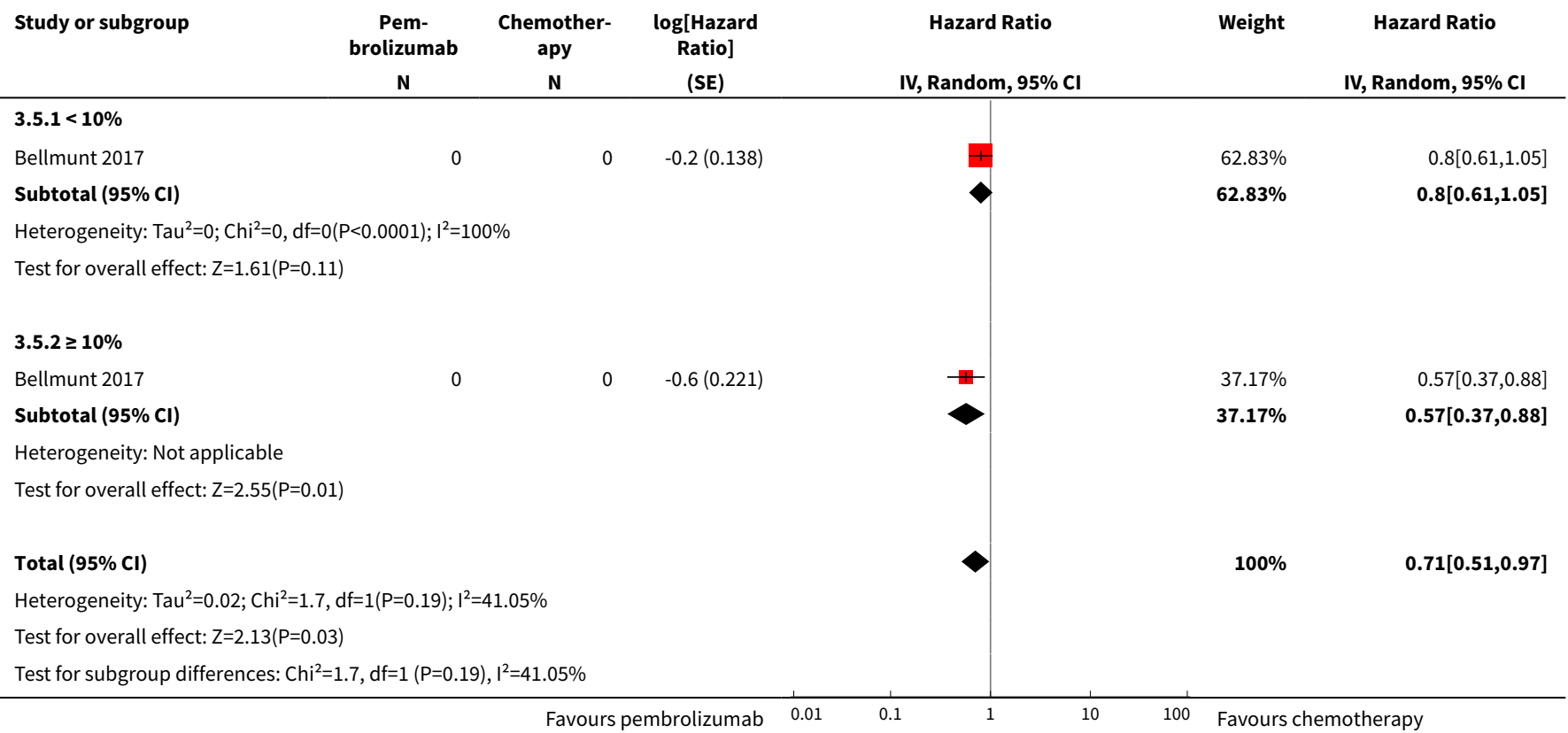

Analysis 3.6. Comparison 3 Pembrolizumab versus chemotherapy (post-hoc included subgroup analyses), Outcome 6 Overall survival based on location of primary tumour.

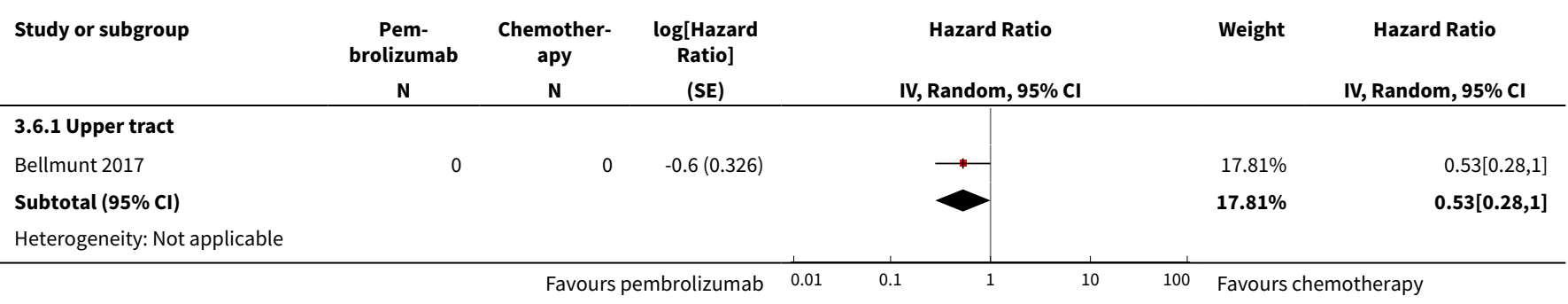




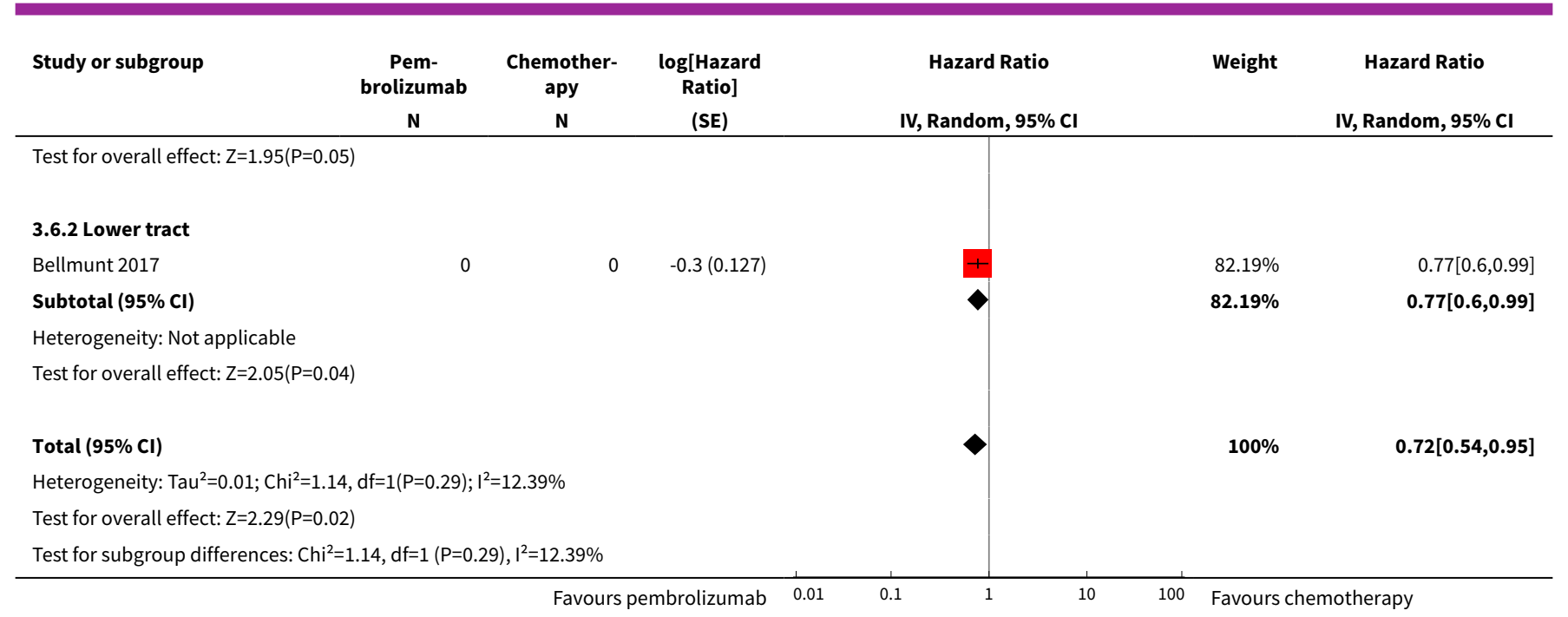

\section{Analysis 3.7. Comparison 3 Pembrolizumab versus chemotherapy (post-hoc included subgroup analyses), Outcome 7 Overall survival based on location of metastases.}

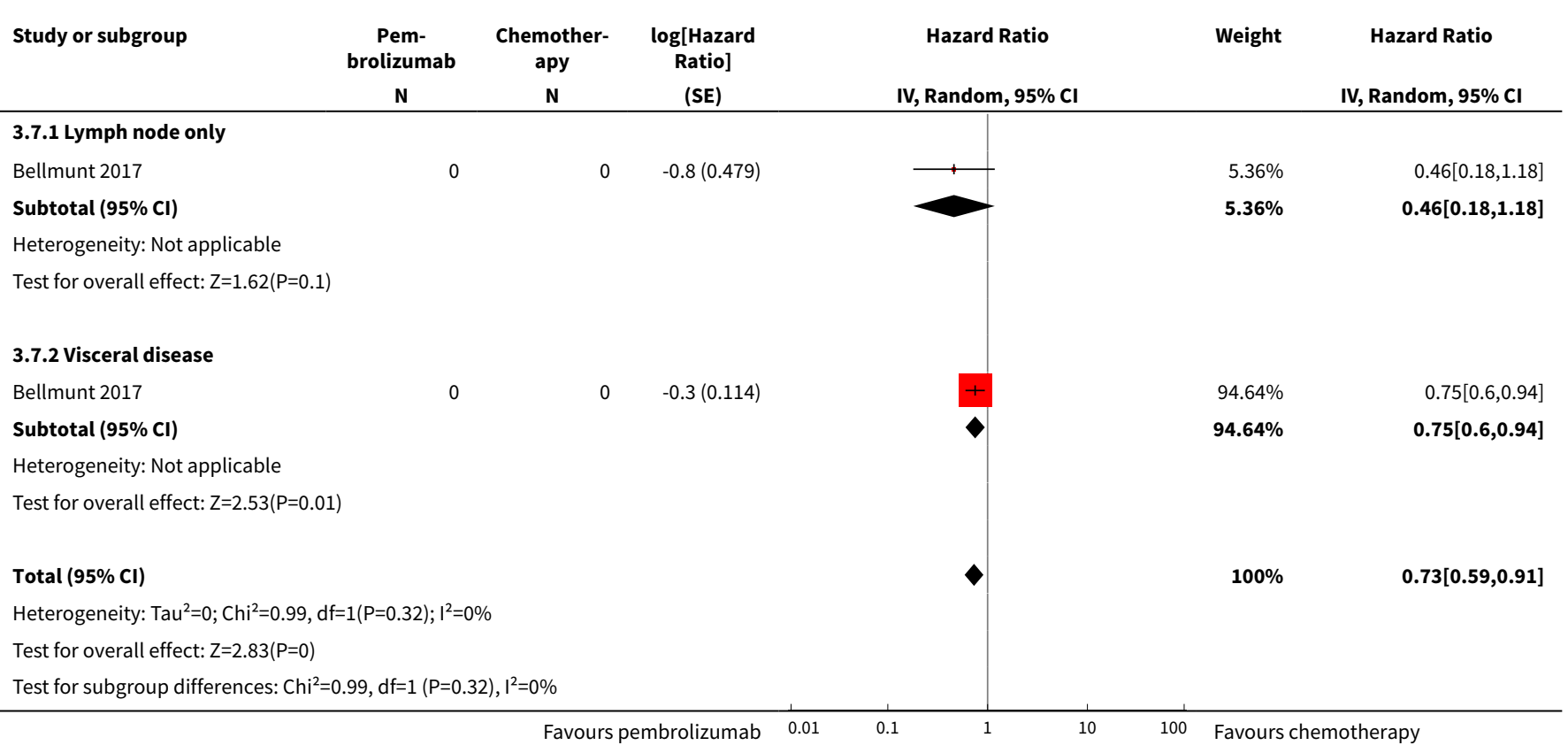

Analysis 3.8. Comparison 3 Pembrolizumab versus chemotherapy (post-hoc included subgroup analyses), Outcome 8 Overall survival based on liver metastases.

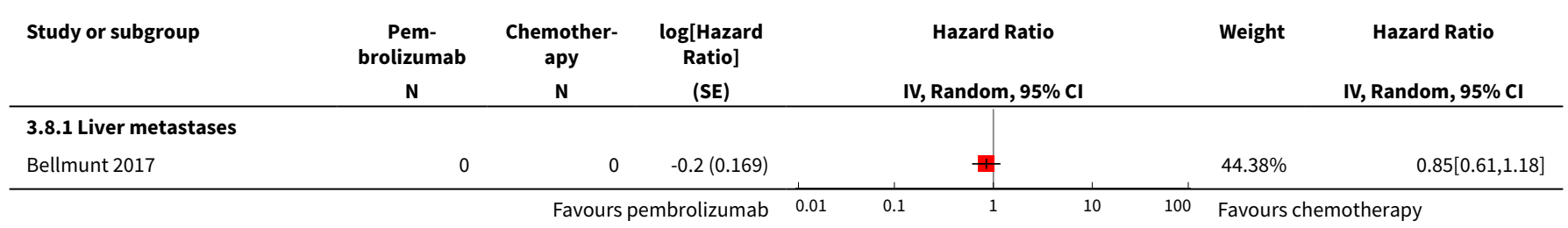




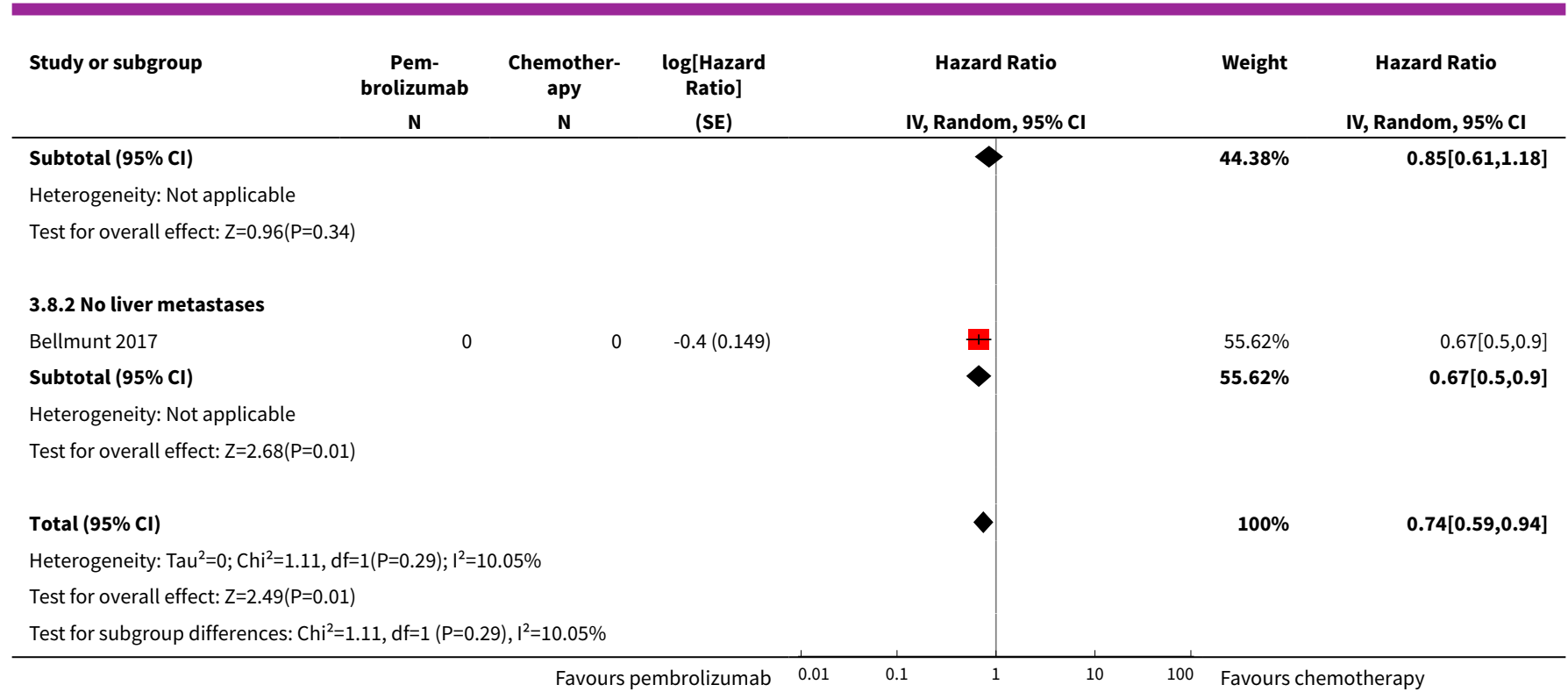

Analysis 3.9. Comparison 3 Pembrolizumab versus chemotherapy (post-hoc included subgroup analyses), Outcome 9 Overall survival based on haemoglobin concentration.

\begin{tabular}{|c|c|c|c|c|c|c|}
\hline Study or subgroup & $\begin{array}{c}\text { Pem- } \\
\text { brolizumab } \\
\text { N }\end{array}$ & $\begin{array}{c}\text { Chemother- } \\
\text { apy } \\
\text { N }\end{array}$ & \multirow[t]{2}{*}{$\begin{array}{c}\log [\text { Hazard } \\
\text { Ratio] } \\
\text { (SE) }\end{array}$} & $\begin{array}{c}\text { Hazard Ratio } \\
\text { IV, Random, } 95 \% \mathrm{CI}\end{array}$ & Weight & \multirow[t]{2}{*}{$\begin{array}{c}\text { Hazard Ratio } \\
\text { IV, Random, } 95 \% \text { CI }\end{array}$} \\
\hline \multicolumn{5}{|l|}{$3.9 .1<10 \mathrm{~g} / \mathrm{dl}$} & & \\
\hline Bellmunt 2017 & 0 & 0 & $-0.3(0.249)$ & $\rightarrow$ & $21.44 \%$ & $0.75[0.46,1.22]$ \\
\hline Subtotal $(95 \% \mathrm{Cl})$ & & & & & $21.44 \%$ & $0.75[0.46,1.22]$ \\
\hline \multicolumn{7}{|c|}{ Heterogeneity: Not applicable } \\
\hline \multicolumn{7}{|l|}{$3.9 .2 \geq 10 \mathrm{~g} / \mathrm{dl}$} \\
\hline Bellmunt 2017 & 0 & 0 & $-0.3(0.13)$ & + & $78.56 \%$ & $0.71[0.55,0.92]$ \\
\hline Subtotal $(95 \% \mathrm{Cl})$ & & & & $\nabla$ & $78.56 \%$ & $0.71[0.55,0.92]$ \\
\hline \multicolumn{7}{|c|}{ Heterogeneity: Not applicable } \\
\hline \multicolumn{7}{|c|}{ Test for overall effect: $Z=2.63(P=0.01)$} \\
\hline Total $(95 \% \mathrm{Cl})$ & & & & $\boldsymbol{\nabla}$ & $100 \%$ & $0.72[0.57,0.9]$ \\
\hline \multicolumn{7}{|c|}{ Heterogeneity: $\operatorname{Tau}^{2}=0 ; \mathrm{Chi}^{2}=0.04, \mathrm{df}=1(\mathrm{P}=0.85) ; \mathrm{I}^{2}=0 \%$} \\
\hline \multicolumn{7}{|c|}{ Test for overall effect: $\mathrm{Z}=2.86(\mathrm{P}=0)$} \\
\hline Test for subgroup dif & $.04, d f=1(P=0$ & ), $I^{2}=0 \%$ & & & & \\
\hline
\end{tabular}


Analysis 3.10. Comparison 3 Pembrolizumab versus chemotherapy (post-hoc included subgroup analyses), Outcome 10 Overall survival based on number of risk factors.

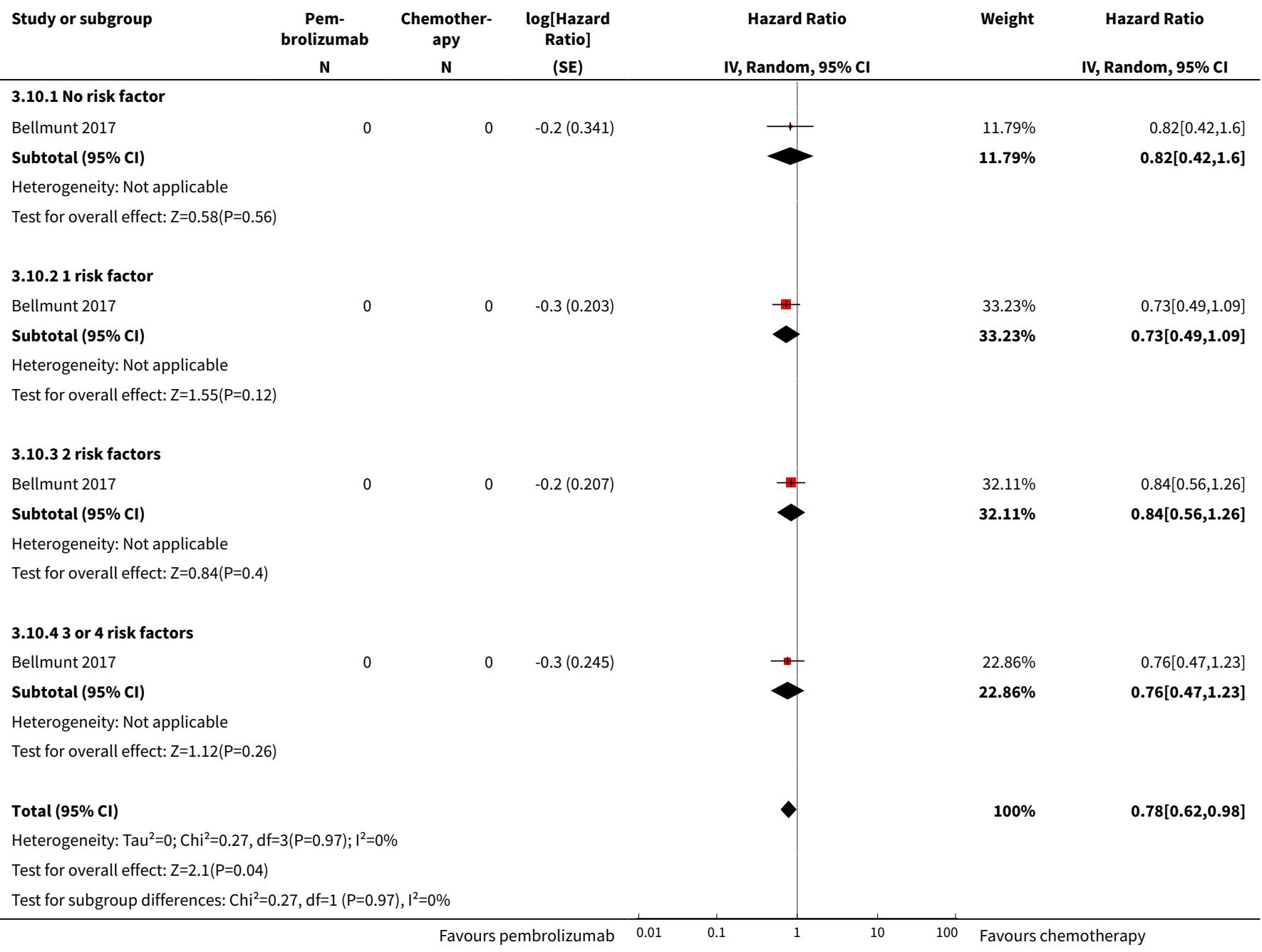

Analysis 3.11. Comparison 3 Pembrolizumab versus chemotherapy (post-hoc included subgroup analyses), Outcome 11 Overall survival based on previous platinum therapy.

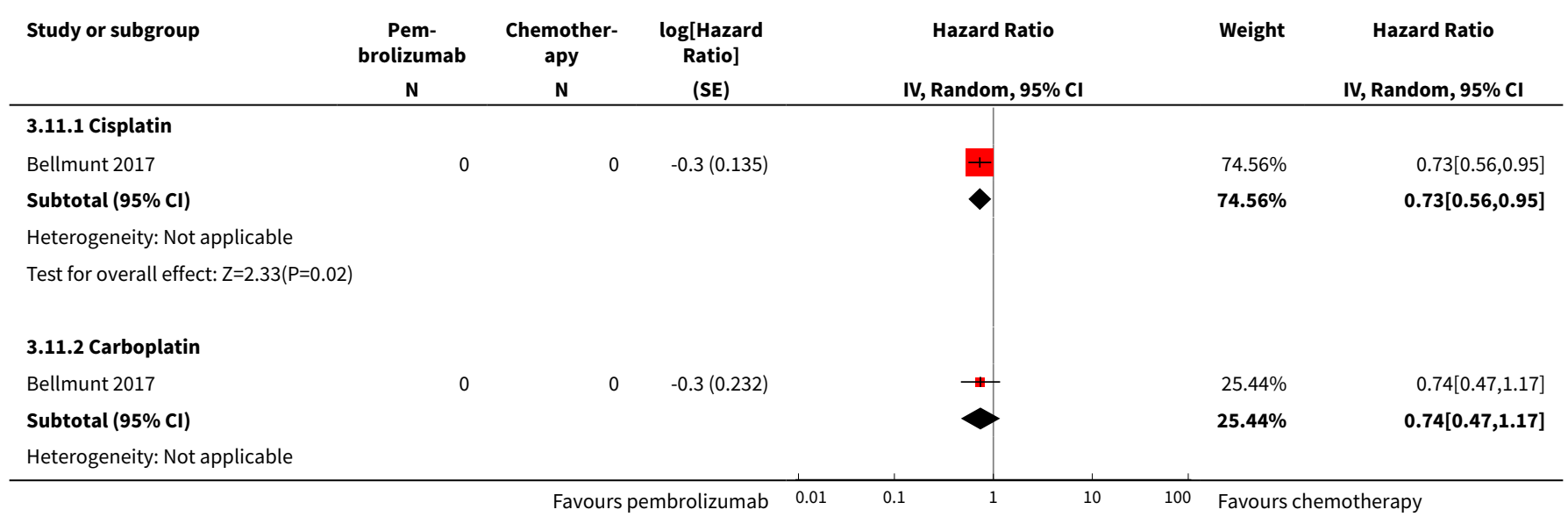

Pembrolizumab monotherapy versus chemotherapy for treatment of advanced urothelial carcinoma with disease progression during or 


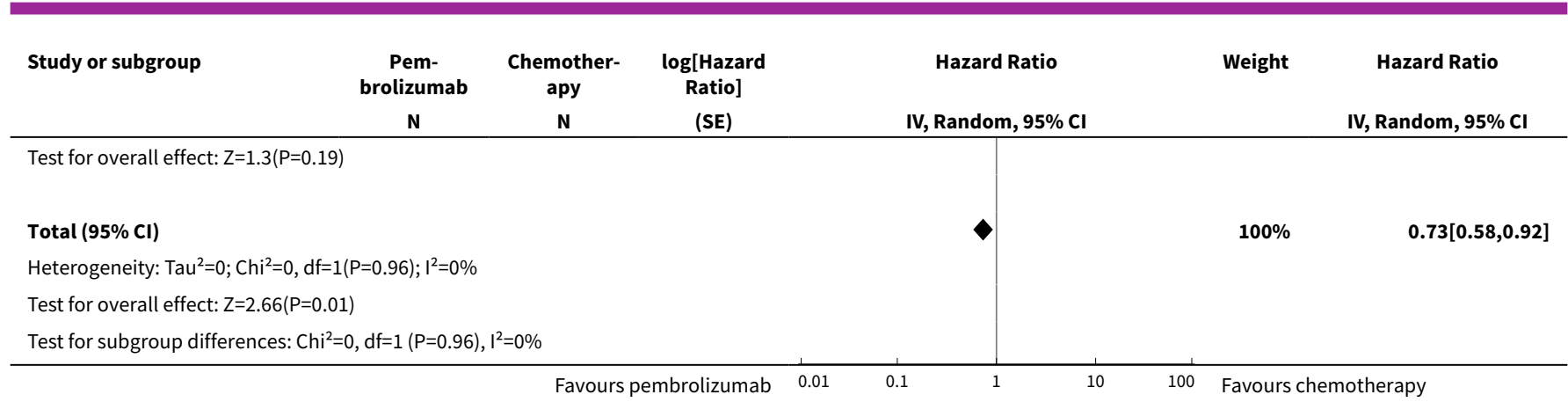

\section{Analysis 3.12. Comparison 3 Pembrolizumab versus chemotherapy (post-hoc included subgroup analyses), Outcome 12 Overall survival based on investigator's choice of chemotherapy.}

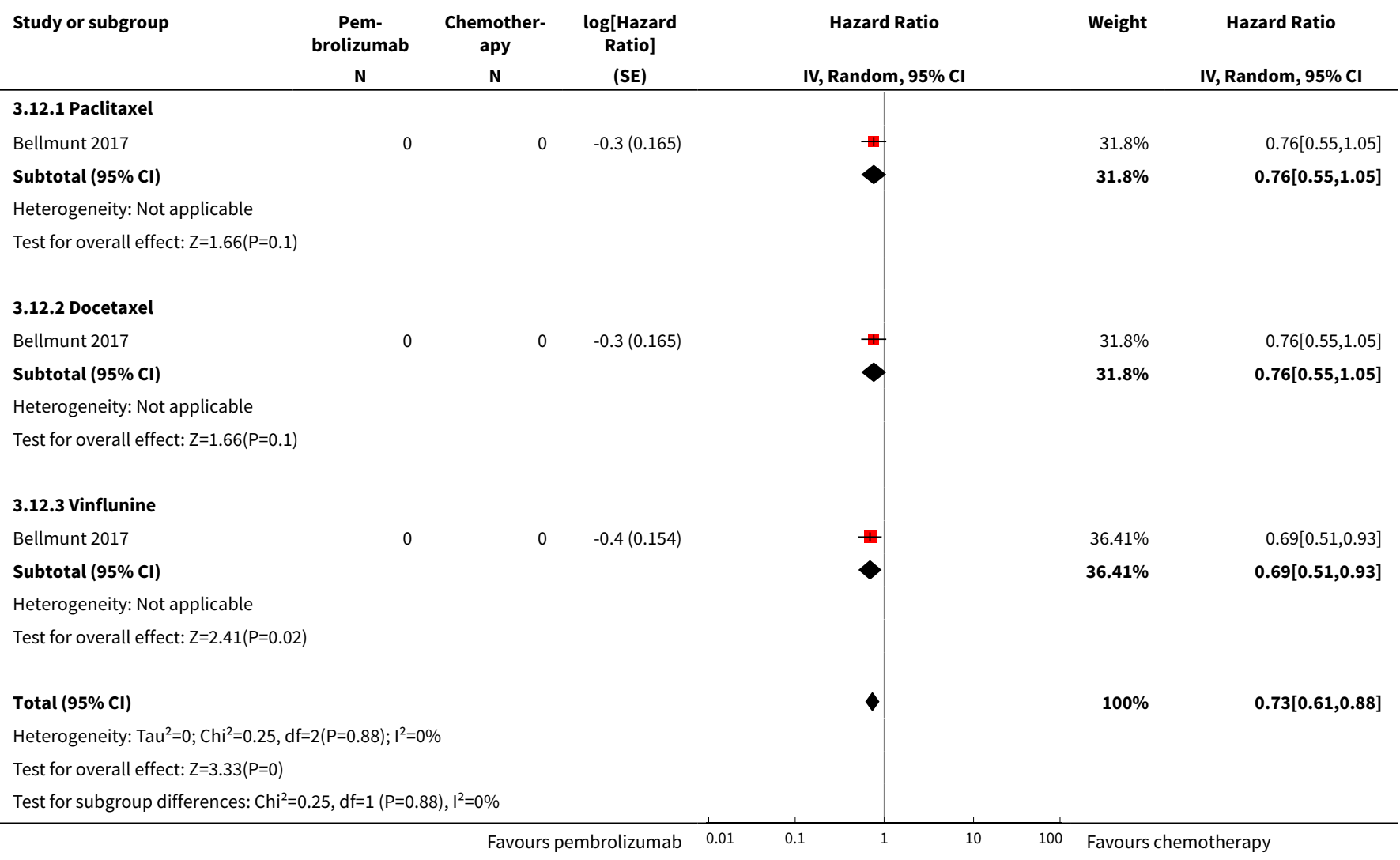




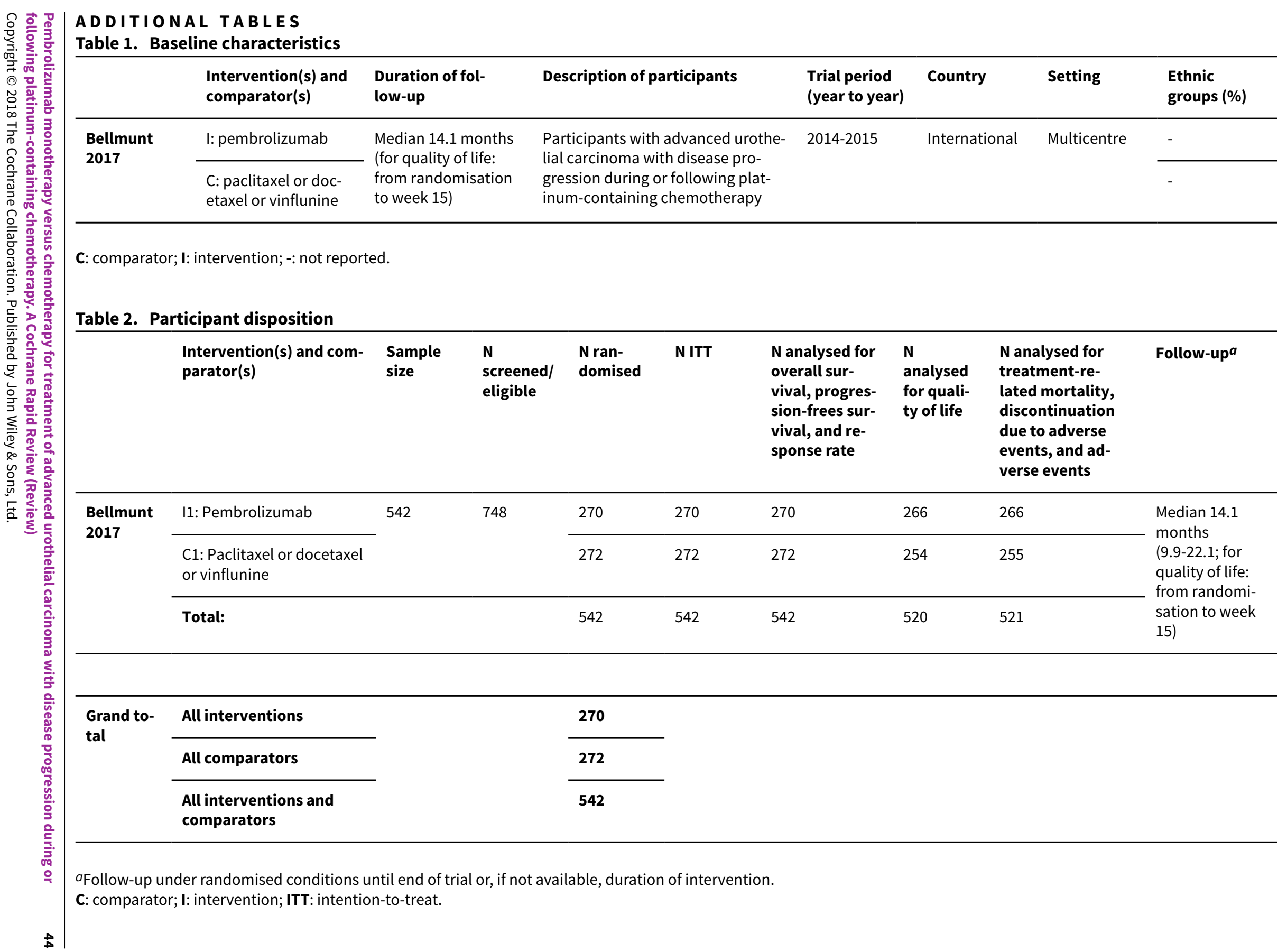




\section{APPENDICES}

\section{Appendix 1. Search strategies}

\section{Search terms for the World Health Organization International Clinical Trials Registry Platform (WHO ICTRP)}

Pembrolizumab, MK-3475, Keytruda

\section{Search strategy for the Cochrane Library}

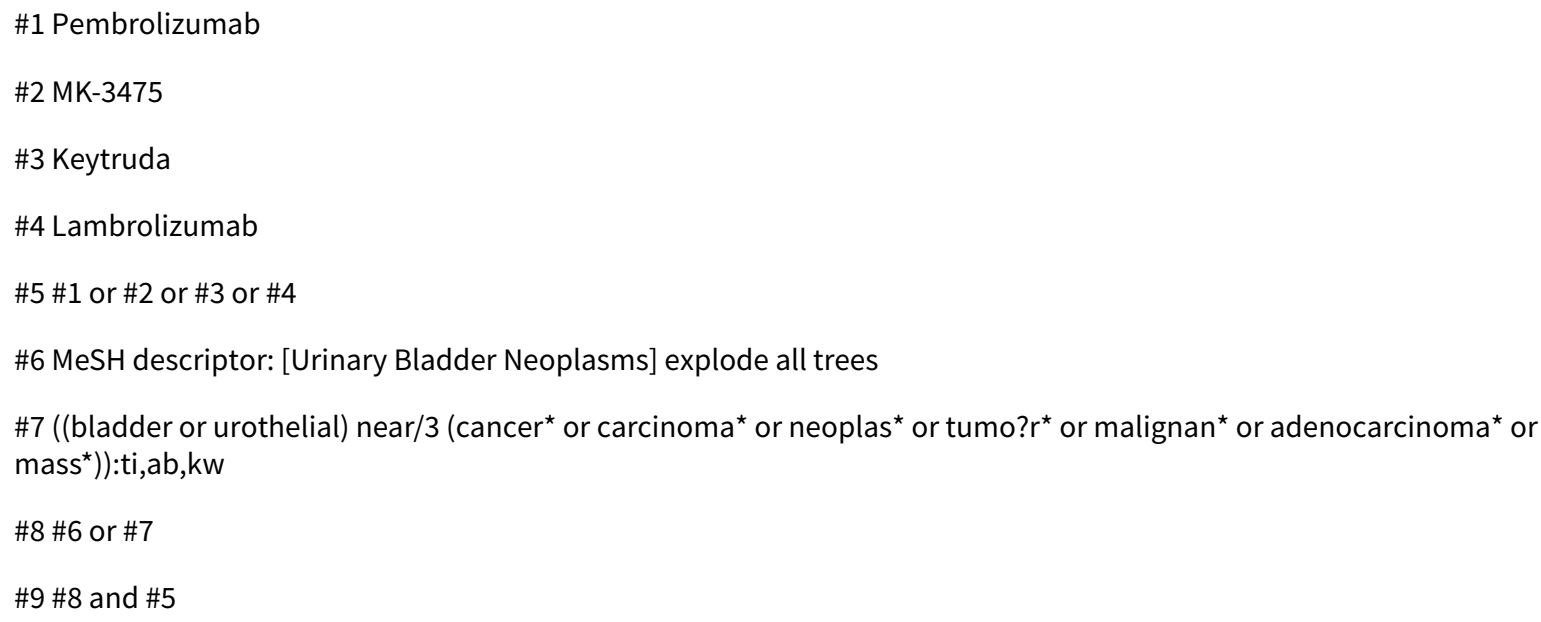

\section{Appendix 2. MEDLINE search strategy}

\begin{tabular}{ll}
\hline$\#$ & Search Statement \\
\hline 1 & pembrolizumab.mp. \\
\hline 2 & keytruda.mp. \\
\hline 3 & (MK adj2 "3475").tw. \\
\hline 5 & mk-3475.mp. \\
\hline 6 & lambrolizumab.mp. \\
\hline 7 & 1 or 2 or 3 or 4 or 5 \\
\hline 8 & exp Urinary Bladder Neoplasms/ \\
\hline 9 & exp Urothelium/ \\
\hline 10 & transitional cell carcinoma.mp. or exp Carcinoma, Transitional Cell/ \\
\hline
\end{tabular}


(Continued)

11 ((bladder or urotheli* or uninary or transitional) adj4 (carcinoma* or cancer* or neoplas $^{\star}$ or adenocarcinoma* or mass or malignan*)).mp.

\begin{tabular}{|c|c|}
\hline 12 & 7 or 9 or 11 \\
\hline 13 & 6 and 12 \\
\hline 14 & urotheli*.mp. \\
\hline 15 & 6 and 10 and 14 \\
\hline 16 & 13 or 15 \\
\hline 17 & 6 and 9 \\
\hline 18 & 16 or 17 \\
\hline 19 & (("tcc" or transitional) adj3 cell adj3 carcinoma*).mp. \\
\hline 20 & 6 and 19 \\
\hline 21 & 18 or 20 \\
\hline 22 & 7 or 10 \\
\hline 23 & 6 and 8 and 22 \\
\hline 24 & 21 or 23 \\
\hline
\end{tabular}

\section{CONTRIBUTIONS OF AUTHORS}

VN drafted the first version; performed literature screening, data extraction, and 'Risk of bias' assessment; and revised/reviewed the final version.

AK provided content expertise and revised/reviewed the final version.

PD provided content expertise; performed literature screening, data extraction, 'Risk of bias' assessment, and interpretation of results including certainty of evidence rating; provided methodological oversight; and revised/reviewed the final version.

NS provided methodological support and reviewed the final version.

MR provided content expertise and revised/reviewed the final version.

CB developed the search strategy and performed the search.

NP provided content expertise and revised/reviewed the protocol.

ECH reviewed and revised the 'Risk of bias' assessment, and contributed to the certainty of evidence ratings.

JHJ provided methodological support.

GG provided methodological support and revised/reviewed the final version.

FK coordinated the work; performed literature screening, data extraction, 'Risk of bias' assessment, and interpretation of results; provided content expertise; and oversaw all aspects of the protocol and rapid review development.

\section{DECLARATIONS OF INTEREST}

VN: none. 
AK: none.

PD: none.

NS: none.

MR: none.

CB: none.

NP: none.

JHJ: none.

$\mathrm{ECH}$ : none

GG: none.

FK: none.

\section{SOURCES OF SUPPORT}

\section{Internal sources}

- University of Erlangen, Germany.

Salary support for Frank Kunath

- Minneapolis VAMC, Minneapolis, MN, USA.

Salary support for Philipp Dahm

\section{External sources}

- No sources of support supplied

\section{DIFFERENCES BETWEEN PROTOCOL AND REVIEW}

This review is based on a published protocol (Narayan 2017).

- We renamed the time-to-event outcomes of overall survival and progression-free survival to time-to-death of any cause and time to progression, respectively, to better reflect the relevant events and aid in the interpretation of the hazard ratios, in particular for the absolute effect size estimates.

- We also performed a post hoc subgroup analysis for smoking status (which did not suggest a subgroup effect).

- We have added the outcome of serious adverse events to the 'Summary of findings' table, given its importance to patients and clinical decision-making.

\section{N O TES}

Parts of the methods section are based on a standard template developed by the Cochrane Metabolic and Endocrine Disorders Group, which has been modified and adapted for use by Cochrane Urology.

\section{NDEX TERMS}

\section{Medical Subject Headings (MeSH)}

Antibodies, Monoclonal, Humanized [adverse effects] [^therapeutic use]; Antineoplastic Agents, Immunological [adverse effects] [ ${ }^{\star}$ therapeutic use]; Antineoplastic Combined Chemotherapy Protocols [adverse effects] [ ${ }^{*}$ therapeutic use]; Carcinoma [ ${ }^{*}$ drug therapy] [pathology]; Disease Progression; Docetaxel; Paclitaxel [administration \& dosage]; Quality of Life; Taxoids [administration \& dosage]; Urinary Bladder Neoplasms [ ${ }^{\star}$ drug therapy] [pathology]; Vinblastine [administration \& dosage] [analogs \& derivatives]

\section{MeSH check words}

Humans 